\title{
Between mood and matter
}

Citation for published version (APA):

de Jong, M-F. (2018). Between mood and matter: studies on the interface between mood disorders and physical conditions. [Doctoral Thesis, Maastricht University]. Datawyse / Universitaire Pers Maastricht. https://doi.org/10.26481/dis.20180518mj

Document status and date:

Published: 01/01/2018

DOI:

10.26481/dis.20180518mj

Document Version:

Publisher's PDF, also known as Version of record

\section{Please check the document version of this publication:}

- A submitted manuscript is the version of the article upon submission and before peer-review. There can be important differences between the submitted version and the official published version of record.

People interested in the research are advised to contact the author for the final version of the publication, or visit the DOI to the publisher's website.

- The final author version and the galley proof are versions of the publication after peer review.

- The final published version features the final layout of the paper including the volume, issue and page numbers.

Link to publication

\footnotetext{
General rights rights.

- You may freely distribute the URL identifying the publication in the public portal. please follow below link for the End User Agreement:

www.umlib.nl/taverne-license

Take down policy

If you believe that this document breaches copyright please contact us at:

repository@maastrichtuniversity.nl

providing details and we will investigate your claim.
}

Copyright and moral rights for the publications made accessible in the public portal are retained by the authors and/or other copyright owners and it is a condition of accessing publications that users recognise and abide by the legal requirements associated with these

- Users may download and print one copy of any publication from the public portal for the purpose of private study or research.

- You may not further distribute the material or use it for any profit-making activity or commercial gain

If the publication is distributed under the terms of Article $25 \mathrm{fa}$ of the Dutch Copyright Act, indicated by the "Taverne" license above, 

(C) copyright Marasha de Jong, Maastricht 2018

Printing: Datawyse | Universitaire Pers Maastricht Layout: Albertine Margaretha Everdina Bosman

ISBN 9789461598042 


\title{
Between mood and matter
}

\section{Studies on the interface between mood disorders and physical conditions}

\author{
ter verkrijging van de graad van doctor aan de Universiteit Maastricht, \\ op gezag van de Rector Magnificus, Prof. dr. Rianne M. Letschert, \\ volgens het besluit van het College van Decanen, \\ in het openbaar te verdedigen \\ op vrijdag 18 mei 2018 om 14.00 uur \\ door
}

Marasha-Fiona de Jong

geboren 6 december 1979 te Dordrecht 


\section{Promotores}

Prof.dr. F.P.M.L. Peeters

Prof.dr. D. Mischoulon, Harvard Medical School, Boston, USA

\section{Beoordelingscommissie}

Prof. dr. J. van Os ( voorzitter)

Prof dr. M. Desseilles, Université de Namur, België

Dr. C. van der Leeuw

Dr. J. Strik

Prof dr. R. van Winkel, Katholieke Universiteit Leuven, België

The studies presented in this thesis were funded by the Mind and Life Institute (Mind and Life Francisco J.Varela research grant), the Brach Family Foundation and Fisher Wallace Inc. 
Aan mama

Albertine Margaretha Everdina Bosman

* 15-10-1938, Den Haag

+ 02-09-2010, Gorinchem 



\section{Table of Contents}

Chapter 1 General introduction

Chapter 2 Metabolic syndrome in Dutch patients with bipolar disorder; a cross sectional study

Chapter 3 A randomized controlled pilot study on mindfulness-based cognitive therapy for unipolar depression in patients with chronic pain

Chapter 4 Effects of mindfulness-based cognitive therapy on body awareness in patients with chronic pain and comorbid depression

Chapter 5 Efficacy and safety of a form of cranial electrical stimulation (CES) as an add-on intervention for treatment-resistant major depressive disorder: a three week double blind pilot study

Chapter 6 General discussion

Summary

Samenvatting

Valorisation addendum

Acknowledgements

Curriculum Vitae

List of publications 



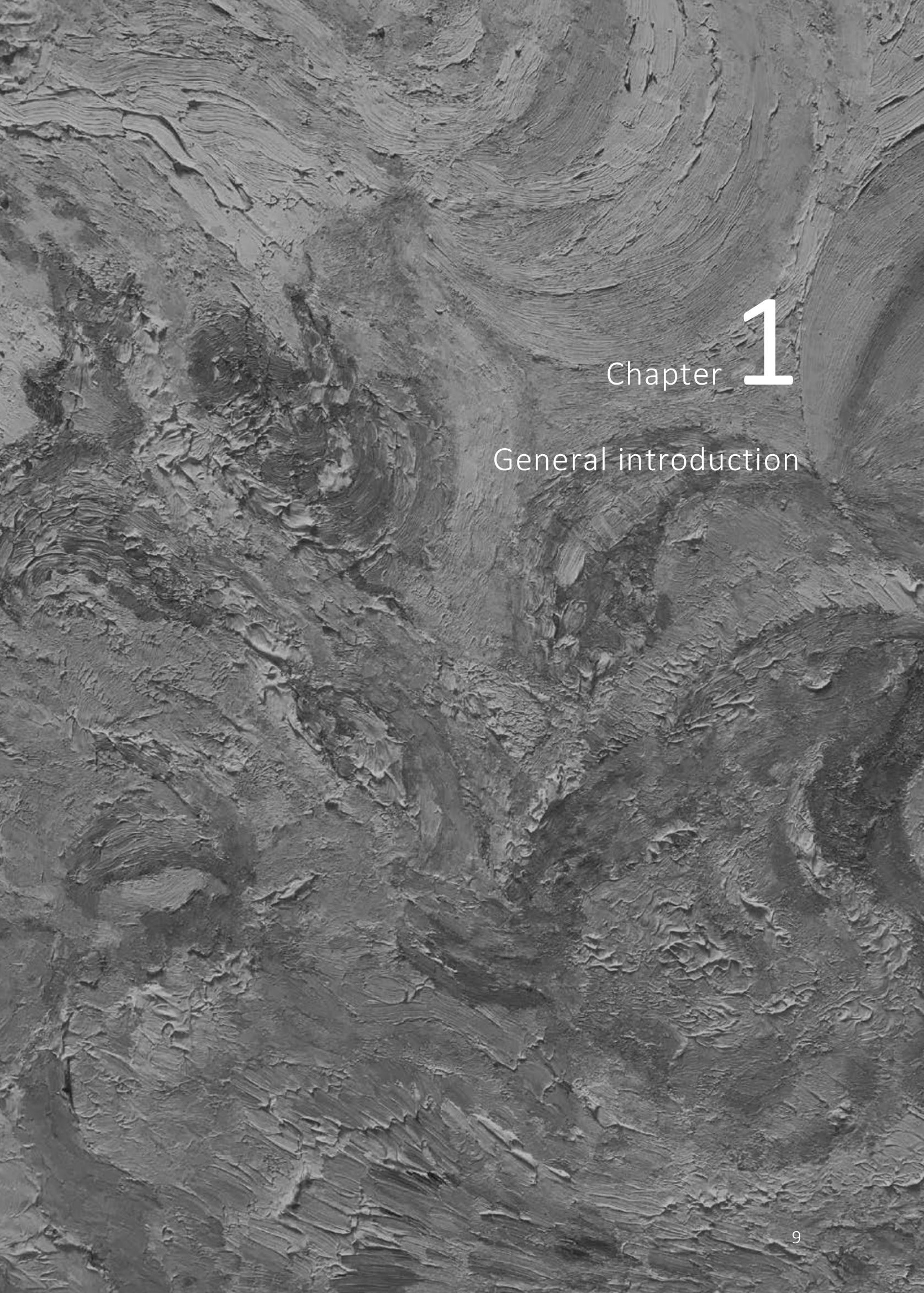





\section{CARTESIAN DUALISM, A PERSISTENT VIEW ON MIND AND BODY}

This thesis focuses on the interface between mind and body, more specifically mood disorders and physical conditions ('mood' and 'matter'). Although there is substantial evidence that mind and body do not operate separately from each other (Bercik et al., 2010; Kiecolt-Glaser et al., 2015), the general notion in current medicine still seems to support the legacy of Cartesian dualism of mind and body (Demertzi et al., 2009). A question often asked in clinical practice is, 'is it 'medical' or 'psychiatric'? Such dualism may deprive patients suffering from psychiatric disorders from adequate medical care and may leave psychiatric comorbidity in general medical conditions underdetected and undertreated.

In this thesis, the interface between mood disorders and physical conditions will be examined by addressing this topic from different angles. The introduction will provide background information on the topics studied in this thesis. First, we will outline current evidence indicating that psychiatric illness is not limited to the area above the eyebrows', but affects the whole body, and is associated with increased risk of physical illness, including an elevated risk of cardiovascular disease. We will specifically focus on a clustering of risk factors for cardiovascular disease, referred to as 'metabolic syndrome' in patients with bipolar disorder. Second, we will examine a dyad of diseases that illustrates the overlap between physical and psychiatric comorbidity: chronic pain and depression. We specifically examine the clinical efficacy of mindfulness-based cognitive therapy (MBCT), a form of psychotherapy that belongs to a new generation of acceptance-based treatments. Specifically, the role of body awareness in the efficacy of this intervention will be discussed. Third, we outline the increased evidence that mood disorders have a physical substrate in the brain and focus on a specific form of noninvasive electrical brain stimulation called cranial electrical stimulation (CES).

\section{Mental illness does not only affect mental health}

Patients suffering from severe mental illnesses (SMI), including schizophrenia, schizoaffective disorder, bipolar disorder and major depressive disorder have a reduced life expectancy ranging from 13-30 years. Approximately $60 \%$ of this excess mortality is accounted for by physical illness (De Hert et al., 2011). A recent meta-analysis from Walker et al. (2015) investigating mortality in mental disorders demonstrated higher mortality rates among patients with mental disorders in more recent studies compared to older studies, indicating that patients with mental disorders did not fully partake in the growing life expectancy of the general population. The authors estimate that $14.3 \%$ of deaths worldwide are attributable to mental health disorders, ranking these disorders among the most substantial causes of death worldwide (Walker et al., 2015). Despite these alarming findings, somatic health care for patients with psychiatric disorders still is largely neglected; only relatively recently have clinical guidelines 
emerged for the treatment of psychiatric disorders in the Netherlands that include recommendations for regular somatic screening. Moreover, not all Dutch clinical guidelines of SMI include somatic aspects. For example, the guideline for major depressive disorder (MDD) pays little attention to this (Spijker et al., 2013). In 2015 the first Dutch multidisciplinary guideline 'Somatic Screening for Patients with Severe Mental Illness' was published (Meeuwissen et al., 2015). Although this guideline represents a step in the right direction, regular somatic screening patients with $\mathrm{SMI}$ is for the most part not structurally implemented in daily clinical psychiatric care.

\section{Metabolic syndrome in bipolar disorder}

Most research on somatic comorbidity in mental illness so far has focused on schizophrenia, leaving physical health risks in other SMIs relatively underreported. In this thesis we focus on somatic comorbidity in bipolar disorder, particularly on metabolic syndrome. Bipolar spectrum disorder (BD) is a severe mental illness characterized by recurrent manic, hypomanic and depressive episodes with a lifetime prevalence of $2.4 \%$ worldwide (Merikangas et al., 2011). In addition to its disabling impact on mental health, it also affects physical health and is associated with premature death with a shortened life expectancy of approximately 10 years (Crump et al., 2013; De Hert et al., 2011). Cardiovascular disease (CVD) is the leading cause of death in BD with a mortality risk up to 2.5 fold higher compared to the general population (Roshanaei-Moghaddam \& Katon, 2009). Metabolic syndrome (MetS) comprises a clustering of interrelated metabolic risk factors for CVD and type 2 diabetes mellitus including central obesity, hypertension, dyslipidemia and glucose metabolism abnormalities (Grundy et al., 2005). MetS doubles the risk of CVD and leads to a five-fold risk of diabetes mellitus type 2 (Grundy, 2016). Much remains unknown about the causes of MetS, but central obesity and insulin resistance are thought to play an important role (Eckel et al., 2010). Research indicates that patients with $\mathrm{BD}$ are prone to having MetS. A recent meta-analysis reported a twofold risk compared to the general population with an overall mean prevalence rate of $37.3 \%$ (Vancampfort et al., 2013). The exact cause of this vulnerability is not known, but it is postulated that, in addition to unhealthy lifestyles and metabolic side effects of psychotropic drugs, genetic, neuroendocrine and immunoinflammatory factors play a role (Leboyer et al., 2012). One of the strongest moderators in the meta-analysis was geographic region, with prevalence rates varying from $64.2 \%$ in New Zealand and Australia, $49.3 \%$ in North America, and $32.4 \%$ in Europe, suggesting that genetic and environmental effects play a role in the influencing the rate of MetS in patients with bipolar disorder (Vancampfort et al., 2013). Within Europe, prevalence rates vary considerably per country as well (Mclntyre et al., 2010). However, to our knowledge, information on prevalence rates of MetS in BD in the Netherlands is lacking. The present study was aimed at estimating prevalence rate of MetS in BD in the Netherlands. Because there is considerable undertreatment of somatic comorbidity in patients with 
$\mathrm{BD}$, due to a variety of reasons including limited medical health care access and adherence problems, we also examined rates of drug treatment for MetS components.

\section{Chronic pain and depression}

Another perspective on the interface between mood and physical disorders studied in this thesis is the overlap between chronic pain and depression and the challenge of how to treat these. Chronic pain (CP) has been defined as "pain that persists past the normal time of healing" (Bonica, 1953). Usually pain is considered to be chronic when it lasts for more than 3 to 6 months (Merskey, 1994). Chronic pain is a disabling, costly condition with an estimated prevalence rate in Europe of $20 \%$ (Breivik et al., 2006). While acute pain is considered a symptom of (potential) tissue damage and has a protective function, chronic pain is considered maladaptive; a growing number of studies, especially from the neuroscience field, suggest that CP should be viewed as a disease rather than a symptom (Tracey \& Bushnell, 2009).

Over the past decades our understanding of chronic pain has grown substantially. The view on the neurobiological mechanisms of CP has shifted from the rather simplistic Cartesian theory explaining chronic pain as ongoing afferent nociceptive input to an otherwise healthy brain (in line with Descartes' famous illustration (Figure 1) of the foot and the flame describing the perception of pain as pulling a thread to the brain), to conceptualizing chronic pain as a multidimensional experience affecting brain structure and function, including both afferent (bottom-up) and efferent (top-down) mechanisms (Melzack \& Wall, 1965). Neuroimaging studies in patients with chronic pain consistently report pathological changes in the central nervous system including enhanced pain processing and grey matter decreases in important pain processing and modulatory regions (Schmidt-Wilcke, 2015).

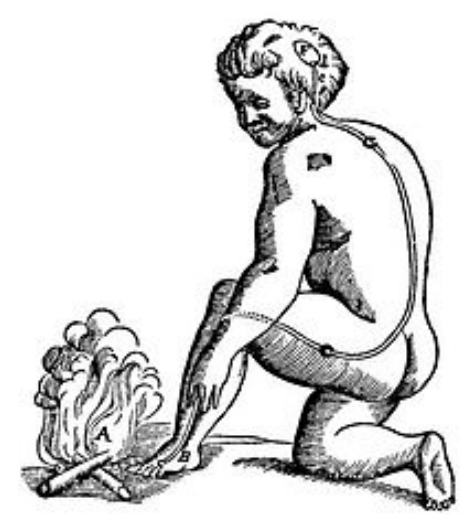

Figure 1. Illustration of the pain pathway according to Descartes. Source: Traite de l'homme (Treatise of Man) René Descartes, 1664. 
$\mathrm{CP}$ is associated with intense suffering and is highly comorbid with psychiatric disorders (Demyttenaere et al., 2007). Depression is the most common comorbid condition, with a mean prevalence rate of major depressive disorder (MDD) in patients with chronic pain ranging from $18 \%$ in population-based settings up to $85 \%$ in specialized pain clinics (Bair et al., 2003). The relationship between chronic pain and depression is complex. These conditions seem to promote each other's development; chronic pain is a strong predictor of developing major depression and vice versa (Kroenke et al., 2011). When CP and depression co-exist, this is associated with worse clinical outcome: patients with chronic pain and coexistent depression experience greater pain intensity, greater interference due to pain, and more pain behaviors (Ciaramella, 2017; Haythornthwaite et al., 1991). In addition, when depression is comorbid with chronic pain this is associated with poorer occupational (Sullivan et al., 1992) and social function (Holroyd et al., 2000), increased health care utilisation (Engel et al., 1996), and increased risk of attempted and completed suicide (Tang \& Crane, 2006).

Because oftentimes in chronic pain no biological substrate can be found, patients are frequently treated as though the problem is 'not real' and 'imaginary', trivializing the intense suffering that patients with $\mathrm{CP}$ experience. At the same time there is paradoxically a high rate of underdetection of highly prevalent comorbid psychiatric disorders, like MDD (Salazar et al., 2013). This is an illustrative example of how patients can be left undermanaged when taking a non-integrative approach to somatic and psychiatric disease.

Chronic pain and depression have substantial overlap in symptomatology and biological underpinnings. Functional Magnetic Resonance Imaging (fMRI) studies show that brain areas central to experiencing physical pain are activated in a similar way when experiencing emotional pain (Doan et al., 2015; Kross et al., 2011). The paindepression link is also supported by similar patterns of changes in neuroinflammatory markers including an increase in interleukins IL6, IL1 and brain-derived neurotrophic factor (BDNF) (Burke et al., 2015) These findings strongly suggest that physical and emotional pain co-occur so often because they share common neural mechanisms. The overlap of physical and emotional components of pain is also reflected in its definition: "...an unpleasant sensory and emotional experience associated with actual or potential tissue damage or described in terms of such damage."(Merskey, 1994).

While conventional analgesic treatments are highly effective for acute pain, chronic pain generally demonstrates poor response to these therapies. In addition, patients also experience burdensome side effects, and opioids - generally the most effective pharmacological intervention - have a substantial risk of addiction (Turk et al., 2011).

It has been suggested that processes underlying the emotional suffering should be the key focus in the treatment of chronic pain. Brain imaging studies in patients with chronic pain demonstrate enhanced activity primarily in emotional and motivational cortical-limbic circuitry, which is also affected in depression (Fang et al., 2012), as opposed to increased nociceptive representation (Mansour et al., 2014). 
In addition, numerous experimental studies have shown that negative affective states increase pain perception (Keefe, Lumley et al. 2001). Since depression has such a profound impact on pain perception, it makes sense to specifically target depressive symptoms when chronic pain is comorbid with clinical depression.

Successful treatment of depression comorbid with chronic pain is challenging, however. Antidepressant medications, including tricyclic antidepressants (TCA's) and serotonin- norepinephrine reuptake inhibitors (SNRI's) which are commonly prescribed to treat depression in chronic pain patients because of their co-occurring analgesic properties, often demonstrate poor response (Bair et al., 2004). Side effects and potential interactions with medications for chronic pain conditions pose an additional challenge for physicians and patients. Established psychotherapeutic interventions that focus on affective components of chronic pain, such as cognitive behavioral therapy (CBT), demonstrate at best only modest improvements in depression (Williams et al., 2012).

\section{Mindfulness-based cognitive therapy for the treatment of depression in chronic pain}

Because established psychotherapeutic interventions have limited efficacy on pain and comorbid depression, there seems room for improvement and alternative approaches. Recently, there has been an increased interest in a new generation of so-called 'third wave' psychological therapies, including mindfulness-based cognitive therapy (Segal, 2013), which contain a significant mindfulness component. Mindfulness has been defined as "paying attention in a particular way: on purpose, in the present moment, and non-judgmentally" (Kabat-Zinn, 1994). Where traditional CBT focuses mainly on the content of thoughts, third wave CBT focuses on one's relationship with thoughts, teaching patients to cultivate a mindful accepting relationship with thoughts, emotions and bodily sensations (Hofmann \& Asmundson, 2008). MBCT is a manualized 8 week group intervention that integrates elements of CBT and mindfulness meditation techniques and was originally developed and proven effective for depression relapse prevention (Kuyken et al., 2016); it focuses specifically on 'decentering' which refers to the process of disengagement of negative automatic thoughts, and it is associated with a significant reduction in depressive symptoms (Fresco et al., 2007). 'Third wave' CBT for acute depression shows promising results, but there is a lack of well-designed studies (Churchill et al., 2013). Studies of MBCT for treating depressive symptoms in chronic general medical conditions have shown encouraging results but have been hampered by methodological shortcomings as well (Gotink et al. 2015).

To our knowledge no study has been performed on MBCT specifically targeting acute depression in patients with chronic pain and comorbid acute depression.

This thesis reports on the results of a randomized controlled trial of an MBCT program specifically targeting acute depression in patients with chronic pain. 


\section{Mindfulness and Body Awareness}

Body awareness is an integral aspect of mindfulness interventions. It is a complex concept that has been ill defined; in earlier studies the term "body awareness" generally has a negative connotation and refers to a maladaptive cognitive attitude specified by hypervigilance to physical sensations, rumination and catastrophizing with a negative impact on pain perception and affective state (Eccleston et al., 1997). More recent research focusing on body awareness as a component of mindfulness, demonstrates that paying attention to bodily cues can actually have beneficial effects for a number of clinical diagnoses, including chronic pain and comorbid depression (van der Maas et al., 2016). Different styles in attention to bodily sensations may explain the contradictory findings of body awareness on clinical outcomes; paying attention to somatic cues in a mindful, non-judgemental way is associated with beneficial outcome whereas a state of anxious hypervigilance of bodily sensations is associated with poor outcome (Mehling et al., 2009). In an attempt to provide more clarity on this construct for research on interoception and assessment of mind-body therapies, Mehling et al. (2012) recently developed the Multidimensional Assessment of Interoceptive Awareness (MAIA), a multidimensional self-report measure of body awareness. This 32-item instrument includes 8 different scales designed to measure different modes in attention to bodily sensations (including pain) such as 'Attention Regulation' and 'Not Worrying' with the aim to distinguish between beneficial and maladaptive aspects of interoceptive body awareness (Mehling et al., 2012). Although body awareness seems to be an important aspect of therapies, particularly for painful conditions, there currently is a dearth of research on body awareness in relation to clinical outcomes. The study presented in this thesis investigated the effects of MBCT on body awareness in a sample of patients with chronic pain and comorbid depression. Furthermore, it explored which aspects of body awareness contribute to improvements in clinical outcome.

\section{Cranial Electrical Stimulation (CES)}

Decades ago psychiatry was unfortunately seperated from neurology and so to say 'left the brain for the mind'. Neurological disorders were thus deemed 'organic disorders of the brain' and psychiatric disorders 'functional disorders of the mind'.

This separation divorce took place in a period when scientists thought that the brain developed only during childhood and then remained relatively unchanged during adulthood. We now know that this was incorrect and that the brain continues to change during adulthood, a phenomenon referred to as neuroplasticity (Draganski et al., 2004; Maguire et al., 2000).

It has, not surprisingly, been shown that psychotherapeutic interventions, such as mindfulness-based therapies, affect brain structure (Fox et al., 2014; Holzel et al., 2011). In the past decade there has been a growing interest in harnessing the neuroplastic 
capacity of the brain for the treatment of psychiatric disorders by employing a variety of neuromodulatory interventions including electroconvulsive therapy (ECT), Deep Brain Stimulation (DBS), Transcranial Magnetic Stimulation (TMS), neurofeedback (NF), and transcranial Direct Current Stimulation (tDCS). Another more direct way of affecting brain activity in order to treat unipolar depression is a way of non-invasive stimulation of the brain called cranial electrical stimulation (CES). CES delivers a low intensity electrical current to the brain. To compare, the electric field induced by electroconvulsive therapy (ECT) is around 100-1000 fold higher (Lee et al., 2012). The electrical current in CES reaches cortical and subcortical areas of the brain and it is postulated that it exerts its effects by changes in neurotransmitters, although the exact mechanism is still not fully understood (Datta et al., 2013; Zaghi et al., 2010). It has been used for over 50 years for the treatment of a variety of conditions, including anxiety and depression, however, there is a lack of well-designed double blind studies on the effectiveness of CES; a recent Cochrane review on the effectiveness of CES for depression was not able to find a single study that met the quality standards for inclusion (Kavirajan et al., 2014).

Electroconvulsive therapy (ECT) is considered a treatment of choice for severe treatment resistant depression (van den Broek et al., 2010). While ECT has proven to be very efficacious in treating depression it also may cause debilitating side effects including significant memory loss (van den Broek et al., 2010). CES might represent an alternative option impacting on brain activity with only mild side effects (skin irritation at the electrode site and headaches) (Kirsch \& Nichols, 2013), which makes it a compelling treatment option, particularly for treatment resistant depression. It would be helpful for both patients and psychiatrists to have more rigorous randomized controlled trials performed on the effectiveness on CES for depression, to make informed choices about this widely available treatment modality. There is a broad variety of CES devices using different electrical parameters. This thesis includes a report of the first double blind randomized controlled study on the safety and effectiveness of one of the more popular CES devices that has been marketed in the US for depression since the seventies; the FW-100 Fisher Wallace Cranial Stimulator model SLB201-M (Fisher Wallace Laboratories, New York, NY), as an add-on therapy for treatment resistant MDD.

\section{AIMS OF THIS THESIS}

We aim to study the interface between mood disorders and their physical aspects, including cardiovascular disease risk in patients with bipolar disorder and the effectiveness of a mindfulness-based intervention for the treatment of depression in patients with chronic pain. This thesis also addresses the notion that mood disturbances have a biological substrate in the brain. This is reflected in a study on CES, a form of 
non-invasive electrical brain stimulation to treat major depressive disorder, that is thought to exert its effects by modulating brain activity.

This thesis has the following specific aims:

1. Examine the prevalence rate and factors associated with metabolic syndrome in patients with bipolar disorder

2. Study the effectiveness of mindfulness-based cognitive therapy (MBCT) for the treatment of unipolar depression in patients with chronic pain

3. Examine the effects of MBCT on body awareness and explore its role in the effectiveness of MBCT for unipolar depression in patients with $\mathrm{CP}$

4. Study the effectiveness of a form of non invasive brain stimulation: cranial electrical stimulation (CES) as add on therapy for treatment resistant depression

\section{OUTLINE}

Part 1

This section concerns elevated cardiovascular risk in patients with bipolar disorder. Chapter 2 reports on the first study that has examined the prevalence rate and factors associated with metabolic syndrome in Dutch patients with bipolar disorder. It also estimates rates of treatment of metabolic syndrome components.

\section{Part 2}

This section concerns two studies performed on mindfulness-based cognitive therapy (MBCT) for unipolar depression in patients with chronic pain. In Chapter 3 we investigate the effectiveness of an 8 weeks mindfulness-based cognitive therapy (MBCT) program for the treatment of depression in patients suffering from chronic pain. Chapter 4 is concerned with the role of body awareness in the effectiveness of MBCT in patients with chronic pain and comorbid depression.

\section{Part 3}

This section concerns the effectiveness of cranial electrical stimulation (CES) for treatment resistant major depressive disorder (MDD). In Chapter 5 we report on a study that aims to provide preliminary evidence for the safety and effectiveness of a specific form of CES as an add-on therapy for treatment resistant MDD.

Chapter 6 summarizes the main findings and provides a general discussion of the implications for clinical practice and future research. 


\section{REFERENCES}

Bair, M. J., Robinson, R. L., Eckert, G. J., Stang, P. E., Croghan, T. W., \& Kroenke, K. (2004). Impact of pain on depression treatment response in primary care. Psychosom Med, 66(1), 17-22.

Bair, M. J., Robinson, R. L., Katon, W., \& Kroenke, K. (2003). Depression and pain comorbidity: a literature review. Arch Intern Med, 163(20), 2433-2445. doi: 10.1001/archinte.163.20.2433

Bercik, P., Verdu, E. F., Foster, J. A., Macri, J., Potter, M., Huang, X., . . Collins, S. M. (2010). Chronic gastrointestinal inflammation induces anxiety-like behavior and alters central nervous system biochemistry in mice. Gastroenterology, 139(6), 2102-2112 e2101. doi: 10.1053/j.gastro.2010.06.063

Bonica, JJ. (1953). The management of pain. Philidelphia: Lea \& Febiger.

Breivik, H., Collett, B., Ventafridda, V., Cohen, R., \& Gallacher, D. (2006). Survey of chronic pain in Europe: prevalence, impact on daily life, and treatment. Eur J Pain, 10(4), 287-333. doi: 10.1016/j.ejpain. 2005.06.009

Burke, N. N., Finn, D. P., \& Roche, M. (2015). Neuroinflammatory Mechanisms Linking Pain and Depression. Mod Trends Pharmacopsychiatri, 30, 36-50. doi: 10.1159/000435931

Churchill, R., Moore, T. H., Furukawa, T. A., Caldwell, D. M., Davies, P., Jones, H., . . Hunot, V. (2013). 'Third wave' cognitive and behavioural therapies versus treatment as usual for depression. Cochrane Database Syst Rev(10), CD008705. doi: 10.1002/14651858.CD008705.pub2

Ciaramella, A. (2017). Mood Spectrum Disorders and Perception of Pain. Psychiatr Q. doi: 10.1007/s11126017-9489-8

Crump, C., Sundquist, K., Winkleby, M. A., \& Sundquist, J. (2013). Comorbidities and mortality in bipolar disorder: a Swedish national cohort study. JAMA Psychiatry, 70(9), 931-939. doi: 10.1001/ jamapsychiatry.2013.1394

Datta, A., Dmochowski, J. P., Guleyupoglu, B., Bikson, M., \& Fregni, F. (2013). Cranial electrotherapy stimulation and transcranial pulsed current stimulation: a computer based high-resolution modeling study. Neuroimage, 65, 280-287. doi: 10.1016/j.neuroimage.2012.09.062

De Hert, M., Correll, C. U., Bobes, J., Cetkovich-Bakmas, M., Cohen, D., Asai, I., . . Leucht, S. (2011). Physical illness in patients with severe mental disorders. I. Prevalence, impact of medications and disparities in health care. World Psychiatry, 10(1), 52-77.

Demertzi, A., Liew, C., Ledoux, D., Bruno, M. A., Sharpe, M., Laureys, S., \& Zeman, A. (2009). Dualism persists in the science of mind. Ann N Y Acad Sci, 1157, 1-9. doi: 10.1111/j.1749-6632.2008.04117.x

Demyttenaere, K., Bruffaerts, R., Lee, S., Posada-Villa, J., Kovess, V., Angermeyer, M. C., . . Von Korff, M. (2007). Mental disorders among persons with chronic back or neck pain: results from the World Mental Health Surveys. Pain, 129(3), 332-342. doi: 10.1016/j.pain.2007.01.022

Doan, L., Manders, T., \& Wang, J. (2015). Neuroplasticity underlying the comorbidity of pain and depression. Neural Plast, 2015, 504691. doi: 10.1155/2015/504691

Draganski, B., Gaser, C., Busch, V., Schuierer, G., Bogdahn, U., \& May, A. (2004). Neuroplasticity: changes in grey matter induced by training. Nature, 427(6972), 311-312. doi: 10.1038/427311a

Eccleston, C., Crombez, G., Aldrich, S., \& Stannard, C. (1997). Attention and somatic awareness in chronic pain. Pain, 72(1-2), 209-215.

Eckel, R. H., Alberti, K. G., Grundy, S. M., \& Zimmet, P. Z. (2010). The metabolic syndrome. Lancet, 375(9710), 181-183. doi: 10.1016/S0140-6736(09)61794-3

Engel, C. C., von Korff, M., \& Katon, W. J. (1996). Back pain in primary care: predictors of high health-care costs. Pain, 65(2-3), 197-204.

Fang, P., Zeng, L. L., Shen, H., Wang, L., Li, B., Liu, L., \& Hu, D. (2012). Increased cortical-limbic anatomical network connectivity in major depression revealed by diffusion tensor imaging. PLoS One, 7(9), e45972. doi: 10.1371/journal.pone.0045972

Fox, K. C., Nijeboer, S., Dixon, M. L., Floman, J. L., Ellamil, M., Rumak, S. P., . . Christoff, K. (2014). Is meditation associated with altered brain structure? A systematic review and meta-analysis of 
morphometric neuroimaging in meditation practitioners. Neurosci Biobehav Rev, 43, 48-73. doi: 10.1016/j.neubiorev.2014.03.016

Fresco, D.M., Segal, Z.V., Buis, T., \& Kennedy, S. (2007). Relationship of posttreatment decentering and cognitive reactivity to relapse in major depression. Journal of Consulting and clinical Psychology, 75(3), 447.

Grundy, S. M. (2016). Metabolic syndrome update. Trends Cardiovasc Med, 26(4), 364-373. doi: 10.1016/ j.tcm.2015.10.004

Grundy, S. M., Cleeman, J. I., Daniels, S. R., Donato, K. A., Eckel, R. H., Franklin, B. A., . . . Blood, Institute. (2005). Diagnosis and management of the metabolic syndrome: an American Heart Association/National Heart, Lung, and Blood Institute Scientific Statement. Circulation, 112(17), 2735-2752. doi: 10.1161/CIRCULATIONAHA.105.169404

Haythornthwaite, J. A., Sieber, W. J., \& Kerns, R. D. (1991). Depression and the chronic pain experience. Pain, 46(2), 177-184.

Hofmann, S. G., \& Asmundson, G. J. (2008). Acceptance and mindfulness-based therapy: new wave or old hat? Clin Psychol Rev, 28(1), 1-16. doi: 10.1016/j.cpr.2007.09.003

Holroyd, K. A., Stensland, M., Lipchik, G. L., Hill, K. R., O'Donnell, F. S., \& Cordingley, G. (2000). Psychosocial correlates and impact of chronic tension-type headaches. Headache, 40(1), 3-16.

Holzel, B. K., Carmody, J., Vangel, M., Congleton, C., Yerramsetti, S. M., Gard, T., \& Lazar, S. W. (2011). Mindfulness practice leads to increases in regional brain gray matter density. Psychiatry Res, 191(1), 3643. doi: 10.1016/j.pscychresns.2010.08.006

Kabat-Zinn, J. (1994). Wherever you go, there you are: Mindfulness meditation in everyday life. New York: Hyperion.

Kavirajan, H. C., Lueck, K., \& Chuang, K. (2014). Alternating current cranial electrotherapy stimulation (CES) for depression. Cochrane Database Syst Rev(7), CD010521. doi: 10.1002/14651858.CD010521.pub2

Kiecolt-Glaser, J. K., Derry, H. M., \& Fagundes, C. P. (2015). Inflammation: depression fans the flames and feasts on the heat. Am J Psychiatry, 172(11), 1075-1091. doi: 10.1176/appi.ajp.2015.15020152

Kirsch, D. L., \& Nichols, F. (2013). Cranial electrotherapy stimulation for treatment of anxiety, depression, and insomnia. Psychiatr Clin North Am, 36(1), 169-176. doi: 10.1016/j.psc.2013.01.006

Kroenke, K., Wu, J., Bair, M. J., Krebs, E. E., Damush, T. M., \& Tu, W. (2011). Reciprocal relationship between pain and depression: a 12-month longitudinal analysis in primary care. J Pain, 12(9), 964-973. doi: 10.1016/j.jpain.2011.03.003

Kross, E., Berman, M. G., Mischel, W., Smith, E. E., \& Wager, T. D. (2011). Social rejection shares somatosensory representations with physical pain. Proc Natl Acad Sci U S A, 108(15), 6270-6275. doi: 10.1073/pnas.1102693108

Kuyken, W., Warren, F. C., Taylor, R. S., Whalley, B., Crane, C., Bondolfi, G., . . Dalgleish, T. (2016). Efficacy of Mindfulness-Based Cognitive Therapy in Prevention of Depressive Relapse: An Individual Patient Data Meta-analysis From Randomized Trials. JAMA Psychiatry, 73(6), 565-574. doi: 10.1001/jamapsychiatry. 2016.0076

Leboyer, M., Soreca, I., Scott, J., Frye, M., Henry, C., Tamouza, R., \& Kupfer, D. J. (2012). Can bipolar disorder be viewed as a multi-system inflammatory disease? J Affect Disord, 141(1), 1-10. doi: 10.1016/j.jad. 2011.12.049

Lee, W. H., Deng, Z. D., Kim, T. S., Laine, A. F., Lisanby, S. H., \& Peterchev, A. V. (2012). Regional electric field induced by electroconvulsive therapy in a realistic finite element head model: influence of white matter anisotropic conductivity. Neuroimage, 59(3), 2110-2123. doi: 10.1016/j.neuroimage.2011.10.029

Maguire, E. A., Gadian, D. G., Johnsrude, I. S., Good, C. D., Ashburner, J., Frackowiak, R. S., \& Frith, C. D. (2000). Navigation-related structural change in the hippocampi of taxi drivers. Proc Natl Acad Sci U S A, 97(8), 4398-4403. doi: 10.1073/pnas.070039597

Mansour, A. R., Farmer, M. A., Baliki, M. N., \& Apkarian, A. V. (2014). Chronic pain: the role of learning and brain plasticity. Restor Neurol Neurosci, 32(1), 129-139. doi: 10.3233/RNN-139003

McIntyre, R. S., Danilewitz, M., Liauw, S. S., Kemp, D. E., Nguyen, H. T., Kahn, L. S., . . Taylor, V. H. (2010). Bipolar disorder and metabolic syndrome: an international perspective. J Affect Disord, 126(3), 366-387. doi: 10.1016/j.jad.2010.04.012 
Meeuwissen, J.A.C., van Meijel, B. , van Piere, M. , Bak, M., Bakkenes, M., van der Kellen, D. , ... Hermens, M. (2015). Multidisciplinaire Richtlijn Somatische Screening bij Patiënten met een Ernstige Psychische Aandoening. Utrecht: Trimbos Instituut.

Mehling, W. E., Gopisetty, V., Daubenmier, J., Price, C. J., Hecht, F. M., \& Stewart, A. (2009). Body awareness: construct and self-report measures. PLoS One, 4(5), e5614. doi: 10.1371/journal.pone.0005614

Mehling, W. E., Price, C., Daubenmier, J. J., Acree, M., Bartmess, E., \& Stewart, A. (2012). The Multidimensional Assessment of Interoceptive Awareness (MAIA). PLoS One, 7(11), e48230. doi: 10.1371/journal.pone.0048230

Melzack, R., \& Wall, P. D. (1965). Pain mechanisms: a new theory. Science, 150(3699), 971-979.

Merikangas, K. R., Jin, R., He, J. P., Kessler, R. C., Lee, S., Sampson, N. A., . . Zarkov, Z. (2011). Prevalence and correlates of bipolar spectrum disorder in the world mental health survey initiative. Arch Gen Psychiatry, 68(3), 241-251. doi: 10.1001/archgenpsychiatry.2011.12

Merskey, H. (1994). Classification of chronic pain (Vol. 2nd ed.). Seattle: IASP Press.

Roshanaei-Moghaddam, B., \& Katon, W. (2009). Premature mortality from general medical illnesses among persons with bipolar disorder: a review. Psychiatr Serv, 60(2), 147-156. doi: 10.1176/appi.ps.60.2.147

Salazar, A., Duenas, M., Mico, J. A., Ojeda, B., Aguera-Ortiz, L., Cervilla, J. A., \& Failde, I. (2013). Undiagnosed mood disorders and sleep disturbances in primary care patients with chronic musculoskeletal pain. Pain Med, 14(9), 1416-1425. doi: 10.1111/pme.12165

Schmidt-Wilcke, T. (2015). Neuroimaging of chronic pain. Best Pract Res Clin Rheumatol, 29(1), 29-41. doi: 10.1016/j.berh.2015.04.030

Segal, Z; Williams, J; Teasdale,J. (2013). Mindfulness-Based Cognitive Therapy for Depression, second edition: The Guilford Press.

Spijker, J, Bockting, C.L.H., Meeuwissen, J.A.C., van Vliet, I.M., Emmelkamp, P.M.G., Hermens, M.L.M., \& Balkom, A.L.J.M. (2013). Multidisciplinaire richtlijn Depressie (Derde revisie). Richtlijn voor de diagnostiek, behandeling en begeleiding van volwassen patiënten met een depressieve stoornis. Utrecht: Trimbos Instituut.

Sullivan, M. J., Reesor, K., Mikail, S., \& Fisher, R. (1992). The treatment of depression in chronic low back pain: review and recommendations. Pain, 50(1), 5-13.

Tang, N. K., \& Crane, C. (2006). Suicidality in chronic pain: a review of the prevalence, risk factors and psychological links. Psychol Med, 36(5), 575-586. doi: 10.1017/S0033291705006859

Tracey, I., \& Bushnell, M. C. (2009). How neuroimaging studies have challenged us to rethink: is chronic pain a disease? J Pain, 10(11), 1113-1120. doi: 10.1016/j.jpain.2009.09.001

Turk, D. C., Wilson, H. D., \& Cahana, A. (2011). Treatment of chronic non-cancer pain. Lancet, 377(9784), 2226-2235. doi: 10.1016/S0140-6736(11)60402-9

van den Broek, W.W., Bïrkenhäger, T.K., de Boer, D., Burggraaf, J.P., van Gemert, B., Groenland, T.H.N., . . . Wijkstra, J. (2010). Richtlijn Elektroconvulsietherapie. Utrecht: Nederlandse Vereniging voor Psychiatrie.

van der Maas, L. C., Koke, A., Bosscher, R. J., Twisk, J. W., Janssen, T. W., \& Peters, M. (2016). Body Awareness as an Important Target in Multidisciplinary Chronic Pain Treatment: Mediation and Subgroup Analyses. Clin J Pain, 32(9), 763-772. doi: 10.1097/AJP.0000000000000320

Vancampfort, D., Vansteelandt, K., Correll, C. U., Mitchell, A. J., De Herdt, A., Sienaert, P., . . . De Hert, M. (2013). Metabolic syndrome and metabolic abnormalities in bipolar disorder: a meta-analysis of prevalence rates and moderators. Am J Psychiatry, 170(3), 265-274. doi: 10.1176/appi.ajp.2012. 12050620

Walker, E. R., McGee, R. E., \& Druss, B. G. (2015). Mortality in mental disorders and global disease burden implications: a systematic review and meta-analysis. JAMA Psychiatry, 72(4), 334-341. doi: 10.1001/ jamapsychiatry.2014.2502

Williams, A. C., Eccleston, C., \& Morley, S. (2012). Psychological therapies for the management of chronic pain (excluding headache) in adults. Cochrane Database Syst Rev, 11, CD007407. doi: 10.1002/14651858. CD007407.pub3 


\section{Chapter 1}

Zaghi, S., Acar, M., Hultgren, B., Boggio, P. S., \& Fregni, F. (2010). Noninvasive brain stimulation with lowintensity electrical currents: putative mechanisms of action for direct and alternating current stimulation. Neuroscientist, 16(3), 285-307. doi: 10.1177/1073858409336227 


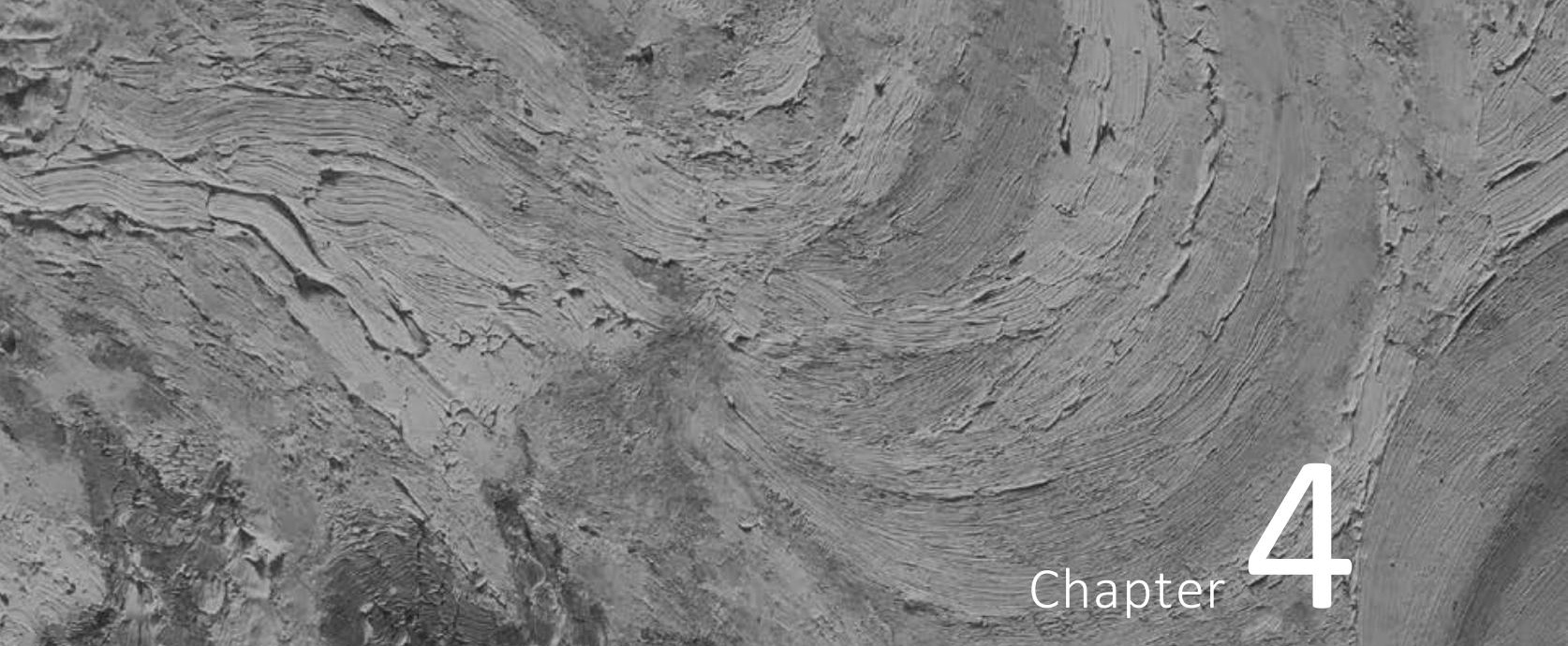




\section{ABSTRACT}

Body awareness has been proposed as one of the major mechanisms of mindfulness interventions, and it has been shown that chronic pain and depression are associated with decreased levels of body awareness. We investigated the effect of mindfulnessbased cognitive therapy (MBCT) on body awareness in patients with chronic pain and comorbid active depression compared to treatment as usual (TAU; N=31). Body awareness was measured by a subset of the Multidimensional Assessment of Interoceptive Awareness (MAIA) scales deemed most relevant for the population. These included: Noticing, Not-Distracting, Attention Regulation, Emotional Awareness, and Self-Regulation. In addition, pain catastrophizing was measured by the Pain Catastrophizing Scale (PCS). These scales had adequate to high internal consistency in the current sample. Depression severity was measured by the Quick Inventory of Depressive Symptomatology - Clinician rated (QIDS- $C_{16}$ ). Increases in the MBCT group were significantly greater than in the TAU group on the 'Self-Regulation' and 'Not Distracting' scales. Furthermore, the positive effect of MBCT on depression severity was mediated by 'Not Distracting'. These findings provide preliminary evidence that a mindfulness-based intervention may increase facets of body awareness as assessed with the MAIA in a population of pain patients with depression. Furthermore, they are consistent with a long hypothesized mechanism for mindfulness and emphasize the clinical relevance of body awareness. 


\section{INTRODUCTION}

Chronic pain is a highly prevalent and disabling condition with major impact on individuals, their significant others, and society (Turk et al., 2011). Prevalence rates for chronic pain range from 10\% to 30\% (K. J. Reid et al., 2011), and Major Depressive Disorder (MDD) is the most frequent psychiatric disorder in patients with chronic pain, with a 12 -month prevalence ranging from $18 \%$ in population based settings up to $85 \%$ in specialized pain clinics (Bair et al., 2003). Since patients who suffer from both chronic pain and depression are particularly difficult to treat (Tunks, 2008), more effective interventions for this population are needed.

Mindfulness-based interventions have recently been shown to be effective for the treatment of chronic pain with small to moderate effect sizes on pain and depression (Veehof et al., 2011). Mindfulness-based therapies, and particularly mindfulness based cognitive therapy (MBCT), also have been shown to be effective for relapse prevention in recurrent depression and the treatment of active depression (Hofmann et al., 2010; Marchand, 2012; Piet \& Hougaard, 2011; Sipe \& Eisendrath, 2012). Results from a recent pilot randomized controlled trial (RCT) suggested that MBCT may be an effective intervention for the treatment of active depression in a population with chronic pain (de Jong et al., 2017)

Because mindfulness-based interventions seem beneficial for chronic pain and depression, the question arises how mindfulness exerts its effects. Mindfulness entails paying attention to present moment experience, including thoughts, emotions and bodily sensations. Training body awareness is a significant component of most mindfulness-based interventions, including a body scan, in which individuals specifically pay attention to all parts of the body; and yoga, which entails paying attention to movements of the body (Kabat-Zinn, 1990; Segal, 2013). Body awareness has been proposed as a potential mechanism for the therapeutic effects of mindfulness and is considered an integral part of the mindfulness construct (N. Farb et al., 2015; Hölzel et al., 2011; Mehling et al., 2009). The definition of body awareness emphasizes the fact that this is a complex multi-dimensional construct: "the sensory awareness that originates from the body's physiological states, processes (including pain and emotion), and actions (including movement), and functions as an interactive process that includes a person's appraisal and is shaped by attitudes, beliefs, and experience in their social and cultural context" (Mehling et al., 2012, p. 2). In this article, the terms body awareness and interoceptive awareness are used interchangeably.

Several studies lend support to the notion of enhanced body awareness through mindfulness training. For example, meditators have been reported to show greater coherence between objective physiological data and their subjective experience - in regard to both emotional experience (Sze et al., 2010) and sensitivity of body regions (Fox et al., 2012). With regard to the heart beat perception task, which assesses the ability of subjects to accurately determine their heartbeat rate by comparing the 
subjectively counted heartbeats to heartbeats measured by an electrocardiogram, a number of studies with small sample sizes did not find increased interoceptive accuracy in meditators (Khalsa et al., 2008; Melloni et al., 2013; Nielsen \& Kaszniak, 2006; Parkin et al., 2013). However, a large $(N=160)$, recent longitudinal study revealed that heart beat accuracy was increased after 39 weeks of a mindfulness-based contemplative intervention (Bornemann \& Singer, 2015). Neuroimaging studies indicate mindfulness training-related changes in brain function and structure in regions that are thought to be involved in body awareness (N. A. Farb et al., 2010; N. A. S. Farb et al., 2013; Gard et al., 2012; Hölzel et al., 2008; Lazar et al., 2005).

It has been long postulated that interoceptive awareness plays an important role in the experience of emotions (James, 1984) and there is empirical evidence that the extent to which one can accurately perceive bodily functions has a positive relationship with the intensity of emotions (Herbert et al., 2007). Former studies on this topic in clinical populations have mainly focused on anxiety disorders, which demonstrated a close association with increased interoceptive awareness (A. Ehlers \& Breuer, 1996). Depression often entails anhedonia and blunted emotions. In fact, body awareness has been found to be reduced in individuals with depression (Dunn et al., 2007; Anke Ehlers \& Breuer, 1992), and higher levels of depressive symptoms are associated with decreased body awareness in healthy subjects (Pollatos et al., 2009). Reduction in interoceptive awareness in depression is also supported by a recent neuro-imaging study, which shows reduced effective connectivity in networks involved in interoception in patients with melancholia (Hyett et al., 2015). A recent study revealed that body awareness therapy resulted in decreased self-rated depressive symptoms, but no changes in body awareness were found (Danielsson et al., 2014). Whether improvements in body awareness lead to reduced depression has yet to be established.

Variations in body awareness appear to be particularly important in patients with chronic pain. Mehling et al. (2013), for example, reported differences in some dimensions of interoceptive awareness between patients with current or past low back pain and mind-body trained individuals. Neuro-scientific evidence indicates that some of the brain regions activated during pain are also activated when engaging in interoceptive awareness (Craig, 2003). Attention styles towards chronic pain sensations are of key importance for psychological pain management (Johnston et al., 2012), and fMRI studies suggest that mindfulness meditation facilitates a reduction of pain through increased sensory processing (Gard et al., 2012). Thus, body awareness and pain perception are closely linked on a neuro-biological level, such that the enhancement of specific styles or dimensions of body awareness may facilitate the self-regulation of pain.

Although body awareness is considered an integral part of the mindfulness construct, there has been a paucity of instruments that measure body awareness (Mehling et al., 2009). Previous body awareness questionnaires either measured nonadaptive forms of body awareness (as indicated in disorders such as panic disorder), 
were uni-dimensional, lacked systematic development, or did not measure body awareness specifically, but rather a more general observation ability (Mehling et al., 2012). The Multidimensional Assessment of Interoceptive Awareness (MAIA; Mehling et al., 2012) scale is a relatively new, multifaceted body awareness questionnaire that intends to fill the apparent gap.

Bornemann et al. (2015), who recently translated the MAIA into German and demonstrated good scale properties, found that a three-month contemplative training that included bodyscan and breath meditation techniques lead to changes on several scales in a sample of individuals with good psychological and physical health. Values on all scales increased following the training, and changes were significantly greater compared to a retest control group for most of the scales.

While there is evidence for an effect of a mind-body intervention on body awareness as measured with the MAIA in a healthy sample, no intervention studies have been reported on effects in chronic pain patients or in depressed individuals. In the present pilot RCT we investigated the longitudinal effects of MBCT on body awareness, as measured by the MAIA in a population of patients with chronic pain and comorbid depression. It was hypothesized that MBCT enhances aspects of body awareness in this population. Furthermore, as this is the first study using the MAIA in a sample of patients with chronic pain and comorbid active depression, we investigated the reliability of the MAIA scales in this population.

\section{METHODS}

\section{Participants}

Participants in this add-on study were part of a larger clinical trial reported elsewhere (de Jong et al., 2017). Patients were recruited from different outpatient clinics through introduction of the study by their physicians, as well as via web-based advertisements and through several online mailing lists. After phone screening and a subsequent inperson screening visit, eligible participants were offered enrollment and were randomly assigned to treatment as usual (TAU) or TAU plus mindfulness-based cognitive therapy (MBCT). English-language literate individuals aged 18 or older were eligible if they (a) had persistent chronic pain for a minimum of 3 months, (b) met the DSM-IV criteria for Major Depressive Disorder (MDD), Dysthymic Disorder, or Depressive disorder Not Otherwise Specified (NOS), and (c) a score $\geq 10$ on the QIDS- $C_{16}$ scale. After initiating the study the cutoff was reduced to a QIDS- $C_{16}$ score $\geq 6$ (indicative of at least mild depressive symptoms) to allow more ample recruitment.

Exclusion criteria were: (a) serious suicide or homicide risk; (b) current or past bipolar disorder, current psychotic symptoms, or a current or past primary psychotic disorder; (c) diagnosis of substance abuse or dependence disorder during the last 3 
months; (d) general condition that impedes attendance in group interventions, such as severe personality disorders, cognitive impairment, or tendencies toward physical aggression; (e) severe and unstable medical illness including cardiovascular, hepatic, renal, respiratory, endocrine, neurological or hematological disease; and (f) significant present meditation practice with more than 3 hours of mindfulness, insight, or vipassana meditation per week. Patients were requested to keep their psychological and pharmacological treatment as stable as possible from 8 weeks before the beginning of the study until its conclusion.

Seventy-one participants were screened, of which 40 were randomized to TAU or $\mathrm{MBCT}+\mathrm{TAU}$ in a 1:2 ratio (Figure 1 ). Participants received $\$ 40$ for completed study participation and provided written informed consent. The study was approved by the Partners Human Research Committee, Massachusetts General Hospital (protocol 2011P-001699/1).

\section{Measures}

Multidimensional Assessment of Interoceptive Awareness (MAIA). The MAIA is a 32-item instrument that assesses body awareness on 6-point Likert-type scales that range from 0 (Never) to 5 (Always). It comprises eight scales, namely Noticing, Not-Distracting, NotWorrying, Attention Regulation, Emotional Awareness, Self-Regulation, Body Listening and Trusting (Mehling et al., 2012). The eight scales have been shown to have adequate to excellent internal-consistency reliabilities, with Cronbach's alphas from 0.66 to 0.87 , and above 0.70 for five of the eight scales (Mehling et al., 2012). Because the current study was an add-on to a larger study, subject burden had to be kept to a minimum. For this reason only the scales deemed most relevant for the specific population were administered, namely Noticing, Not-Distracting, Attention Regulation, Emotional Awareness, and Self-Regulation.

The Noticing scale assesses the awareness of comfortable, neutral, and uncomfortable body sensations. Not-Distracting refers to not ignoring or distracting oneself from uncomfortable body sensations such as pain. Attention Regulation is the ability to maintain and regulate attention to body sensations, and Emotional Awareness is defined as consciousness of the interrelation of emotions and body sensations. SelfRegulation refers to the ability to control psychological distress by consciously attending to body sensations (Mehling et al., 2013). The MAIA Not Worrying scale assesses worrying or feeling emotionally distressed in response to uncomfortable body sensations including pain and was not administered, since its items are similar to the Pain Catastrophizing Scale, which was included in the larger study.

Pain Catastrophizing Scale (PCS). The PCS is a 13-item scale, comprised of three subscales, that measures pain catastrophizing. Pain catastrophizing is defined as "an exaggerated negative mental set brought to bear during (actual or anticipated) painful experience" (Sullivan et al., 2001, p. 52). The PCS total score can range from 0 to 52 and 
has been shown to have excellent reliability (Cronbach's alpha $=0.87$; Sullivan et al., 2001).

Quick Inventory of Depressive Symptomatology - Clinician rated (QIDS- $C_{16}$ ). The QIDS$\mathrm{C}$ is a widely used clinician rated instrument to assess depression symptom severity. The instrument is comprised of 16 items, has good psychometric properties, score range from 0-27 and is sensitive to changes in depressive severity (Rush et al., 2003; Trivedi et al., 2004).

\section{Procedure}

Eligible participants were randomly assigned to TAU (control group) or MBCT + TAU (intervention group) in a 1:2 ratio, which allowed the main project to fill the MBCT groups with participants more quickly. An independent researcher not involved in the project generated the randomisation sequence in blocks of five (using the sequence generator on www.random.org). In order to assure equal gender distribution in both groups we stratified for gender. The intervention group received an 8-week MBCT group skills program. Interoceptive awareness, pain catastrophizing, and depression were assessed at baseline (week 0), midpoint (week 4), and endpoint (week 8)).

\section{Intervention}

The intervention consisted of an 8-week group skills program with one 2-hour mindfulness training session each week and individual exercises for homework practice. It was modeled on the MBCT program developed by Segal (2013), which was developed as a program to address recurrent depressive episodes and combines elements of cognitive behavioral therapy (CBT), such as psycho-education, with experiential mindfulness practices. The program is intended to teach and foster a non-judgmental, accepting attitude towards one's internal and external experience. For the current study the original program was adapted to our specific population by modifying the psychoeducation and cognitive behavioral therapy elements to a depressed CP population. This included psycho-education linking $\mathrm{CP}$, negative thoughts, negative emotions, and depressive behaviors such as withdrawal; identifying automatic thoughts related to $\mathrm{CP}$; and paying attention to behavioral elements such as pacing of activities. We also included meditations that specifically focused on cultivating mindfulness in relationship to $\mathrm{CP}$. The $\mathrm{MBCT}$ program was led by two instructors, an experienced licensed independent clinical social worker (LICSW) and a fellow in psychology and was provided free of charge. Subjects that were assigned to TAU were waitlisted and offered the MBCT treatment after completion of the study. TAU included all regular visits with the pain physician, psychiatrist, psychotherapist and prescribed pain and/or antidepressant medications. 


\section{Statistical analyses}

Differences in patient characteristics at baseline were assessed by performing independent-samples t-tests for continuous variables and Chi-square tests for categorical variables. To evaluate internal consistency/reliability, Cronbach's alphas were assessed. Inter-scale correlations were obtained for the MAIA subscales and the PCS total score based on the data of all subjects at baseline. The effects of intervention/group (MBCT + TAU vs TAU) and time (baseline vs. endpoint) on the dependent variables body awareness and pain catastrophizing were assessed by conducting repeated measures analysis of variance (rmANOVA), with time as repeated measure, treatment group as between-subjects factor, and MAIA scales and PCS as dependent variables. Assumptions of normality and homogeneity for all outcome variables were met. Paired samples t-tests were conducted to compare baseline and endpoint scores on the MAIA scales and the PCS within each group. As a measure of effect size, Cohen's d was calculated for each pre-post change. Analyses were conducted according to a modified intention-to-treat (ITT) principle with the last observation carried forward (LOCF). When endpoint measures were missing, midpoint measures were imputed, and if midpoint data were missing, baseline data were used. Only participants who attended at least 4 of the 8 classes were included in the analyses.

The main study, to which this study was added on, revealed a significant effect of MBCT (group by time interaction) on depression as measured with the Quick Inventory of Depressive Symptomatology - Clinician rated (QIDS-C ${ }_{16}$ ) (de Jong et al., 2017). To explore if and how this effects is mediated by the MAIA, a multiple mediator model was tested. The model comprised group (MBCT + TAU vs TAU) as independent variable, depression measured at week 8 as dependent variable and MAIA scales (measured at week 8 ) that revealed significant group by time interactions, as mediators. Depression and respective MAIA scales measured at baseline (week 0 ) were included as covariates. Mediation analyses were conducted with a macro by Preacher and Hayes (2008) that implements a bootstrapping procedure to create confidence intervals for partial and total indirect effects. For mediation analyses only participants who participated in at least 4 classes and who had week 0 and week 8 data available were included in the analyses and 10,000 bootstrap iterations were used. All analyses were conducted with SPSS 21 (SPSS Inc., Chicago, IL, USA).

\section{RESULTS}

\section{Participant characteristics}

For the main study, 71 patients were screened, of which 40 were randomized to TAU $(n=14)$ or MBCT + TAU $(n=26)$ in a $1: 2$ ratio. Of those 40,34 completed the pain 
catastrophizing scale (PCS) and 31 the MAIA at baseline. Of the 14 patients in the TAU, 12 had PCS and MAIA data and were included in modified ITT analyses. Of the 26 patients in MBCT + TAU, 22 had PCS and 19 MAIA data. Five of the patients with MAIA and PCS data participated in less than 4 sessions of MBCT and were excluded from further analyses, resulting in 17 patients with PCS data and 14 with MAIA data in the modified ITT analyses (Figure 1). For the mediation analyses 11 subjects with MAIA data were in MBCT + TAU and 7 in TAU.
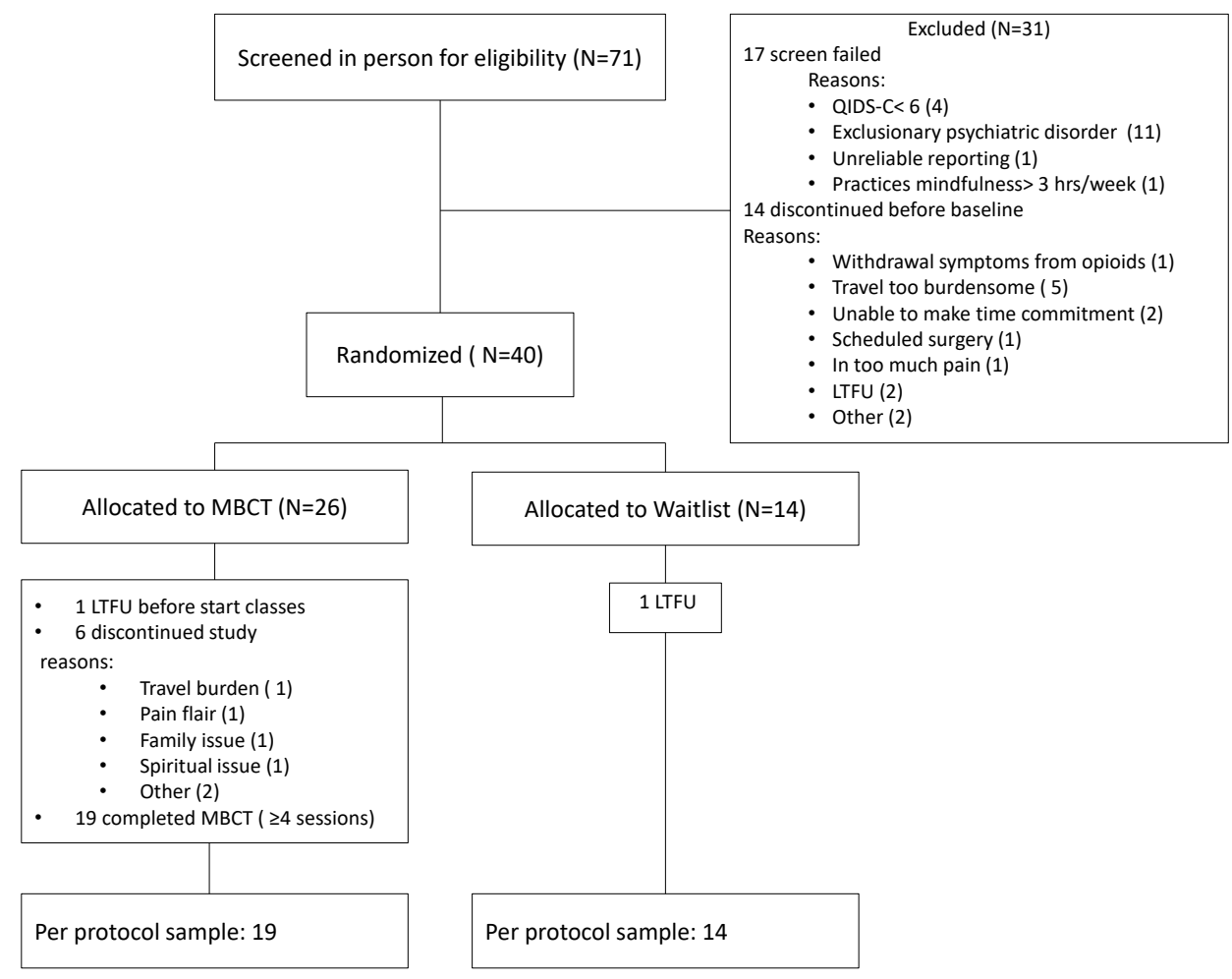

Figure 1: Patient Flow

LTFU, lost to follow up; MAIA, Multidimensional Assessment of Interoceptive Awareness; MBCT, MindfulnessBased Cognitive Therapy; PCS, Pain Catastrophizing; QUIDS-C, Quick Inventory of Depressive SymptomsClinician Rated; TAU, Treatment As Usual.

Characteristics of participants $(n=29)$ who attended at least 4 classes (MBCT+TAU) or had 4 clinic visits (TAU), are shown in Table 1. Types of chronic pain included: chronic back pain, neuropathic pain, osteoarthritis, fibromyalgia, and migraines. There were no significant differences in demographics and patient characteristics (see Table 1) or in average baseline scores on the five MAIA scales or total PCS scores between the two groups at baseline (see Table 2). For the collapsed sample that completed the MAIA, regardless of class attendance, participants $(n=31)$ were on average 50 years old 
$(M=49.45, S D=10.58)$, and college graduates $(M=16.30, S D=2.55$ years of education). Most of the participants were female (74.2\%), Caucasian (90.3\%), and non-Hispanic (83.9\%). Three (9.7\%) participants were African American and one (3.2\%) was Hispanic. The largest proportion of participants was married $(46.7 \%)$ or never married $(36.7 \%)$, and five were separated or divorced (16.7\%). Employed participants comprised $32.3 \%$ of the sample, and disabled ones comprised $32.3 \%$ of the sample. Most participants had Major Depressive Disorder (MDD; 83.9\%), with the remaining 16.1\% suffering from Depressive Disorder not otherwise specified (NOS). $46.4 \%$ of the participants were taking Anti-Depressant medication.

Table 1 Participant characteristics $(n=29)$

\begin{tabular}{|c|c|c|c|c|c|c|c|}
\hline & \multicolumn{2}{|l|}{ TAU } & \multicolumn{2}{|c|}{$\mathrm{MBCT}+\mathrm{TAU}$} & \multicolumn{3}{|c|}{$t / x 2$-test } \\
\hline & $M / \%$ & $S D$ & $M$ & $S D$ & $t / x^{2}$ & $d f$ & $p$ \\
\hline Age (years) & 51.67 & 10.08 & 50.06 & 11.68 & 0.39 & 27 & 0.703 \\
\hline Education (years) $^{a}$ & 16.58 & 2.61 & 15.94 & 2.56 & 0.65 & 26 & 0.519 \\
\hline Gender (\% female) & 66.7 & & 76.5 & & 0.34 & 1 & 0.561 \\
\hline Race (\%) & & & & & 0.88 & 1 & 0.348 \\
\hline African-American & 16.7 & & 5.9 & & & & \\
\hline Caucasian & 83.3 & & 94.1 & & & & \\
\hline Ethnicity (\%) & & & & & 3.28 & 2 & 0.194 \\
\hline Hispanic & 0.0 & & 5.9 & & & & \\
\hline Non-Hispanic & 100.0 & & 76.5 & & & & \\
\hline Unknown/Not reported & & & 17.6 & & & & \\
\hline Marital status (\%) & & & & & 0.933 & 2 & 0.627 \\
\hline Never married & 25.0 & & 37.5 & & & & \\
\hline Married/Live together & 50.0 & & 50.0 & & & & \\
\hline Separated/Divorced & 25.0 & & 12.5 & & & & \\
\hline Employment status (\%) & & & & & 1.67 & 2 & 0.435 \\
\hline Employed & 16.7 & & 37.5 & & & & \\
\hline Disabled & 41.7 & & 37.5 & & & & \\
\hline Other/Not reported & 41.7 & & 25.0 & & & & \\
\hline Type depression (\%) & & & & & 0.20 & 1 & 0.653 \\
\hline NOS & 16.7 & & 23.5 & & & & \\
\hline MDD & 83.3 & & 76.5 & & & & \\
\hline ADM (\% taking) $)^{\mathrm{b}}$ & 50.0 & & 35.3 & & 0.564 & 1 & 0.453 \\
\hline
\end{tabular}

Note. ADM: Anti-Depressant Medication, MDD: Major Depressive Disorder, MBCT: Mindfulness-Based Cognitive Therapy, NOS: Depressive Disorder Not Otherwise Specified, SD: Standard Deviation, TAU: Treatment As Usual, ${ }^{a}$ : Based on $\mathrm{N}=28$ due to missing value, ${ }^{\mathrm{b}}$ : Based on $\mathrm{N}=27$ due to missing values. 
Table 2 Baseline scores on MAIA and PCS

\begin{tabular}{|c|c|c|c|c|c|c|c|}
\hline & \multicolumn{2}{|l|}{ TAU } & \multicolumn{2}{|c|}{$\mathrm{MBCT}+\mathrm{TAU}$} & \multicolumn{3}{|c|}{$t$-test } \\
\hline & $M$ & $S D$ & $M$ & $S D$ & $t$ & $d f$ & $p$ \\
\hline \multicolumn{8}{|l|}{ MAIA } \\
\hline Noticing & 3.13 & 1.26 & 2.86 & 1.01 & 0.60 & 24 & 0.553 \\
\hline Attention Regulation & 2.08 & 1.34 & 2.37 & 1.05 & 0.60 & 24 & 0.550 \\
\hline Emotional Awareness & 2.65 & 1.63 & 2.71 & 1.29 & 0.11 & 24 & 0.912 \\
\hline Self-Regulation & 2.10 & 1.42 & 1.98 & 1.24 & 0.23 & 24 & 0.817 \\
\hline Not Distracting & 2.14 & 0.80 & 1.95 & 1.23 & 0.45 & 24 & 0.657 \\
\hline PCS & 27.17 & 10.67 & 31.82 & 12.28 & 1.06 & 27 & 0.299 \\
\hline
\end{tabular}

Abbreviations. MAIA, Multidimensional Assessment of Interoceptive Awareness; PCS, Pain Catastrophizing Scale.

\section{Scale properties}

Table 3 summarizes scale means with standard deviations, range of observed values, Cronbach's alphas, and range of item-scale correlations of the MAIA and the PCS for the entire sample ( $n=31$ and 34 respectively) at baseline. Cronbach's alphas for three of the five administered MAIA scales were excellent and ranged from 0.92 (Attention Regulation) to 0.94 (Emotional Awareness). The Not-Distracting and Noticing scales had alphas of 0.72 and 0.67 respectively. The PCS had a Cronbach's alpha of 0.93 .

Table 4 shows Pearson correlations between the MAIA scales. The correlations ranged from 0.76 for Self-regulation and Emotional awareness and 0.71 for Emotional awareness and Noticing, to less than 0.29 for Not Distracting, which did not correlate significantly with any other MAIA scale $(r \leq|0.29|)$.

Table 3 Scale properties. Reliability (Cronbach's alpha), Item-Scale Correlations, and Descriptive Statistics for MAIA Scales and PCS Total Score in the Total Sample

\begin{tabular}{|c|c|c|c|c|c|c|}
\hline & & & Range of Item-Scale & & & \\
\hline Scale & \# of items & Alpha & Correlations & Mean (SD) & Observed range & $N$ \\
\hline \multicolumn{7}{|l|}{ MAIA } \\
\hline Noticing & 4 & 0.67 & $0.65-0.74$ & $3.10(1.15)$ & $1-5$ & 31 \\
\hline Attention Regulation & 7 & 0.92 & $0.64-0.91$ & $2.42(1.22)$ & $0.1-4.57$ & 31 \\
\hline Emotional Awareness & 5 & 0.94 & $0.85-0.93$ & $2.73(1.50)$ & $0-5$ & 31 \\
\hline Self-Regulation & 4 & 0.93 & $0.89-0.96$ & $1.92(1.37)$ & $0-4.5$ & 31 \\
\hline Not Distracting & 3 & 0.72 & $0.49-0.84$ & $2.04(1.06)$ & $0.3-5$ & 31 \\
\hline PCS & 13 & 0.93 & $0.51-0.85$ & $30.18(11.63)$ & $4-52$ & 34 \\
\hline
\end{tabular}

Notes. ${ }^{a}$ Range of item-scale correlations; ${ }^{b}$ Possible range for MAIA: 0-5; for PCS: 0-52.

Abbreviations. MAIA, Multidimensional Assessment of Interoceptive Awareness; PCS, Pain Catastrophizing Scale. SD: Standard deviation 
Table 4 Scale-scale correlations. Pearson product moment correlations among MAIA scales in the total sample $(N=31)$

\begin{tabular}{|c|c|c|c|c|c|}
\hline Scale & Noticing & $\begin{array}{l}\text { Attention } \\
\text { Regulation }\end{array}$ & $\begin{array}{l}\text { Emotional } \\
\text { Awareness }\end{array}$ & $\begin{array}{l}\text { Self- } \\
\text { Regulation }\end{array}$ & Not Distracting \\
\hline Noticing & - & & & & \\
\hline Attention Regulation & $0.53 * *$ & - & & & \\
\hline Emotional Awareness & $0.71 * *$ & $0.62 * *$ & - & & \\
\hline Self-Regulation & $0.52 * *$ & $0.50 * *$ & $0.76^{* *}$ & - & \\
\hline Not Distracting & 0.02 & 0.17 & -0.29 & -0.09 & - \\
\hline
\end{tabular}

Notes. ${ }^{*}$ Correlations are significant at $p<0.01$.

Abbreviations. MAIA, Multidimensional Assessment of Interoceptive Awareness.

\section{Effects of MBCT on Body Awareness}

For Noticing, no significant group-by-time interaction $(F=(1,24)=0.18, p=0.676$, $\left.\eta_{p}{ }^{2}=0.007\right)$ and no significant main effect of time $\left(F=(1,24)=2.59, p=0.121, \eta_{p}^{2}=0.097\right)$ was found. No significant within group changes between the pre- and the posttreatment measurements were found in either group (Figure 2a, Table 5), with effect sizes of the pre-post change being medium for the treatment group but small for the control group (Table 5).

For the Attention Regulation scale, no significant group-by-time interaction effect $\left(F(1,24)=0.03, p=0.863, \eta_{p}{ }^{2} \leq 0.001\right)$ was found, but a significant main effect of time was revealed $\left(F(1,24)=5.34, p=0.030, \eta_{p}{ }^{2}=0.182\right)$. Paired sample t-tests showed significant, medium size increases of Attention Regulation scores in the control group (Figure $2 \mathrm{~b}$, Table 5). The increase in Attention Regulation in the MBCT group did not reach statistical significance, despite its large effect size (Figure 2b, Table 5).

For Emotional Awareness, no significant group-by-time interaction effect $(F(1$, $\left.24)=2.17, p=0.153, \eta_{p}{ }^{2}=0.083\right)$ was found, but a significant main effect of time was revealed $\left(F(1,24)=4.63, p=0.042, \eta_{p}{ }^{2}=0.162\right)$. Paired samples t-tests revealed a large and significant increase in Emotional Awareness over time within the treatment group, while the change within the control group was small and not significant (Figure 2c, Table 5)

A rmANOVA revealed a significant group-by-time interaction for Self-Regulation ( $F(1$, 24)=5.93, $\left.p=0.023, \eta_{p}{ }^{2}=0.198\right)$. This interaction was driven by large and significant increases in Self-Regulation over time in the treatment group and small but significant increases in the control group (Figure $2 d$, Table 5 ). Furthermore, the analyses revealed a significant main effect of time $\left(F(1,24)=22.86, p<0.001, \eta_{p}{ }^{2}=0.488\right)$.

For the Not Distracting scale, a significant group-by-time interaction was revealed $\left(F(1,24)=4.87, p=0,037, \eta_{p}{ }^{2}=0.169 ;\right.$ Figure 2e). This interaction was driven by an increase in Not Distracting scores in the treatment group and a decrease within the 
control group, none of which reached statistical significance. No main effect of time $\left(F(1,24)=0.45, p=0.511, \eta_{p}{ }^{2}=0.018\right)$ was found.

For pain catastrophizing, no significant group-by-time interaction effect ( $F=(1$, $\left.27)=1.15, p=0.294, \eta_{p}^{2}=0.041\right)$ was revealed. The main effect of time approached significance $\left(F=(1,27)=3.60, p=0.069, \eta_{p}{ }^{2}=0.118\right)$. Analysis showed a large and significant decrease of pain catastrophizing within the MBCT group, but only a small and not significant decrease in the control group (Figure 2f, Table 5).
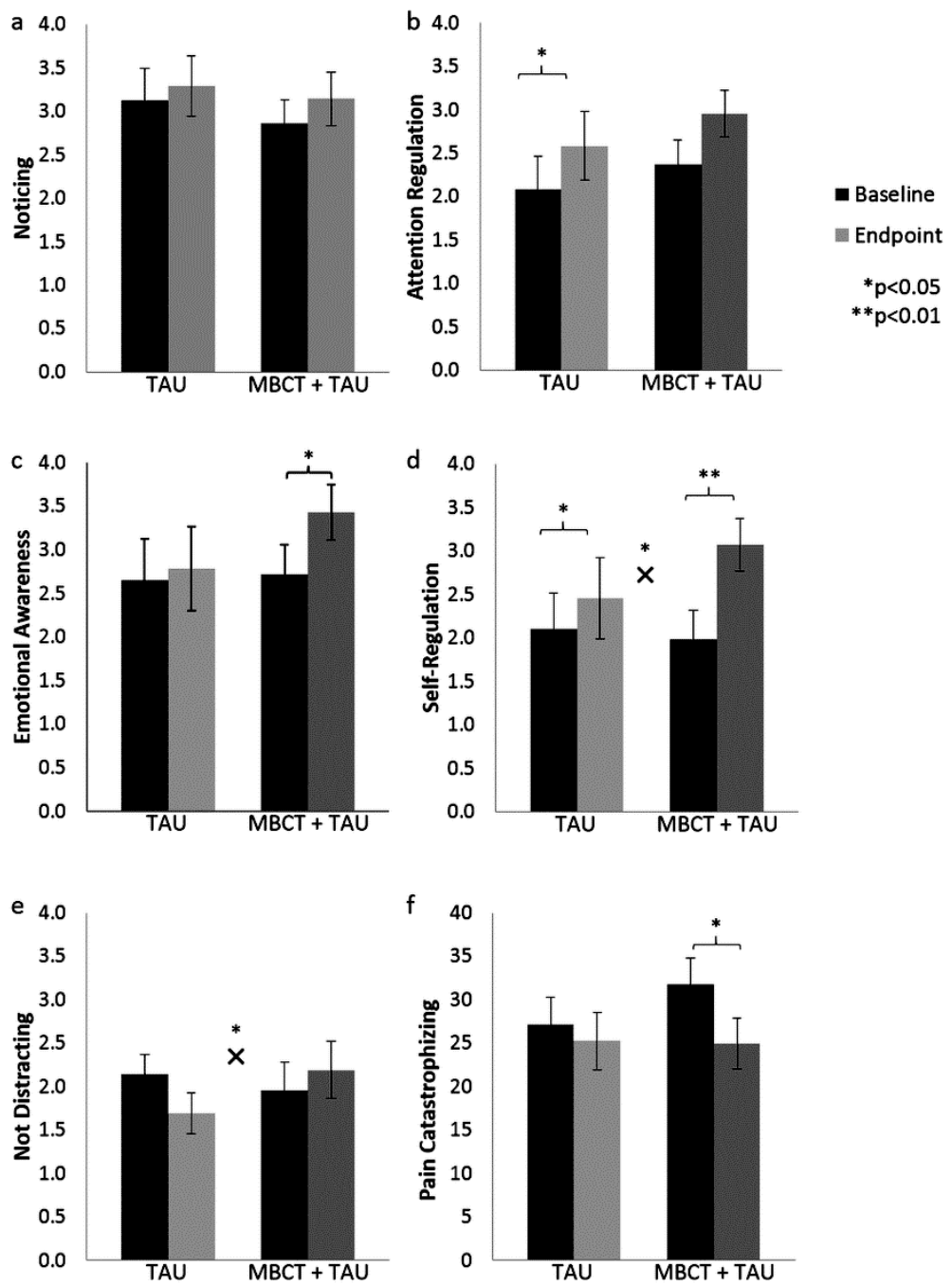

Figure 2. Pre-post changes and group by time interactions.

Error bars are \pm 1 SEM; Asterisks above the $\times$ symbols indicate significant $p$-values based on group by time interaction effects as revealed by repeated measures ANOVAs; Asterisks above the bars indicate significant $p$ values based on pre-post treatment changes as revealed by paired-samples t-tests 
Chapter 4

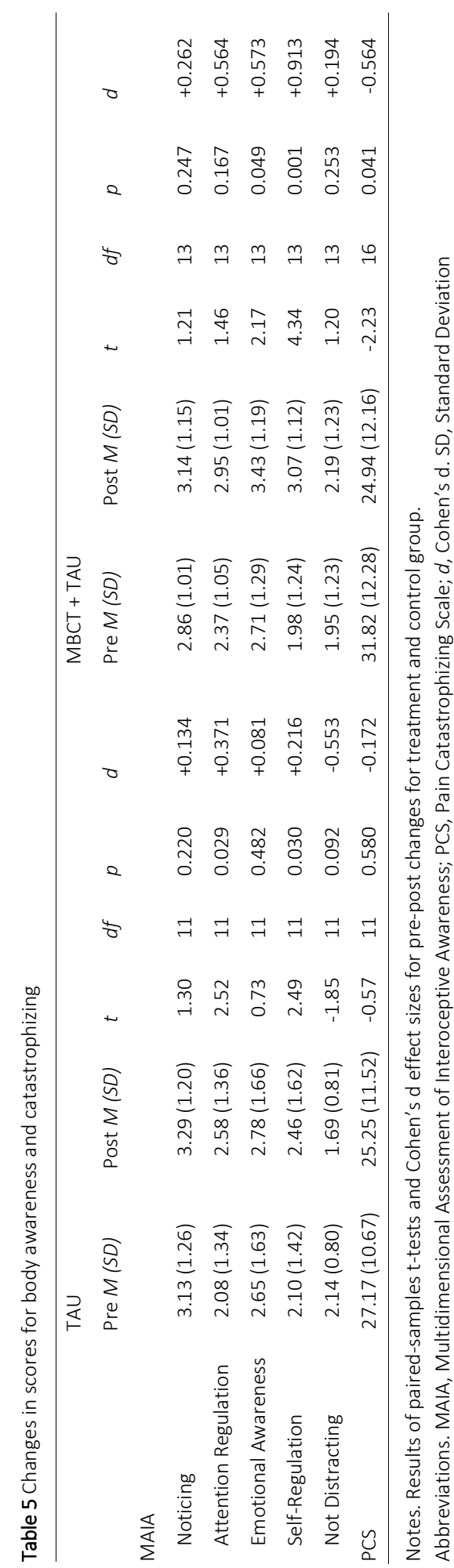




\section{Body Awareness as mediator}

A multiple mediator model as described by Preacher and Hayes (2008) was tested. The model (Figure 3) was comprised of group (MBCT + TAU vs TAU) as independent variable, depression measured with QIDS-C16 at week 8 as dependent variable, and the MAIA Not Distracting and Self-Regulation scales, measured at week 8, as mediators. QIDSC16, MAIA Not Distracting and Self-Regulation scales measured at week 0 were included as covariates.

Analyses resulting in bias-corrected confidence intervals $(\mathrm{Cl})$ based on 10,000 bootstrap iterations, revealed a significant indirect effect of group on depression through the MAIA scale Not Distracting $\left(a_{1} \times b_{1}=-3.584,95 \% \mathrm{Cl}-8.880\right.$ to -0.357$)$, but not through the Self-Regulation scale $\left(a_{2} \times b_{2}=-2.317,95 \% \mathrm{Cl}-8.733\right.$ to 0.284$)$. There also was a significant direct effect of group on depression ( $c^{`}=4.817, p=0.0485$ ) independent of Self-Regulation or Not Distracting. These findings indicate that the effect of MBCT on depression was partially mediated by Not Distracting but not by Self-Regulation.

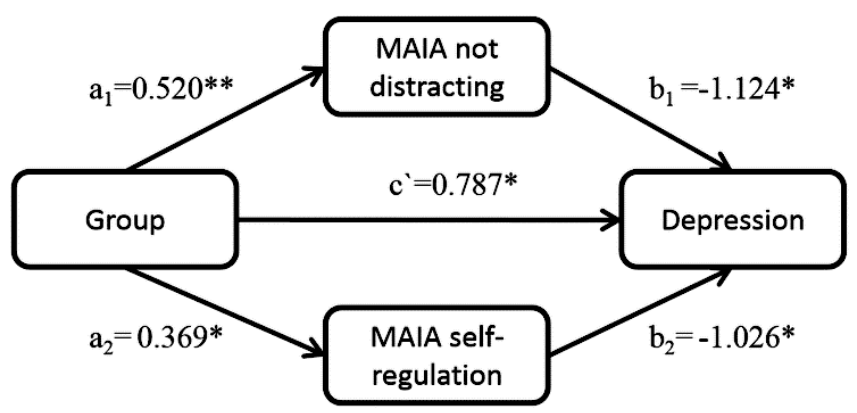

Figure 3. Mediation model.

Mediation model for the effect of group (Mindfulness-Based Cognitive Therapy + treatment as usual (TAU), vs TAU alone) on depression (measured with the Quick Inventory of Depressive Symptomatology - Clinician rated) through the Not Distracting and Self-Regulation scales of body awareness as measured with the Multidimensional Assessment of Interoceptive Awareness (MAIA). Analyses are based on $\mathrm{N}=18$ and numbers are standardized regression coefficients. Note: ${ }^{*} p<0.05,{ }^{* *} p<0.01$.

\section{DISCUSSION}

In the present study, we investigated the effects of $\mathrm{MBCT}$ on body awareness as measured with the MAIA in patients with chronic pain and comorbid active depression. To our knowledge, this is the first RCT that investigates the effects of MBCT on body awareness as measured with the MAIA in patients with chronic pain and depression. The MAIA appears a reliable instrument with scales of adequate consistency in this newly studied population. In accordance with our hypothesis, MBCT resulted in increases for several dimensions of body awareness in the studied patient population. 
More specifically, a significantly greater increase in Self-Regulation and Not Distracting, but no changes in Noticing in the MBCT group as compared to the TAU group were observed. In addition, participants in the MBCT group, but not in the control group, had increases in Emotional Awareness. For Pain Catastrophizing, we found significant decreases within the treatment group, but not within the control group. Furthermore, mediation analyses revealed that the effect of MBCT on depression was mediated by Not Distracting, but not by Self-Regulation. We discuss these results for each dimension of body awareness separately in more detail below.

\section{Self-Regulation}

The finding of a significantly greater increase in Self-Regulation ratings in the treatment than in the control group is in line with findings by Mehling et al. (2013; 2014). In two cross-sectional studies they showed that patients with chronic lower back pain who were practicing mind-body therapies (Mehling et al., 2013), or Yoga and meditation (Mehling et al., 2014) had greater self-regulatory body awareness than patients without such practice. In the cohort study (Mehling et al., 2014), this difference was more pronounced for the Self-Regulation dimension than for any of the other dimensions of body awareness. Similarly, Bornemann et al. (2015) also found that increases following three months of contemplative training including bodyscan and breath awareness meditation were largest on the Self-Regulation scale (effect size $d=0.72$ ). Our study extends the previous findings by demonstrating effects through a well-established intervention (MBCT) in a patient population (chronic pain with active depression).

The present findings of a change in Self-Regulation through a mindfulness intervention are consistent with a hypothesized link between mindfulness and enhanced self-management (Baer, 2003), a concept closely related to general selfregulation (Vohs \& Baumeister, 2011). Our findings also converge with empirical evidence for better general self-regulation of chronic pain through a mindfulness intervention (Kabat-Zinn et al., 1985), as well as with evidence from paradigms with acute pain induction, in which mindfulness practice enhanced pain tolerance (Gard et al., 2012; Kingston et al., 2007), thereby having potential clinical implications.

\section{Emotional awareness}

Paired samples t-tests revealed a large and significant increase in Emotional Awareness over time within the treatment group, while the change within the control group was small and not significant However, no significant group by time interaction was found. The significant increase in Emotional Awareness over time in the treatment group is in line with the expectation that the MBCT intervention increases the awareness of the connection between body sensations and emotional states and corresponds to results by Mehling et al. (2013; 2014). Their group found that levels of Emotional Awareness 
were higher in chronic pain patients with mind-body practice than in patients without such practice (Mehling et al., 2013). Bornemann et al. (2015) also found significant increases of scores of the Emotional Awareness scale following three months of bodyscan and breath awareness training, but the effect size was rather small $(<0.20)$. Beyond the body awareness specific construct of Emotional Awareness, our findings confirm theory (Bishop et al., 2004; Phillipot \& Segal, 2009) and previous evidence that suggests an association between mindfulness and general emotional awareness (Boden et al., 2014; Sze et al., 2010).

In light of evidence that demonstrates that emotional awareness is linked to better clinical outcomes and quality of life (Boden et al., 2014; V. Williams et al., 2010), as well as to reductions in depression symptomatology and in depression-related affective and cognitive outcomes (Arch \& Craske, 2006; N. A. Farb et al., 2010; Goldman et al., 2005), the present findings of increased Emotional Awareness in the MBCT group may be relevant for clinical practice.

In the present study, the Emotional Awareness and Self-Regulation scores were strongly correlated ( $r=0.76)$. Similarly, Mehling et al. (2013) found a relatively high correlation between these two scales $(r=0.60)$ in patients with chronic pain, as well as in body-mind practitioners, and Bornemann et al., (2015) also found a considerable interscale correlation between these two scales $(r=0.46)$. These findings may correspond to the notion of the general self-regulation concept (Baumeister et al., 1998; Muraven \& Baumeister, 2000) as being closely related to emotion regulation (Vago \& Silbersweig, 2012; Vohs \& Baumeister, 2011).

\section{Not Distracting}

The significant group-by-time interaction on Not Distracting was driven by a decrease in the TAU group and an increase in the MBCT+TAU group. Distracting oneself from uncomfortable body sensations or ignoring them, is a common coping strategy in chronic pain (Peres \& Lucchetti, 2010; M. C. Reid et al., 2002), as well as in depression (Matheson \& Anisman, 2003). In the intervention group, however, subjects learned to pay mindful attention to all body sensations including pain and depression-related symptoms, independent of their valence. In the control group, subjects did not learn to use this alternative approach and may have practiced the more common coping strategy of distraction so that they became 'better' at ignoring and distracting themselves from uncomfortable body sensations.

Correspondingly, when a sample of patients with chronic lower-back pain was compared to healthy mind-body therapy practitioners, the mind-body sample had significantly higher Not Distracting scores (Mehling et al., 2013). However, contrary to our findings, Mehling et al. (2013) found no significant difference between the Not Distracting capacities of those patients with past or current pain that did have mindbody therapy experience and those that did not have such practice. Bornemann et al. 
(2015) did not find that changes on the Not Distracting scale in healthy participants, following bodyscan and breath awareness training were significantly higher than those in the retest control group. These discrepancies between the studies may be due to methodological differences, differences in the interventions, and differences in the studied population. Our findings are further aligned with prior studies showing a negative association between mindfulness and experiential avoidance (Riley, 2014), and general distraction (Jain et al., 2007).

In the present study, we did not find correlations between the Not Distracting scale and any other MAIA scales. This result corresponds to the finding by Mehling et al. (2013) that Not Distracting scores were not correlated with the other scales in their large ( $N=301-434)$ chronic pain sample. Bornemann et al. (2015) on the other hand found that the Not Distracting scale was significantly correlated with all other scales in their sample of healthy patients. This difference might be due to their very large sample size $(N=1,076)$ or due to the fact that they investigated a sample of healthy participant. These findings may indicate that in patients with chronic pain, a coping style of not distracting from pain is independent of the other aspects of body awareness.

A striking finding of the present study is that Not Distracting mediates the effect of $\mathrm{MBCT}$ on depressive symptom reduction. This finding supports the clinical importance of the Not Distracting aspect of body awareness. Furthermore, while it has long been hypothesized that the effects of MBCT on depression are mediated by body awareness, this is to our knowledge the first study supporting such a relationship (Michalak et al., 2012; Michalak et al., 2011; Michalak et al., 2010; van der Velden et al., 2015).

Although previous research has shown that for depression, distraction may be an effective coping style, mindfulness is even more effective in reducing negative mood (Broderick, 2005; Huffziger \& Kuehner, 2009). Furthermore, mindfulness has been shown to be better in reducing acute pain than distraction in individuals with high levels in pain catastrophizing (Prins et al., 2014). Similarly, in patients with chronic pain that had high health anxiety, paying attention to sensations resulted in greater pain relief than distraction (Hadjistavropoulos et al., 2000), which is in line with the notion that "one problem in chronic pain is not only the pain itself, but the 'turning away' from, the averting of attention from the regions that give rise to painful sensations, either through deliberate distraction, or by thinking about the pain (conceptually) rather than experiencing the sensations directly" (J. M. G. Williams, 2010). More in general, experiential avoidance is associated with a wide variety of psychopathology (S. C. Hayes et al., 1996) and coping strategies that work contrary to avoidance, such as mindfulness are related to better mental health outcomes (V. Williams et al., 2010).

Together these findings suggest that the Not Distracting aspect of body awareness may be an important predictor of depressive symptoms and potentially of mental health in general, and that it can be cultivated through mindfulness based interventions. 


\section{Noticing and Attention Regulation}

The present study did not detect significant changes in the awareness of uncomfortable, comfortable, and neutral body sensations as a result of the MBCT intervention. However, the effect sizes of the pre-post changes in the treatment group were of medium size, whereas the increases in the control group only had a small effect size. These findings contrast earlier findings where large differences in MAIA Noticing scores were found between individuals with chronic pain who had mind-body practice and those patients who did not have such practice (Mehling, 2012). Our findings are in line with those of Bornemann et al. (2015), who despite a very large sample size did not find a significantly greater increase in the contemplative training group than in the rest control group.

No significant group by time interaction was revealed for Attention Regulation, indicating that MBCT did not result in increases of the ability to sustain and control attention to body sensations. The absence of a significant increase of Attention Regulation in the MBCT group is surprising, given that previous studies found that mindbody therapy practicing patients with back pain had higher scores of Attention Regulation than non-practicing patients (Mehling et al., 2013; Mehling et al., 2012), and that bodyscan and breath awareness training lead to large effects on Attention Regulation in healthy participants (effect size $d=0.54$; Bornemann et al., 2015).

It remains an open question whether the absence of significantly greater increases in Noticing and Attention Regulation in MBCT+TAU than in TAU is specific for the studied patient population and intervention, or just a lack of power. Larger studies are warranted.

\section{Pain Catastrophizing}

The absence of a group by time interaction for pain catastrophizing indicates that there were no greater changes in pain catastrophizing in the $\mathrm{MBCT}$ group than in the control group. However, the main effect of time was approaching significance and was driven by a large and significant decrease within the MBCT group and a small, non-significant decrease in the control group.

Consistent with the significant decrease in pain catastrophizing within the MBCT group, Mehling et al. (2013) showed that pain patients who practiced mind-body therapies worried less about their pain or other uncomfortable body sensations than individuals without mind-body practice. Furthermore, our findings are aligned with a growing body of evidence showing that in patients with chronic pain, mindfulness and participation in mindfulness-based interventions are related to decreases in pain catastrophizing (e.g. Cassidy et al., 2012; Day et al., 2014; Garland et al., 2012; Schutze et al., 2010) but see (De Boer et al., 2014). 


\section{Limitations}

The present study has several limitations. First, this pilot study had a relatively small sample size, resulting in low power to detect true effects. Yet despite this limitation, some significant effects were found. However, it must be mentioned that because of the small sample size we chose a less conservative statistical approach and did not correct for multiple comparisons. Second, because of the pilot nature of this study, we used TAU as a control group, which does not adequately control for 'placebo effects' induced by non-specific factors like attention in patient-provider interactions.(Goyal et al., 2014). This means that, theoretically, the clinical improvement could be due to nonspecific factors like attention and expectations about improvement and not due to the specific effects of MBCT. We did try to control for attention as much as possible by keeping all office and phone visits with the clinician equal in both the MBCT group and TAU group. In future larger studies it would be imperative to compare MBCT to an active non specific control group, such as group sessions including psycho-education and gentle stretching exercises without any mindfulness components, as in the study of Hoge et al. (Hoge et al., 2013). Third, the MAIA is a relatively new scale that requires further refinement and validation in different populations. Fourth, because the intervention produced skills and understanding of concepts that were relatively new to participants at baseline, subjects may have reached a different understanding of the concepts enquired by the MAIA items post-treatment. While the first three limitations can be addressed by larger studies with active control groups and future versions of the MAIA, the last limitation is probably inherent to interventions that result in a change of perspective and thus more difficult to address. Using behavioral data might help to validate self-report instruments. Finally, because there were too many missing midpoint data, we conducted mediation analysis only on the endpoint data, which decreases the degree of causal specificity (Kazdin, 2007). However, Hayes argues that mediation analysis is still valuable, even when data collection of the mediator and outcome variable is at the same timepoint (A. F. Hayes, 2013). The findings on the mediation analysis in this study should be interpreted as tentative and purely hypothesis generating. Future larger studies with MBCT in this population with the assessment of the MAIA subscales of potential mediators at multiple time points are warranted, to permit more conclusive statements.

\section{CONCLUSION}

In summary, our data suggest that MBCT can increase several dimensions of body awareness as measured with the MAIA in patients with chronic pain and comorbid active depression. In particular, the Not Distracting aspect of body awareness mediated the positive effect of MBCT on depressive symptoms. Furthermore, the MAIA appears 
to be a reliable instrument for measuring self-reported body awareness in this population. This finding is important because the reliability of this new and increasingly used instrument for measuring body awareness has so far not been assessed in a population of patients with chronic pain and comorbid depression. Our finding that MBCT can increase self-reported body awareness represents the first preliminary evidence in support of a causal link between a mindfulness-based intervention and increased body awareness (as measured with the MAIA) in this population. Finally, the fact that body awareness mediated the effect of MBCT on depressive symptoms provides preliminary first evidence for this long-hypothesized relationship and indicates that body awareness has clinical relevance as an element of mindfulness approaches in the studied population. 


\section{REFERENCES}

Arch, Joanna J., \& Craske, Michelle G. (2006). Mechanisms of mindfulness: Emotion regulation following a focused breathing induction. Behaviour research and therapy, 44(12), 1849-1858. doi: 10.1016/j.brat.2005.12.007

Baer, Ruth A. (2003). Mindfulness training as a clinical intervention: A conceptual and empirical review. Clinical psychology: Science and practice, 10(2), 125-143. doi: 10.1093/clipsy.bpg015

Bair, M. J., Robinson, R. L., Katon, W., \& Kroenke, K. (2003). Depression and pain comorbidity: a literature review. Arch Intern Med, 163(20), 2433-2445. doi: 10.1001/archinte.163.20.2433

Baumeister, Roy F., Bratslavsky, Ellen, Muraven, Mark, \& Tice, Dianne M. (1998). Ego depletion: is the active self a limited resource? Journal of personality and social psychology, 74(5), 1252. doi: 10.1037/00223514.74.5.1252

Bishop, S.R., Lau, M., Shapiro, S., Carlson, L., Anderson, N.D., Carmody, J., . . Velting, D. (2004). Mindfulness: A proposed operational definition. Clinical psychology: Science and practice, 11(3), 230-241.

Boden, Matthew Tyler, Irons, Jessica G., Feldner, Matthew T., Bujarski, Sarah, \& Bonn-Miller, Marcel O. (2014). An Investigation of Relations Among Quality of Life and Individual Facets of Emotional Awareness and Mindfulness. Mindfulness, 1-8. doi: 10.1007/s12671-014-0308-0

Bornemann, B., Herbert, B.M., Mehling, W.E., \& Singer, T. (2015). Differential changes in self-reported aspects of interoceptive awareness through three months of contemplative training. Frontiers in Psychology, 5, 1504. doi: 10.3389/fpsyg.2014.01504

Bornemann, B., \& Singer, T. (2015). Taking Time to Get In Touch with our Body: Heart Beat Perception Accuracy Increases linearly over nine Months of Contemplative Training. Paper presented at the International Convention of Psychological Science, Amsterdam.

Broderick, P. C. . (2005). Mindfulness and coping with dysphoric mood: Contrasts with rumination and distraction. Cognitive Therapy and Research, 29(5), 501-510. doi: 10.1007/s10608-005-3888-0

Cassidy, Emma Louise, Atherton, Rachel Jane, Robertson, Noelle, Walsh, David Andrew, \& Gillett, Raphael. (2012). Mindfulness, functioning and catastrophizing after multidisciplinary pain management for chronic low back pain. Pain, 153(3), 644-650. doi: 10.1016/j.pain.2011.11.027

Craig, A. D. (2003). A new view of pain as a homeostatic emotion. Trends in neurosciences 26(6), 303-307. doi: S0166223603001231

Danielsson, Louise, Papoulias, Ilias, Petersson, Eva-Lisa, Carlsson, Jane, \& Waern, Margda. (2014). Exercise or basic body awareness therapy as add-on treatment for major depression: A controlled study. Journal of Affective Disorders, 168(0), 98-106. doi: 10.1016/j.jad.2014.06.049

Day, M. A., Thorn, B. E., Ward, L. C., Rubin, N., Hickman, S. D., Scogin, F., \& Kilgo, G. R. (2014). Mindfulnessbased cognitive therapy for the treatment of headache pain: a pilot study. Clin J Pain, 30(2), 152-161. doi: 10.1097/AJP.0b013e318287a1dc

De Boer, Maaike J., Steinhagen, Hannemike E., Versteegen, Gerbrig J., Struys, Michel M. R. F., \& Sanderman, Robbert. (2014). Mindfulness, Acceptance and Catastrophizing in Chronic Pain. Plos one, 9(1), e87445. doi: 10.1371/journal.pone.0087445

de Jong, M., Peeters, F., Gard, T., Ashih, H., Doorley, J., Walker, R., . . Mischoulon, D. (2017). A Randomized Controlled Pilot Study on Mindfulness-Based Cognitive Therapy for Unipolar Depression in Patients With Chronic Pain. J Clin Psychiatry. doi: 10.4088/JCP.15m10160

Dunn, B. D., Dalgleish, T., Lawrence, A. D., \& Ogilvie, A. D. (2007). The accuracy of self-monitoring and its relationship to self-focused attention in dysphoria and clinical depression. Journal of Abnormal Psychology, 116(1), 1-15. doi: 10.1037/0021-843X.116.1.1

Ehlers, A., \& Breuer, P. (1996). How good are patients with panic disorder at perceiving their heartbeats? Biol Psychol, 42(1-2), 165-182.

Ehlers, Anke, \& Breuer, Peter. (1992). Increased cardiac awareness in panic disorder. Journal of Abnormal Psychology, 101(3), 371-382. doi: 10.1037/0021-843X.101.3.371 
Farb, N. A., Anderson, A. K., Mayberg, H., Bean, J., McKeon, D., \& Segal, Z. V. (2010). Minding one's emotions: mindfulness training alters the neural expression of sadness. Emotion, 10(1), 25-33. doi: 10.1037/a0017151

Farb, Norman A. S., Segal, Zindel V., \& Anderson, Adam K. (2013). Mindfulness meditation training alters cortical representations of interoceptive attention. Social cognitive and affective neuroscience, 8(1), 1526. doi: $10.1093 /$ scan/nss066

Farb, Norman, Daubenmier, Jennifer J, Price, Cynthia J, Gard, Tim, Kerr, Catherine, Dunn, Barney, ... Mehling, Wolf E. (2015). Interoception, Contemplative Practice, and Health. Name: Frontiers in Psychology, 6, 763. doi: 10.3389/fpsyg.2015.00763

Fox, Kieran CR, Zakarauskas, Pierre, Dixon, Matt, Ellamil, Melissa, Thompson, Evan, \& Christoff, Kalina. (2012). Meditation experience predicts introspective accuracy. PLoS One, 7(9), e45370. doi: 10.1371/journal.pone.0045370

Gard, T., Hölzel, B. K., Sack, A. T., Hempel, H., Lazar, S. W., Vaitl, D., \& Ott, U. (2012). Pain attenuation through mindfulness is associated with decreased cognitive control and increased sensory processing in the brain. Cerebral Cortex, 22(11), 2692-2702. doi: 10.1093/cercor/bhr352

Garland, E. L., Gaylord, S. A., Palsson, O., Faurot, K., Mann, J. D., \& Whitehead, W. E. (2012). Therapeutic mechanisms of a mindfulness-based treatment for IBS: effects on visceral sensitivity, catastrophizing, and affective processing of pain sensations. Journal of Behavioral Medicine, 35(6), 591-602. doi: DOI 10.1007/s10865-011-9391-z

Goldman, Rhonda N., Greenberg, Leslie S., \& Pos, Alberta E. (2005). Depth of emotional experience and outcome. Psychotherapy Research, 15(3), 248-260. doi: 10.1080/10503300512331385188

Goyal, M., Singh, S., Sibinga, E. M., Gould, N. F., Rowland-Seymour, A., Sharma, R., . . Haythornthwaite, J. A. (2014). Meditation programs for psychological stress and well-being: a systematic review and metaanalysis. JAMA Intern Med, 174(3), 357-368. doi: 10.1001/jamainternmed.2013.13018

Hadjistavropoulos, Heather D., Hadjistavropoulos, Thomas, \& Quine, Allisson. (2000). Health anxiety moderates the effects of distraction versus attention to pain. Behaviour research and therapy, 38(5), 425-438. doi: 10.1016/S0005-7967(99)00044-3

Hayes, A.F. (2013). Introduction to Mediation, Moderation, and Conditional Process Analysis. New York, NY: The Guilford Press.

Hayes, Steven C., Wilson, Kelly G., Gifford, Elizabeth V., Follette, Victoria M., \& Strosahl, Kirk. (1996). Experiential avoidance and behavioral disorders: a functional dimensional approach to diagnosis and treatment. Journal of consulting and Clinical Psychology, 64(6), 1152.

Herbert, B. M., Pollatos, O., \& Schandry, R. (2007). Interoceptive sensitivity and emotion processing: an EEG study. Int J Psychophysiol, 65(3), 214-227. doi: 10.1016/j.ijpsycho.2007.04.007

Hofmann, S. G., Sawyer, A. T., Witt, A. A., \& Oh, D. (2010). The effect of mindfulness-based therapy on anxiety and depression: A meta-analytic review. J Consult Clin Psychol, 78(2), 169-183. doi: 10.1037/a0018555

Hoge, E. A., Bui, E., Marques, L., Metcalf, C. A., Morris, L. K., Robinaugh, D. J., . . . Simon, N. M. (2013). Randomized controlled trial of mindfulness meditation for generalized anxiety disorder: effects on anxiety and stress reactivity. J Clin Psychiatry, 74(8), 786-792. doi: 10.4088/JCP.12m08083

Hölzel, B. K., Lazar, S. W., Gard, T., Schuman-Olivier, Z., Vago, D. R., \& Ott, U. (2011). How does mindfulness meditation work? Proposing mechanisms of action from a conceptual and neural perspective. Perspectives on Psychological Science, 6(6), 537-559. doi: 10.1177/1745691611419671

Hölzel, B. K., Ott, Ulrich, Gard, Tim, Hempel, Hannes, Weygandt, Martin, Morgen, Katrin, \& Vaitl, Dieter (2008). Investigation of mindfulness meditation practitioners with voxel-based morphometry. Social Cognitive and Affective Neuroscience, 3(1), 55-61. doi: 10.1093/scan/nsm038

Huffziger, Silke, \& Kuehner, Christine. (2009). Rumination, distraction, and mindful self-focus in depressed patients. Behaviour Research and Therapy, 47(3), 224-230. doi: 10.1016/j.brat.2008.12.005

Hyett, M. P., Breakspear, M. J., Friston, K. J., Guo, C. C., \& Parker, G. B. (2015). Disrupted effective connectivity of cortical systems supporting attention and interoception in melancholia. JAMA Psychiatry, 72(4), 350358. doi: 10.1001/jamapsychiatry.2014.2490 
Jain, Shamini, Shapiro, ShaunaL, Swanick, Summer, Roesch, ScottC, Mills, PaulJ, Bell, Iris, \& Schwartz, GaryE R. (2007). A randomized controlled trial of mindfulness meditation versus relaxation training: Effects on distress, positive states of mind, rumination, and distraction. Annals of Behavioral Medicine, 33(1), 1121. doi: 10.1207/s15324796abm3301_2

James, W. (1984). What is an emotion? Mind, 9(34), 188-205.

Johnston, Natalie E, Atlas, Lauren Y, \& Wager, Tor D. (2012). Opposing effects of expectancy and somatic focus on pain. PloS one, 7(6), e38854. doi: 10.1371/journal.pone.0038854

Kabat-Zinn, J. (1990). Full catastrophe living: Using the wisdom of your body and your mind to face stress, pain and illness. New York, NY: Delta.

Kabat-Zinn, J., Lipworth, L., \& Burney, R. (1985). The clinical use of mindfulness meditation for the selfregulation of chronic pain. Journal of Behavioral Medicine, 8(2), 163-190. doi: 10.1007/bf00845519

Kazdin, A. E. (2007). Mediators and mechanisms of change in psychotherapy research. Annu Rev Clin Psychol, 3, 1-27. doi: 10.1146/annurev.clinpsy.3.022806.091432

Khalsa, S. S., Rudrauf, D., Damasio, A. R., Davidson, R. J., Lutz, A., \& Tranel, D. (2008). Interoceptive awareness in experienced meditators. Psychophysiology, 45(4), 671-677. doi: 10.1111/j.1469-8986.2008.00666.x

Kingston, Jessica, Chadwick, Paul, Meron, Daniel, \& Skinner, T. Chas. (2007). A pilot randomized control trial investigating the effect of mindfulness practice on pain tolerance, psychological well-being, and physiological activity. Journal of psychosomatic research, 62(3), 297-300. doi: 10.1016/j.jpsychores. 2006.10.007

Lazar, S. W., Kerr, C. E., Wasserman, R. H., Gray, J. R., Greve, D. N., Treadway, M. T., . . . Fischl, B. (2005). Meditation experience is associated with increased cortical thickness. Neuroreport, 16(17), 1893-1897.

Marchand, William R. (2012). Mindfulness-based stress reduction, mindfulness-based cognitive therapy, and Zen meditation for depression, anxiety, pain, and psychological distress. Journal of Psychiatric Practice ${ }^{\circledR}$, 18(4), 233-252. doi: 10.1097/01.pra.0000416014.53215.86

Matheson, Kimberly, \& Anisman, Hymie. (2003). Systems of coping associated with dysphoria, anxiety and depressive illness: a multivariate profile perspective. Stress: The International Journal on the Biology of Stress, 6(3), 223-234. doi: 10.1080/10253890310001594487

Mehling, W. E., Daubenmier, J., Price, C. J., Acree, M., Bartmess, E., \& Stewart, A. L. (2013). Self-reported interoceptive awareness in primary care patients with past or current low back pain. Journal of pain research, 6, 403-418. doi: 10.2147/JPR.S42418

Mehling, W. E., Gopisetty, V., Daubenmier, J., Price, C. J., Hecht, F. M., \& Stewart, A. (2009). Body awareness: construct and self-report measures. PLoS One, 4(5), e5614. doi: 10.1371/journal.pone.0005614

Mehling, W. E., Price, C., Daubenmier, J. J., Acree, M., Bartmess, E., \& Stewart, A. (2012). The Multidimensional Assessment of Interoceptive Awareness (MAIA). PLoS One, 7(11), e48230. doi: 10.1371/journal.pone.0048230

Mehling, W. E., Price, C. J., Daubenmier, J., Mike, A., Bartmess, E., \& Stewart, A. (2014). Body awareness and the practice of yoga or meditation in 435 primary care patients with past or current low back pain. $J$ Altern Complement Med, 20(5), A63-A64. doi: 10.1089/acm.2014.5165.abstract

Melloni, M., Sedeno, L., Couto, B., Reynoso, M., Gelormini, C., Favaloro, R., . . I Ibanez, A. (2013). Preliminary evidence about the effects of meditation on interoceptive sensitivity and social cognition. Behavioral and Brain Functions, 9(47), 10.1186. doi: 10.1186/1744-9081-9-47

Michalak, Johannes, Burg, Jan, \& Heidenreich, Thomas. (2012). Don't forget your body: Mindfulness, embodiment, and the treatment of depression. Mindfulness, 3(3), 190-199. doi: 10.1007/s12671-0120107-4

Michalak, Johannes, Troje, N, \& Heidenreich, Thomas. (2011). The effects of mindfulness-based cognitive therapy on depressive gait patterns. Journal of Cognitive and Behavioral Psychotherapies, 11(1), 13-27.

Michalak, Johannes, Troje, Nikolaus F., \& Heidenreich, Thomas. (2010). Embodied effects of mindfulnessbased cognitive therapy. Journal of Psychosomatic Research, 68(3), 312-313. doi: 10.1016/j.jpsychores.2010.01.004

Muraven, Mark, \& Baumeister, Roy F. (2000). Self-regulation and depletion of limited resources: Does selfcontrol resemble a muscle? Psychological bulletin, 126(2), 247. doi: 10.1037/0033-2909.126.2.247 
Nielsen, Lisbeth, \& Kaszniak, Alfred W. (2006). Awareness of subtle emotional feelings: a comparison of longterm meditators and nonmeditators. Emotion, 6(3), 392. doi: 10.1037/1528-3542.6.3.392

Parkin, Lucy, Morgan, Ruth, Rosselli, Anna, Howard, Maxine, Sheppard, Alicia, Evans, Davy, . . Dalgleish, Tim. (2013). Exploring the relationship between mindfulness and cardiac perception. Mindfulness, 1-16. doi: 10.1007/s12671-012-0181-7

Peres, M. F., \& Lucchetti, G. (2010). Coping strategies in chronic pain. Current pain and headache reports, 14(5), 331-338. doi: 10.1007/s11916-010-0137-3

Phillipot, Pierre, \& Segal, Zindel. (2009). Mindfulness based psychological interventions: Developing emotional awareness for better being. Journal of Consciousness Studies, 16(10-12), 10-12.

Piet, J., \& Hougaard, E. (2011). The effect of mindfulness-based cognitive therapy for prevention of relapse in recurrent major depressive disorder: a systematic review and meta-analysis. Clinical Psychology Review, 31(6), 1032-1040. doi: 10.1016/j.cpr.2011.05.002

Pollatos, O., Traut-Mattausch, E., \& Schandry, R. (2009). Differential effects of anxiety and depression on interoceptive accuracy. Depress Anxiety, 26(2), 167-173. doi: 10.1002/da.20504

Preacher, K. J., \& Hayes, A. F. (2008). Asymptotic and resampling strategies for assessing and comparing indirect effects in multiple mediator models. Behavior Research Methods, 40(3), 879. doi: 10.3758/BRM.40.3.879

Prins, Björn, Decuypere, Anouk, \& Van Damme, Stefaan. (2014). Effects of mindfulness and distraction on pain depend upon individual differences in pain catastrophizing: An experimental study. European Journal of Pain, 18(9), 1307-1315. doi: DOI 10.1002/j.1532-2149.2014.491.x

Reid, K. J., Harker, J., Bala, M. M., Truyers, C., Kellen, E., Bekkering, G. E., \& Kleijnen, J. (2011). Epidemiology of chronic non-cancer pain in Europe: narrative review of prevalence, pain treatments and pain impact. Current Medical Research \& Opinion, 27(2), 449-462. doi: 10.1185/03007995.2010.545813

Reid, M. C., Barry, L. C., Kerns, R. D., Duong, B. D., \& Concato, J. (2002). Coping strategies and their associations with levels of disability or pain, among older veterans receiving primary care. Journal of Clinical Epidemiology, 55(6), 629. doi: 10.1016/s0895-4356(02)00420-1

Riley, Ben. (2014). Experiential Avoidance Mediates the Association Between Thought Suppression and Mindfulness with Problem Gambling. Journal of Gambling Studies, 30(1), 163-171. doi: 10.1007/s10899012-9342-9

Rush, A John, Trivedi, Madhukar H, Ibrahim, Hicham M, Carmody, Thomas J, Arnow, Bruce, Klein, Daniel N, ... Manber, Rachel. (2003). The 16-Item Quick Inventory of Depressive Symptomatology (QIDS), clinician rating (QIDS-C), and self-report (QIDS-SR): a psychometric evaluation in patients with chronic major depression. Biological psychiatry, 54(5), 573-583. doi: 10.1016/S0006-3223(02)01866-8

Schutze, R., Rees, C., Preece, M., \& Schutze, M. (2010). Low mindfulness predicts pain catastrophizing in a fear-avoidance model of chronic pain. Pain, 148(1), 120-127. doi: 10.1016/j.pain.2009.10.030

Segal, Z. V., Williams, J. M. G., and Teasdale, J. D. (2013). Mindfulness-Based Cognitive Therapy for Depression. New York: The Guilford Press.

Sipe, W. E., \& Eisendrath, S. J. (2012). Mindfulness-based cognitive therapy: theory and practice. Canadian journal of psychiatry. Revue canadienne de psychiatrie, 57(2), 63-69.

Sullivan, Michael J. L., Thorn, Beverly, Haythornthwaite, Jennifer A., Keefe, Francis, Martin, Michelle, Bradley, Laurence A., \& Lefebvre, John C. (2001). Theoretical perspectives on the relation between catastrophizing and pain. The Clinical journal of pain, 17(1), 52-64. doi: 10.1097/00002508-20010300000008

Sze, Jocelyn A, Gyurak, Anett, Yuan, Joyce W, \& Levenson, Robert W. (2010). Coherence between emotional experience and physiology: does body awareness training have an impact? Emotion, 10(6), 803. doi: 10.1037/a0020146

Trivedi, Madhukar H, Rush, AJ, Ibrahim, HM, Carmody, TJ, Biggs, MM, Suppes, T, . . Dennehy, EB. (2004). The Inventory of Depressive Symptomatology, Clinician Rating (IDS-C) and Self-Report (IDS-SR), and the Quick Inventory of Depressive Symptomatology, Clinician Rating (QIDS-C) and Self-Report (QIDS-SR) in public sector patients with mood disorders: a psychometric evaluation. Psychological medicine, 34(01), 73-82. doi: 10.1017/S0033291703001107 


\section{Chapter 4}

Tunks, Eldon R. (2008). Epidemiology of chronic pain with psychological comorbidity: prevalence, risk, course, and prognosis. Canadian Journal of Psychiatry, 53(4), 224.

Turk, D. C., Wilson, H. D., \& Cahana, A. (2011). Treatment of chronic non-cancer pain. Lancet, 377(9784), 2226-2235. doi: 10.1016/S0140-6736(11)60402-9

Vago, D. R., \& Silbersweig, D. A. (2012). Self-awareness, self-regulation, and self-transcendence (S-ART): a framework for understanding the neurobiological mechanisms of mindfulness. Frontiers in human neuroscience, 6, 296. doi: 10.3389/fnhum.2012.00296

van der Velden, Anne Maj, Kuyken, Willem, Wattar, Ulla, Crane, Catherine, Pallesen, Karen Johanne, Dahlgaard, Jesper, ... Piet, Jacob. (2015). A Systematic Review of Mechanisms of Change in MindfulnessBased Cognitive Therapy in the Treatment of Recurrent Major Depressive Disorder. Clinical Psychology Review, 37, 26-39. doi: 10.1016/j.cpr.2015.02.001

Veehof, M. M., Oskam, M. J., Schreurs, K. M., \& Bohlmeijer, E. T. (2011). Acceptance-based interventions for the treatment of chronic pain: a systematic review and meta-analysis. Pain, 152(3), 533-542. doi: 10.1016/j.pain.2010.11.002

Vohs, K. D., \& Baumeister, R. F. (2011). Handbook of Self-Regulation: Research, Theory, and Applications. New York: The Guilford Press.

Williams, J. Mark G. (2010). Mindfulness and Psychological Process. Emotion, 10(1), 1-7. doi: 10.1037/ a0018360

Williams, Virginia, Ciarrochi, Joseph, \& Deane, Frank Patrick. (2010). On being mindful, emotionally aware, and more resilient: Longitudinal pilot study of police recruits. Australian Psychologist, 45(4), 274-282. doi: 10.1080/00050060903573197 



\section{ABSTRACT}

We examined efficacy and safety of one specific cranial electrical stimulator (CES) device at a fixed setting in subjects with treatment-resistant major depressive disorder (MDD). Thirty subjects (57\% female, mean age $48.1 \pm 12.3$ years) with MDD and inadequate response to standard antidepressants were randomized to 3 weeks of treatment with CES $(15 / 500 / 15000 \mathrm{~Hz}$, symmetrical rectangular biphasic current of 1-4 mAmp, 40 Volts) or sham CES (device off) for 20 minutes, 5 days per week. The primary outcome measure was improvement in the 17-item Hamilton Depression Rating Scale (HAM-D-17). Adverse effects (AEs) were assessed using the Patient Related Inventory of Side Effects (PRISE). Completion rates were $88 \%$ for CES, $100 \%$ for sham. Both treatment groups demonstrated improvement of about 3-5 points in HAM-D-17 scores ( $p<0.05$ for both), and no significant differences were observed between groups. Remission rates were $12 \%$ for CES, and $15 \%$ for sham, a nonsignificant difference. CES was deemed safe, with good tolerability; poor concentration and malaise were the only distressing AEs that differed significantly between CES and sham ( $p=0.019$ and $p=0.043$, respectively). Limitations include a small sample and lack of an active comparator therapy. Although both treatment groups improved significantly, this CES at the setting chosen did not separate from sham in this sample. Thus we cannot rule out that the benefit from this setting used in this particular form of CES was due to placebo effects. Since this form of CES has other settings, future studies should test these settings and compare it against other CES devices. 


\section{INTRODUCTION}

Cranial Electrical Stimulation (CES) has been used for more than a half century in Europe and the US for various indications (Smith, 2008). The device transmits a small electrical pulse through the surface of the head and into the brain, often below threshold level of sensation (Smith, 2008). The general and psychotropic mechanisms are unknown. Various models have been proposed, including increasing/rebalancing of endorphins, neuroransmitters and neurohormones; regulation of body energy flow; effects on the limbic system, reticular activating system, and hypothalamus; vascular effects; positive impact on brain neural firing patterns and default network connectivity; circadian regulation; and adaptogenic function (assisting the body to battle effects of chronic stress). All these putative mechanisms may be relevant to CES's psychotropic effects, with the adaptogenic mechanism appearing to be the most favored, as it is the sum total of all the other mechanisms mentioned, and considering the role of stress in psychiatric illness (Feusner et al., 2012; Gunther \& Phillips, 2010; Kavirajan et al., 2014; Smith, 2008).

Effectiveness of CES is supported by hundreds of clinical and mechanistic studies. Adverse effects occur at rates of less than $1 \%$ and tend to be mild (skin irritation at the electrode site, and headaches) (Kirsch \& Nichols, 2013). Given its safety and tolerability, the United States Food and Drug Administration (FDA) grandfathered the device for approval in the 1970s (Smith, 2008). There are 11 different approved CES devices in the US, and probably many other unregistered devices (Kavirajan et al., 2014) .

Despite many published studies, rigorous randomized controlled trials (RCTs) of CES are lacking (Kavirajan et al., 2014; Kirsch \& Nichols, 2013; Smith, 2008). Several systematic reviews and meta-analyses have emerged over the past 2 decades. Klawansky et al. (1995) focused on anxiety and other conditions, but not depression. Kirsch and Gilula (2007) examined CES in depression, but their meta-analysis had several limitations: they did not specify a search strategy or study inclusion criteria; their summary effect size was based only on active CES treatment, and did not compare CES versus sham; they combined data from open uncontrolled trials and blinded RCTs, which likely overestimated effect sizes; they included trials with heterogenous primary diagnoses, which limits generalisability; and one negative trial with heavily medicated inpatients was excluded because improvement in the sham group 'invalidated' the study (Kirsch \& Gilula, 2007). This study, conducted in 1974 and later invalidated in a Cochrane review (Kavirajan et al., 2014), probably had an inefficient CES device.

A monograph by Smith (2008) summarized different meta-analyses covering various human clinical trials of CES for various conditions, including 18 depression studies comprising 853 subjects. Seven of these studies were double-blind, two single blind, two crossover, and seven open-label. Various types of depression were included. In many studies, depression was specifically a symptom within another syndrome, such as fibromyalgia or substance abuse. Few, if any, of these studies examined major 
depressive disorder (MDD) as the primary disorder, which significantly limits this work (Smith, 2008).

A recent Cochrane Review (Kavirajan et al., 2014), the most comprehensive thus far, examined 270 RCTs comparing efficacy and tolerability of CES versus sham CES for depressive disorders in adults. Only 7 studies (Feighner et al., 1973; Greenblatt et al., 1964; Hearst et al., 1974; Levitt et al., 1975; Marshall \& Izard, 1974; Passini et al., 1976; Rosenthal, 1972) were judged rigorous enough for full eligibility assessment, but were ultimately excluded for various reasons: failing to use (or not reporting) specific diagnostic criteria (5 studies); focus on subjects with chronic (> 2 years duration) rather than acute depression ( 2 studies); lack of appropriate comparator groups (4 studies); and sham CES that (unlike the active CES) did not produce tingling, potentially compromising the blind ( 3 trials). These results emphasize the dearth of rigorously designed trials of CES in depression.

In an RCT not mentioned in the Cochrane Review, Rose et al. (2009) examined CES versus sham in 38 subjects with sleep disturbances and depressive symptoms. While both groups improved after 4 weeks, no significant differences between the two groups were observed for depressive symptoms, though a trend favored CES for sleep. More recently, Barclay and Barclay (2014) performed a 5-week double-blind RCT of CES in 115 primary care patients with anxiety disorders and comorbid depression. Results based on the Hamilton Anxiety and Depression scales showed a significant difference between CES and the sham intervention for anxiety $(p=0.001, d=0.94)$ and depression $(p=0.001$, $\mathrm{d}=0.78$ ), favoring active CES, with good tolerability (Barclay \& Barclay, 2014).

Smith's (2008) and other systematic reviews (Shealy, 2003; Shealy et al., 1989), as well as an email poll of 152 veterans who used CES for various indications (Kirsch et al., 2014) suggest an overall average symptomatic improvement of about 50\% for depression, a figure comparable to standard antidepressants. Reports often described symptomatic improvement after one week (5 daily treatments), and clinical symptom reduction by two weeks (10 daily treatments) (Smith, 2008). Yet these encouraging studies are limited by small samples, symptom heterogeneity, and overlap of conditions, though they may better reflect 'real world' populations in which comorbidity is often the norm.

Interpreting these findings is also difficult due to the wide variety of marketed CES devices, different treatment procotols, and because published trials do not always provide detailed stimulation parameters. Treatment typically involves 20-60 minutes of daily stimulation for three weeks based on a current strength that is comfortable to the patient, followed by less frequent treatments that may go on indefinitely (Gilula \& Kirsch, 2005). Frequencies used range from $0.5 \mathrm{~Hz}$ to $167 \mathrm{kHz}$, and current flow amplitude from $100 \mu \mathrm{A}$ to $4 \mathrm{~mA}$ (Kavirajan et al., 2014); duration of stimulation and/or continuous application may vary from five minutes to six consecutive days (Zaghi et al., 2010). 
Given the accessibility of CES, and the growing demand for alternatives to conventional antidepressants and somatic therapies, we carried out a pilot, doubleblind, randomized controlled trial of CES in subjects with treatment-resistant MDD who were not responding adequately to standard antidepressants. We sought to generate preliminary evidence of the efficacy and safety of a particular CES device as adjunctive therapy for MDD. We hypothesized that subjects who received active as opposed to sham CES would have a significantly greater improvement in their depression symptoms. Due to the small sample, we could not hypothesize an effect size, but would calculate one to determine signal strength to guide the design of a larger, more rigorous study. As an exploratory aim, we examined whether CES would benefit sleep.

\section{MATERIALS AND METHODS}

The investigation was carried out per the latest version of the Declaration of Helsinki, and approved by our institutional review board (IRB). We screened 53 potential participants, and enrolled 30 adults of both genders, with major depressive disorder (MDD) diagnosed by Structured Clinical Interview for DSM-IV Axis I Disorders (SCID-I/P) (First et al., 1995). Severity of depression was determined by Structured Interview for the 17-item Hamilton Depression Rating Scale (SIGH-D HAM-D 17; (Hamilton, 1960; Williams, 1988). Subjects were required to be taking any current antidepressant and not responding in a satisfactory manner. See Figure 1 for subject characteristics.

Subjects were recruited by general and community advertisement from our Depression Clinical and Research Program (DCRP). Informed consent was obtained per IRB guidelines. Investigators who screened subjects to ascertain relevant psychiatric, medical, and neurological history, were our program's psychiatrists and psychologists, trained and certified in the use of appropriate diagnostic instruments such as the SCID and HAM-D. Our program holds regular re-training sessions to ensure inter-rater reliability.

Inclusion criteria were: age 18-65; good general health; meeting criteria for MDD based on the DSM-IV; a HAM-D-17 score $\geq 15$ and $\leq 23$; treatment-resistance, defined as meeting the above DSM-IV and HAM-D criteria while taking an approved antidepressant at minimum adequate and stable dose for $\geq 6$ weeks with $<50 \%$ response per MGH-Antidepressant Treatment Response Questionnaire (ATRQ; (Chandler et al., 2010). Per our IRB, the HAM-D score eligibility range was set to include subjects who were partial or non-responders (HAM-D 15-18) but not too severely depressed (HAMD $\leq 23$ ), given CES's experimental nature.

Subjects were excluded for any of the following: unstable health conditions that in the opinion of the investigators represented a risk to the subject; having any electrical stimulation implants - i.e. pacemaker, deep brain stimulators (e.g. vagal nerve stimulator, deep brain stimulator), or transcutaneous electrical nerve stimulator (TENS); 
psychotic or manic symptoms, or other evidence of a psychotic disorder; recent history of substance abuse or dependence; electroconvulsive therapy during the last year; previous course of CES; current active suicidal or self-injurious potential necessitating immediate treatment; in women, pregnancy, plans to conceive, or unwillingness to comply with birth control requirements; and a baseline HAM-D-17 score $>23$.

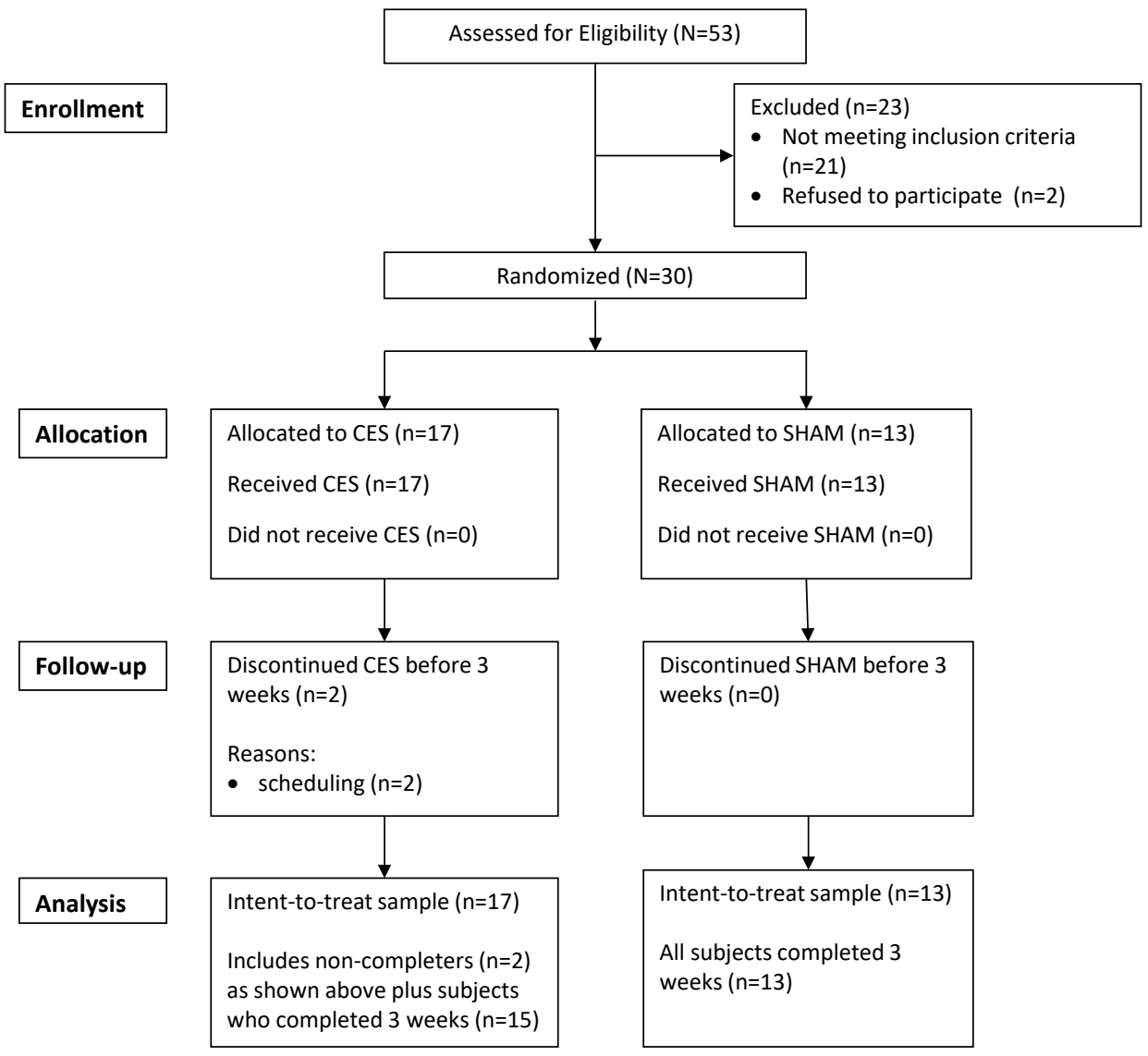

Figure 1: CONSORT Statement Flow Diagram

Randomisation numbers were provided by the study biostatistician and maintained by an unblinded research coordinator. Subjects were randomized equally to receive active CES or inactive (sham) CES in a double-blind manner.

Subjects who passed the screen visit returned a week later for the baseline visit. At that time, subjects received their first treatment (or sham) at the site for 20 minutes, including personal instruction of proper technique and electrode placement, and were allowed to take the device home and self-administer CES for the remaining 4 treatments (total of 5 per week, no more than once daily), until their next appointment. 
Thus, during the 3-week double blind treatment course, all subjects received one clinician-supervised weekly stimulation during their regular clinic visit, with review of technique to ensure correct use. The remaining 4 treatments for the week were selfadministered by the subject. All subjects agreed to self-administer treatment this way, so as not to be required to come to the clinic 5 days a week.

All subjects could self-administer CES at any convenient time of day, as long as each treatment was done on a separate day. After each treatment, subjects wrote down the date and time in the study-provided diary and noted any problems that may have occurred. Subjects brought the diary to every visit, so the study clinicians could document treatments and address any difficulties. The diary and direct subject inquiry comprised the main check for adherence.

Following completion of the 3-week double-blind phase, subjects were given an active CES device to use at home for 3 more weeks, with weekly check-in visits at our clinic.

The FW-100 Fisher Wallace Cranial Stimulator (model SLB201-M; formerly the Liss Cranial Stimulator Model SBL202-B), marketed for depression, anxiety, and insomnia since the 1970s, was used. The headset (two current applicators with moist sponges to transmit the current) was placed on the scalp (one current applicator on each side), over the two dorsolateral prefrontal cortex areas using an elastic headband to keep it in place (Figure 2).

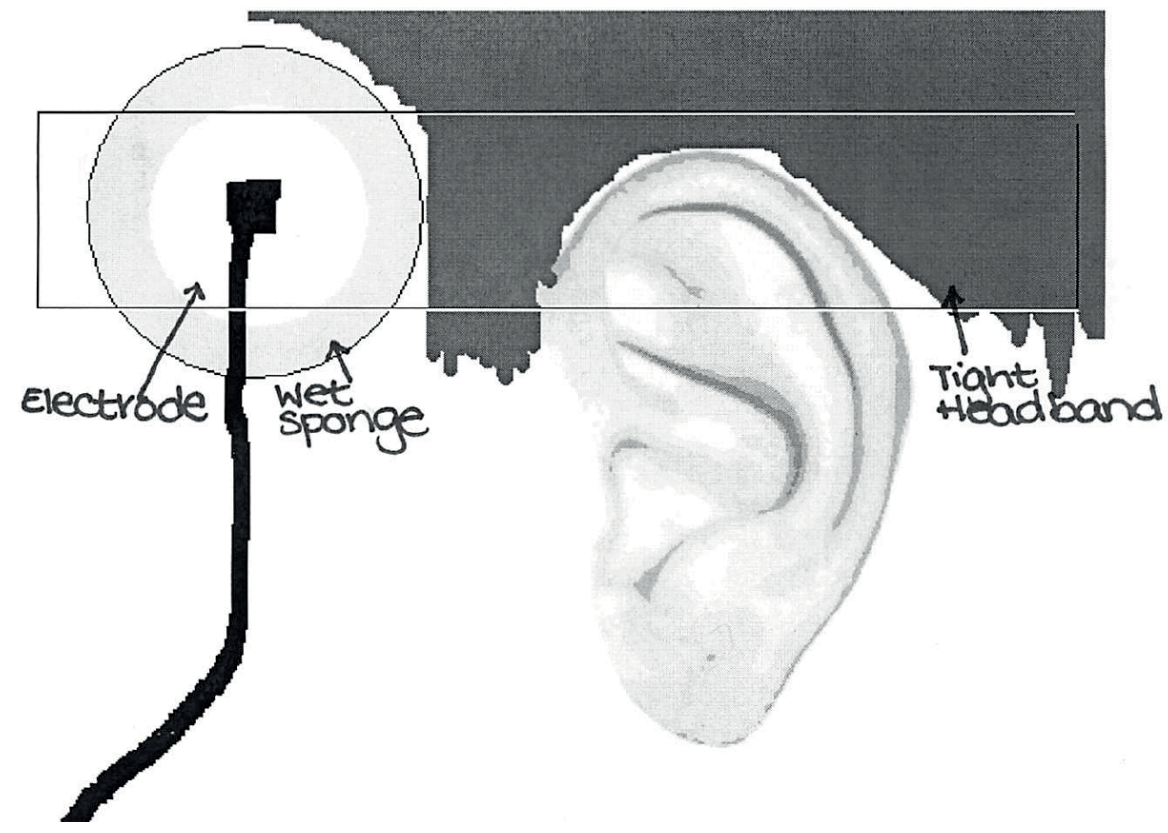

Figure 2: Proper Placement of the Electrodes of the CES Device 
Devices were calibrated such that the power knob was to be turned up all the way for the required dose, and subjects were explicitly told to set the wheel to the maximum level. The controller (or subject, in the case of a home session) slowly turned up the CES current until the knob was at the maximum setting.

The device's electronic waveform contains a $15,000 \mathrm{~Hz}$ (to traverse the skull) square wave carrier which is rectified, varying from 0-4 milliamperes (mAmp). The first $15 \mathrm{~Hz}$ modulating signal (to theoretically influence brain neurochemical activity) provides 50 milliseconds of 'on' time and 16.7 milliseconds of 'off' time (total pulse period 66.7 msec, $50 \%$ duty cycle). A second, $500 \mathrm{~Hz}$ modulating signal changes the 'on' time series of $15,000 \mathrm{~Hz}$ carrier pulses (750 pulses in 50 milliseconds) into 25 smaller bursts of 15 pulses each of the $15,000 \mathrm{~Hz}$ carrier signal, for 375 pulses in the same 50 milliseconds. The consecutive positive burst and 'off' time is followed by an equal and opposite negative burst and 'off' time, balancing the direct current component to zero. Output voltage ranges from 0-40 volts, first positive and then negative. CES was left at this level until it automatically shut off after 20 minutes. Based on the current strength, subjects receiving active or sham treatment were not expected to feel any current and were told that they should feel nothing.

The sham devices were modified to not deliver current to the headset. The current from the active device departs from the posts at the top of the device into the headsets, creating a loop when the headset is worn by the subject with the wet electrode sponges. This loop is eliminated in the sham devices by wrapping wire around the posts, thus containing the loop within the device, with no electricity leaving the headsets. This approach allows the loop to be maintained, and therefore all of the device's green and yellow amperage lights still light up, protecting the blind.

Severity of depression was measured at every study visit with the HAM-D 17. Sleep quality was assessed at the baseline and final visits, with the Pittsburgh Sleep Quality Index (PSQI; (Buysse et al., 1989). Adverse effects (AEs) were assessed at each visit, using the Patient Related Inventory of Side Effects Adverse Effects Visit Checklist (PRISE) (Rush et al., 2004), which measures presence and intensity of AEs. AEs were recorded as any emerging or worsening during treatment course, and those emerging or worsening to a distressing level.

Subjects were paid $\$ 50$ for each week of participation, plus an additional $\$ 50$ completion bonus for attending the final visit and returning the device. Total remuneration per subject was $\$ 200$.

An intent-to-treat analysis with last observation carried forward (LOCF) was performed for all randomized subjects. Significance of improvement in HAM-D-17 scores was assessed by paired samples t-test and by the equivalent non-parametric procedure, Wilcoxon Signed Ranks Test, given the small sample size. Improvement in HAM-D-17 was compared between treatment groups using independent samples t-test and its nonparametric counterpart, Mann Whitney $U$ Test. Rates of response $(\geq 50 \%$ decrease in HAM-D-17 score) and remission (final HAM-D-17 score $\leq 7$ ) were compared 
between treatment groups by chi-square and Fisher's exact test. Two-tailed significance was defined as $P<0.05$. Effect sizes for HAM-D-17 score improvement were determined by Cohen's d statistic (Cohen, 1988) and for response and remission rates by Odds Ratio (OR). Statistical analyses were performed using SPSS version 17.0 (Chicago, Illinois).

\section{RESULTS}

The sample had a mean age $48.1 \pm 12.3$ years, was predominantly female $(57 \%)$, White (97\%), with $27 \%$ college graduates and $54 \%$ employed. All subjects were taking at least one antidepressant and 26 were taking at least two psychotropic agents. Antidepressants used, including primary and secondary (combination), included psychostimulants $(n=8)$, bupropion $(n=7)$, fluoxetine $(n=6)$, trazodone $(n=6)$, citalopram $(n=3)$, escitalopram $(n=3)$, paroxetine $(n=3)$, duloxetine $(n=3)$, venlafaxine $(n=3)$, lamotrigine $(n=2)$, omega-3 fatty acids $(n=2)$, fluvoxamine $(n=1)$, L-methylfolate $(n=1)$, amitriptyline $(n=1)$, selegiline patch $(n=1)$, sertraline $(n=1)$, and mirtazapine $(n=1)$.

The overall completion rate was very high (93\%), including a 100\% completion rate in the sham group (Table 1). All subjects who discontinued early attended a termination visit and returned their device. Active CES and sham both produced significant improvements in HAM-D-17 score after 3 weeks, and significance for both held up under nonparametric analysis. The difference in improvement between the 2 treatment groups was nonsignificant. Figure 3 illustrates the time course of clinical improvement per HAM-D-17 scale. Response and remission rates did not differ significantly between treatment arms (Table 1).

Cohen's d for active CES based on change in HAM-D-17 score was -0.32, a small effect size favoring sham CES. The odds ratios for response and remission with active CES were 0.34 and 0.73 respectively, again suggesting a weak advantage for sham CES.

Results for the PSQI were examined based on component and global scores. Components included sleep quality, latency, duration, efficiency, and disturbance. We found no significant improvement for any individual component or for the global score in either treatment arm, and no significant differences between treatments (data not shown). 


\section{Chapter 5}

Table 1: Depression Outcomes for Double-Blind Treatment Period (Intent-to-Treat Sample)

\begin{tabular}{|c|c|c|}
\hline & CES & Sham \\
\hline $\mathrm{N}$ randomized & 17 & 13 \\
\hline \multirow[t]{2}{*}{$\mathrm{n}(\%)$ female } & $10(59 \%)$ & $7(54 \%)$ \\
\hline & Mean \pm SD & Mean \pm SD \\
\hline Age (years) & $45.5 \pm 12.3$ & $51.4 \pm 11.9$ \\
\hline Total HAMD-Baseline & $18.1 \pm 1.5$ & $18.7 \pm 3.9$ \\
\hline Total HAMD-Week 1 & $15.8 \pm 4.2$ & $14.5 \pm 4.1$ \\
\hline t-test for Week 1 vs Baseline & $t=-2.212, p=0.043^{*}$ & $t=-3.627, p=0.003^{*}$ \\
\hline Wilcoxon for Week 1 vs Baseline & $Z=-1.934, p=0.053$ & $Z=-2.908, p=0.004^{*}$ \\
\hline Total HAMD-Week 2 & $14.6 \pm 6.1$ & $15.3 \pm 5.5$ \\
\hline t-test for Week 2 vs Baseline & $\mathrm{t}=-2.252, \mathrm{p}=0.040^{*}$ & $t=-2.352, p=0.037^{*}$ \\
\hline Wilcoxon for Week 2 vs Baseline & $Z=-1.994, p=0.046^{*}$ & $Z=-2.036, p=0.042^{*}$ \\
\hline Total HAMD-Week 3 & $14.8 \pm 6.3$ & $13.6 \pm 5.8$ \\
\hline t-test for Week 3 vs Baseline & $t=-1.912, p=0.077$ & $t=-3.113, p=0.009 *$ \\
\hline Wilcoxon for Week 3 vs Baseline & $Z=-1.872, p=0.061$ & $Z=-2.045, p=0.016^{*}$ \\
\hline Total HAMD-Last (LOCF) & $14.8 \pm 6.3$ & $13.6 \pm 5.8$ \\
\hline t-test for Last vs Baseline & $t=-2.184 p=0.044^{*}$ & $t=-3.113, p=0.009 *$ \\
\hline Wilcoxon for Last vs Baseline & $Z=-2.044 ; p=0.041^{*}$ & $Z=-2.045, p=0.016^{*}$ \\
\hline \multirow{3}{*}{$\begin{array}{l}\text { Change in Total HAM-D score } \\
\text { (from baseline to last value obtained) }\end{array}$} & $-3.2 \pm 6.1$ & $-5.1 \pm 5.9$ \\
\hline & & \\
\hline & $\mathrm{n}(\%)$ & $\mathrm{n}(\%)$ \\
\hline Responders $^{a}$ & $3(17.6 \%)$ & $5(38.5 \%)$ \\
\hline Remitters $^{\mathrm{b}}$ & $2(11.8 \%)$ & $2(15.4 \%)$ \\
\hline Completers & $15(88.2 \%)$ & $13(100 \%)$ \\
\hline
\end{tabular}

* Statistically significant

a Based on improvement in Total HAMD $\geq 50 \%$

${ }^{b}$ Based on final Total HAMD $\leq 7$

All comparisons between treatment arms (CES vs sham) were non-significant ( $p>0.05$ for all). 


\section{HAM-D-17 Scores over Time}

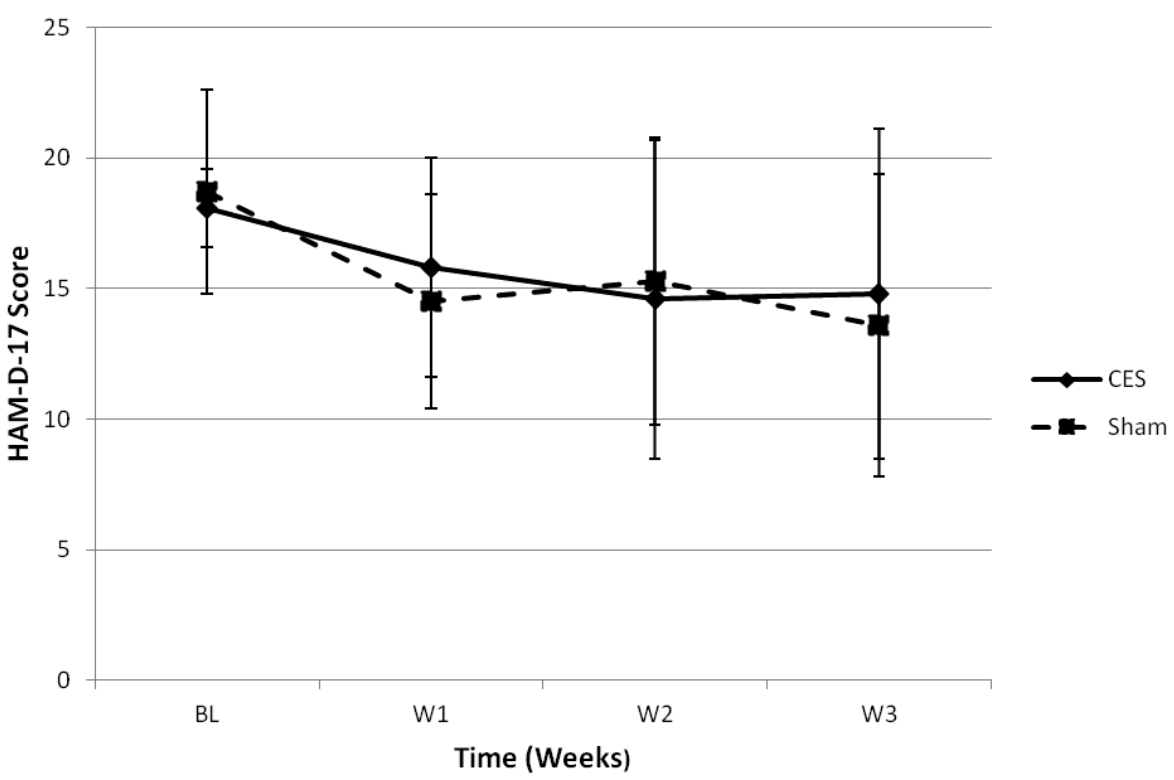

Figure 3: Time Course of HAM-D-17 Scores for CES vs Sham Intervention

Abbreviations: BL: Baseline; W1: Week 1; W2: Week 2: W3: Week 3

Differences between treatment arms were non-significant at all timepoints

Tolerability data were available for all subjects. The most common AEs that emerged to a distressing level with active CES were poor concentration (59\%), decreased energy (35\%), fatigue (29\%), general malaise (29\%), and anxiety (29\%). Only poor concentration $(p=0.019)$ and malaise $(p=0.043)$ attained a significant separation from sham CES. Bonferroni correction was not applied, since the large number of PRISE symptoms (total 32) would make it difficult to find any significant differences. We erred on the side of false positives to communicate what AEs might be more likely to occur with active CES. Five subjects assigned to active CES (29\%) reported a mild flashing light sensation in their peripheral vision and/or a tingling sensation in their temples. No such effects were reported among sham-assigned subjects. The difference between treatment groups was not significant (Fisher's $\mathrm{p}=0.052$ ). No subjects discontinued specifically because of AEs.

\section{DISCUSSION}

Our study failed to find a significant difference between the use of this particular CES device at the setting chosen and the sham intervention. Although both treatment groups improved significantly by 3-5 HAM-D-17 points, the effect size did not suggest that a larger sample would produce a significant advantage for CES. In fact, sham CES 
performed slightly better. The low response and remission rates for CES also suggested limited clinical significance of the modest improvement. No benefits to sleep were noted from either intervention. The results were surprising, in view of the generally supportive literature, including the recent positive study from Barclay and Barclay (2014), which also recruited treatment-resistant patients taking antidepressants, and the Rose et al. (2009) study that reported a trend to sleep improvement with CES . While there was no objective measure of adherence besides the diaries and direct inquiry, the high completion rate supports strong subject motivation, and we thus do not suspect any significant nonadherence.

The degree of sham improvement (5 points on the HAM-D-17) is consistent with a treatment resistant population; therefore, one possible explanation is that this study was enriched in subjects less likely to respond to any form of treatment, despite the upper limit of the baseline HAM-D score of 23. Our IRB requested this upper limit as a safety measure, since this was the first trial of CES conducted at MGH for depression, and they preferred that we not recruit subjects who were too severely depressed. This upper limit of the HAM-D could have impaired detection of an active-sham difference, and it also prevents us from knowing how well this treatment may work in more severely depressed populations. The HAM-D instrument also has potential limitations, such as an uneven reliance on a limited number of depressive symptoms, including sleep, which did not improve in our sample.

The device was found to be safe, and tolerability was very good; this likely contributed to high retention rates. Subjects had been informed that both devices would have electricity flowing through them, but one would be circuited such that the current would not travel into the brain, and that they would likely not feel anything regardless of intervention, since the current was very weak. During the course of the study, however, 5 CES subjects reported a mild flashing light sensation in their peripheral vision and/or a tingling sensation in their temples. Smith (2008) noted that in at least two thirds of blinded studies, subjects received stimulation below their level of sensation, with no disadvantage in efficacy compared to studies that used a stronger stimulation. Only one CES subject reported a distressing episode of dizziness, but not during or immediately following treatment; likewise, frequency of distressing dizziness was not significantly different between CES $(n=1)$ and sham groups $(n=0)$, suggesting that dizziness was not directly related to CES. No subjects reported vertigo, which may sometimes occur due to vestibular disturbance.

Although we informally tested the active devices on ourselves prior to starting the study, and could not feel anything, some subjects may have been more sensitive, or influenced by suggestion. We chose to proactively address any risk of nonblinding by telling subjects that both the active and sham devices would produce electricity but that the sham's current would not penetrate the brain (a true statement). Thus, if subjects felt anything at all, they would not necessarily assume that the device was active as opposed to sham. 
While our goal was to protect the blind by administering a current below level of sensation, one would expect that subjects who perceived any sign of an active current would be more likely to respond, given the placebo effect secondary to suggestion of active treatment. However, CES-assigned subjects did not fare better than those assigned to sham therapy. Among the 5 subjects reporting these effects, 4 were nonresponders, which suggests that even if they surmised that they were receiving CES, this did not contribute to a greater improvement. Blinding was not formally tested by inquiring whether subjects believed they had received active or sham treatment. Future investigations should do this to confirm the blind's integrity.

Other investigations have found therapeutic effects without significant sensation at frequencies of 0.5 to $1.5 \mathrm{~Hz}$ and currents of 100 microAmps. The Fisher Wallace device has higher frequencies of 15/500/15000 Hz and currents of 1-4 mAmps. Ideally, CES treatments should be studied at different frequencies, currents, and durations (i.e. >20 mins.), times given (e.g. once vs twice daily) and placement (since the Alpha-Stim device is clipped on the earlobes, and has a patent on this position). Unfortunately our budget would not permit such studies requiring larger samples. Because a few subjects complained of tingling and lights flashing, the device should be studied at lower settings, to maximize comfort and protect the blind. Perhaps a lower setting would have been more effective. Again, this is a goal of future research, as there is not enough evidence to know which is the optimal setting.

Other limitations include that this was an augmentation study in treatment-resistant subjects, although Barclay and Barclay (2014) also included medicated subjects and obtained positive results. We selected partial and non-responders to facilitate recruitment, since many depressed patients who enter our program are already taking antidepressants. A more rigorous test of efficacy would require subjects to discontinue their baseline antidepressant and administer CES as monotherapy. Alternatively, a less treatment-resistant population could have been selected, e.g. patients with no prior antidepressant treatment, or having previously responded to an antidepressant.

Finally, our study had no active comparator. An active, established antidepressant agent might have helped to determine the assay sensitivity of the study. Subjects were taking a wide range of antidepressants, which makes it unlikely that findings were impacted by a particular agent or type of agent.

In summary, subjects with MDD had a significant clinical improvement in HAM-D-17 scores with both CES and its sham counterpart, and neither treatment demonstrated a significant advantage over the other. These results are essentially negative in that the active treatment did not separate from placebo, and the improvement observed in subjects who received the active CES treatment may have been due to a placebo effect, since the sham group improved comparably.

As previously noted, not all CES devices are the same, and differences in waveform and other parameters may determine specific therapeutic effects. Given the wide range of CES devices reported in the literature, differences between studies may be due, at 


\section{Chapter 5}

least in part, to differences in the devices. Without head to head comparisons between devices, our results should not be considered as generalisable to all CES device types. Future studies should examine different frequency $(\mathrm{Hz})$ settings of the Fisher-Wallace machine and comparing it to other microcurrent devices at therapeutic frequencies, as well as sessions of varying lengths and more than once a day (classic meditators, for instance, are instructed to meditate twice a day for 20 minutes). A good candidate for such a comparison might be the Alpha-Stim Stress Control System, which delivers rectangular pulses with frequencies of $0.5,1.5$ and $100 \mathrm{~Hz}$, with a total current output of 10 to $600 \mu \mathrm{A}$ (Kavirajan et al., 2014), that was recently found to be effective for depression (Barclay \& Barclay, 2014). Because these devices are quite expensive, consumers often inquire about the relative merits of different devices. Further research into different kinds of CES devices, comparisons between them, and against standard antidepressants are therefore necessary to better understand the potential role of CES in the psychiatrist's armamentarium. 


\section{REFERENCES}

Barclay, T. H., \& Barclay, R. D. (2014). A clinical trial of cranial electrotherapy stimulation for anxiety and comorbid depression. J Affect Disord, 164, 171-177. doi: 10.1016/j.jad.2014.04.029

Buysse, D. J., Reynolds, C. F., 3rd, Monk, T. H., Berman, S. R., \& Kupfer, D. J. (1989). The Pittsburgh Sleep Quality Index: a new instrument for psychiatric practice and research. Psychiatry Res, 28(2), 193-213.

Chandler, G. M., losifescu, D. V., Pollack, M. H., Targum, S. D., \& Fava, M. (2010). RESEARCH: Validation of the Massachusetts General Hospital Antidepressant Treatment History Questionnaire (ATRQ). CNS Neurosci Ther, 16(5), 322-325. doi: 10.1111/j.1755-5949.2009.00102.x

Cohen, J. (1988). Statistical Power Analysis for the Behavioral Sciences, 2nd ed. . Hillsdale, NJ: Lawrence Erlbaum.

Feighner, J. P., Brown, S. L., \& Olivier, J. E. (1973). Electrosleep therapy. A controlled double blind study. J Nerv Ment Dis, 157(2), 121-128

Feusner, J. D., Madsen, S., Moody, T. D., Bohon, C., Hembacher, E., Bookheimer, S. Y., \& Bystritsky, A. (2012). Effects of cranial electrotherapy stimulation on resting state brain activity. Brain Behav, 2(3), 211-220. doi: $10.1002 /$ brb3.45

First, M.B., Spitzer, R.L., Gibbon, M., \& Williams, J.B.W. (1995). Structured Clinical Interview for Axis I DSM-IV Disorders - Patient Edition (With Psychotic Screen) (SCID-I/P (W/ PSYCHOTIC SCREEN)) (VERSION 2.0). 722 West 168th Street, New York, NY 10032: Biometrics Research Department, New York State Psychiatric Institute.

Gilula, M.F., \& Kirsch, D.L. (2005). Cranial electrotherapy stimulation review: a safer alternative to psychopharmaceuticals in the treatment of depression. Journal of Neurotherapy 9(2), 7-26.

Greenblatt, M., Grosser, G. H., \& Wechsler, H. (1964). Differential Response of Hospitalized Depressed Patients to Somatic Therapy. Am J Psychiatry, 120, 935-943. doi: 10.1176/ajp.120.10.935

Gunther, M., \& Phillips, K. D. (2010). Cranial electrotherapy stimulation for the treatment of depression. J Psychosoc Nurs Ment Health Serv, 48(11), 37-42. doi: 10.3928/02793695-20100701-01

Hamilton, M. (1960). A rating scale for depression. Journal of neurology, neurosurgery, and psychiatry, 23(1), 56.

Hearst, E. D., Cloninger, C. R., Crews, E. L., \& Cadoret, R. J. (1974). Electrosleep therapy: a double-blind trial. Arch Gen Psychiatry, 30(4), 463-466.

Kavirajan, H. C., Lueck, K., \& Chuang, K. (2014). Alternating current cranial electrotherapy stimulation (CES) for depression. Cochrane Database Syst Rev(7), CD010521. doi: 10.1002/14651858.CD010521.pub2

Kirsch, D. L., \& Gilula, M.F. (2007). CES in the treatment of depression, part 2. Practical Pain Management (6), 32-40.

Kirsch, D. L., \& Nichols, F. (2013). Cranial electrotherapy stimulation for treatment of anxiety, depression, and insomnia. Psychiatr Clin North Am, 36(1), 169-176. doi: 10.1016/j.psc.2013.01.006

Kirsch, D. L., Price, L. R., Nichols, F., Marksberry, J. A., \& Platoni, K. T. (2014). Military service member and veteran self reports of efficacy of cranial electrotherapy stimulation for anxiety, posttraumatic stress disorder, insomnia, and depression. US Army Med Dep J, 46-54.

Klawansky, S., Yeung, A., Berkey, C., Shah, N., Phan, H., \& Chalmers, T. C. (1995). Meta-analysis of randomized controlled trials of cranial electrostimulation. Efficacy in treating selected psychological and physiological conditions. J Nerv Ment Dis, 183(7), 478-484.

Levitt, E. A., James, N. M., \& Flavell, P. (1975). A clinical trial of electrosleep therapy with a psychiatric inpatient sample. Aust N Z J Psychiatry, 9(4), 287-290. doi: 10.3109/00048677509159864

Marshall, A. G., \& Izard, C. E. (1974). Cerebral electrotherapeutic treatment of depressions. J Consult Clin Psychol, 42(1), 93-97.

Passini, F. G., Watson, C. G., \& Herder, J. (1976). The effects of cerebral electric therapy (electrosleep) on anxiety, depression, and hostility in psychiatric patients. J Nerv Ment Dis, 163(4), 263-266. 


\section{Chapter 5}

Rose, K. M., Taylor, A. G., \& Bourguignon, C. (2009). Effects of cranial electrical stimulation on sleep disturbances, depressive symptoms, and caregiving appraisal in spousal caregivers of persons with Alzheimer's disease. App/ Nurs Res, 22(2), 119-125. doi: 10.1016/j.apnr.2007.06.001

Rosenthal, S. H. (1972). Electrosleep: a double-blind clinical study. Biol Psychiatry, 4(2), 179-185.

Rush, A. J., Fava, M., Wisniewski, S. R., Lavori, P. W., Trivedi, M. H., Sackeim, H. A., . . . Group, Star D. Investigators. (2004). Sequenced treatment alternatives to relieve depression (STAR*D): rationale and design. Control Clin Trials, 25(1), 119-142.

Shealy, C. N. (2003). Transcutaneous electrical nerve stimulation: the treatment of choice for pain and depression. J Altern Complement Med, 9(5), 619-623. doi: 10.1089/107555303322524463

Shealy, C. N., Cady, R.K., Wilkie, R.G., Cox, R., Liss, S., \& Clossen, W. (1989). Depression: a diagnostic, neurochemical profile and therapy with cranial electrical stimulation (CES). Journal of Neurological and Orthopaedic Medicine and Surgery 10, 319-321.

Smith, R.B. (2008). Cranial Electrotherapy Stimulation: Its First Fifty Years, plus Three: A Monograph Mustang, OK: Tate Publishing \& Enterprises.

Williams, J. B. (1988). A structured interview guide for the Hamilton Depression Rating Scale. Arch Gen Psychiatry, 45(8), 742-747.

Zaghi, S., Acar, M., Hultgren, B., Boggio, P. S., \& Fregni, F. (2010). Noninvasive brain stimulation with lowintensity electrical currents: putative mechanisms of action for direct and alternating current stimulation. Neuroscientist, 16(3), 285-307. doi: 10.1177/1073858409336227 


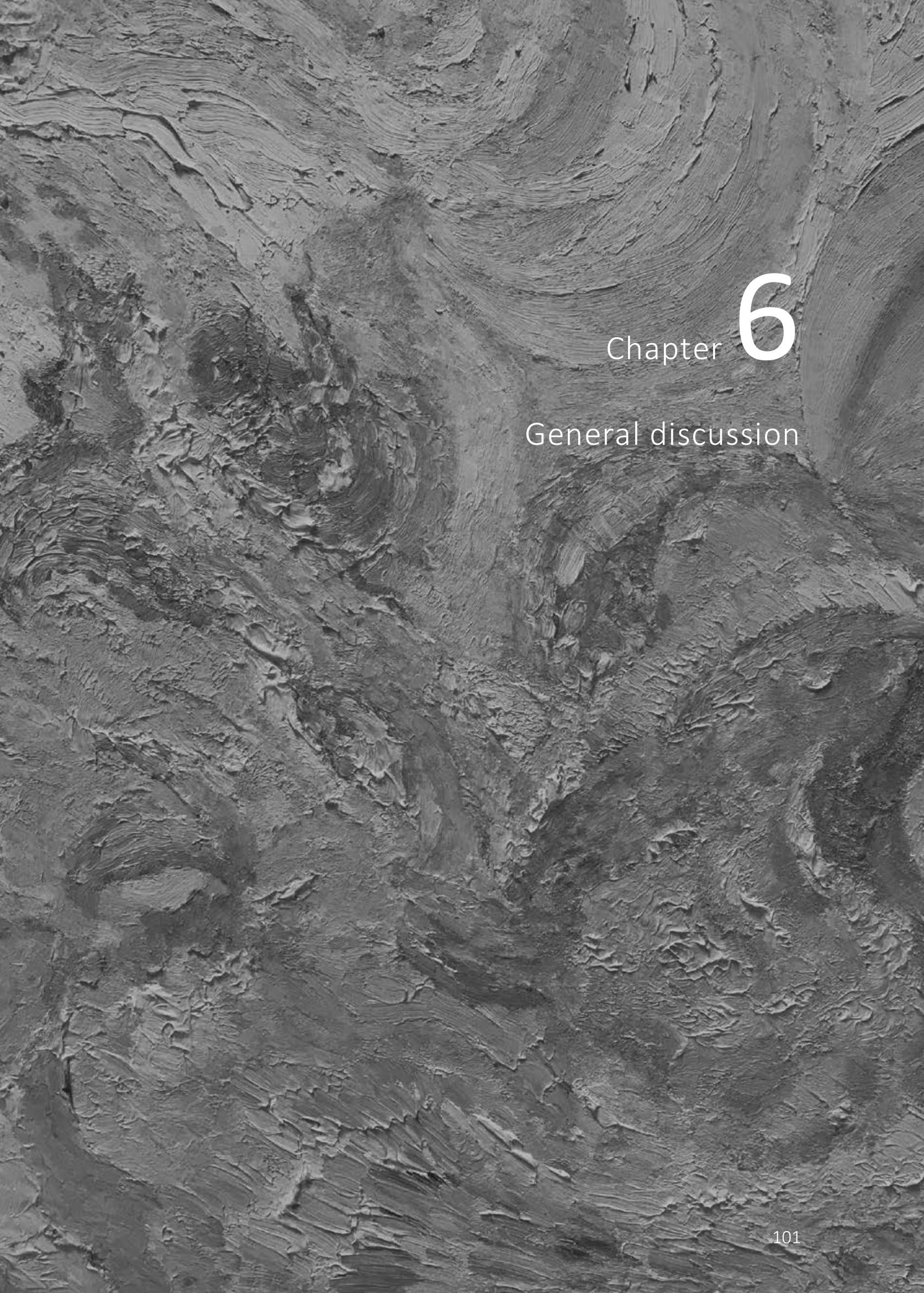



The central theme of this thesis was the interface between mood disorders and related physical aspects; it contains three main separate projects, providing different angles on this topic. In this chapter, clinical implications of the findings of the studies will be discussed and suggestions for future directions in research will be provided.

The study presented in Chapter 2, focusing on metabolic syndrome (MetS) in bipolar disorder (BD), was spawned by the author's clinical experience with patients with BD in an outpatient clinic for mood disorders in Maastricht, where high rates of obesity and rapid weight gain were observed, especially in young patients who were started on second generation antipsychotics (SGAs). This raised a concern about potentially high rates of metabolic syndrome in this population. This was confirmed by our prevalence study that found an alarmingly high rate of metabolic syndrome: more than $40 \%$ of the patients in the sample were affected. In the light of the rapidly increasing prevalence rate of MetS in the general population (Mozumdar \& Liguori, 2011) this high rate is expected to be even higher in the near future. The big challenge arising from these findings is what to do about it. Different factors play a role in the excess risk of MetS in $\mathrm{BD}$, including genetic factors, disparities in health care access, unhealthy life styles and prolonged psychotropic drugs treatment with adverse metabolic side effects (De Hert, Cohen, et al., 2011). Here, each of the modifiable factors relevant to the reduction of metabolic risk in patients with BD will be discussed.

\section{Disparities in health care access}

Patients with severe mental illness (SMI) have an unfortunate combination of elevated cardiovascular risk but suboptimal medical health care access. This is reflected in our results of low rates of drug treatment for MetS components; approximately two thirds of the affected patients received no drug treatment.

Several factors play a role in this limited medical health care. First, patients with SMI might have more difficulties seeking health care and communicating their symptoms and generally demonstrate lower adherence to treatment (Chadwick et al., 2012). Second, there seems to be a lack of awareness in both mental health and general medical health care providers of the elevated risk of cardiovascular disease in BD (De Hert, Cohen, et al., 2011). At the time of conducting our study on MetS there was an increasing awareness of the importance of assessing physical health, such as metabolic risk factors in patients with SMI including BD. However, to date a substantial number of outpatient clinics for SMI still do not systematically assess metabolic risk factors; in fact our own department for the treatment of mood disorders had no structural implementation of a metabolic risk screening until 2015. Also, the guideline for general practitioners (GPs) for cardiovascular risk management ('NHG standaard Cardiovasculair Risicomanagement,' 2012) does not take in to account the elevated risk on CVD in patients with SMI. In the Dutch multidisciplinary guideline for the treatment of schizophrenia (van Alphen et al., 2012) it has been recommended that GPs should add 
15 years to the age factor to adjust for excess risk of cardiovascular disease in SMI. No such recommendations have been made for bipolar disorder, and many GPs may not be aware of this resulting in undertreatment of CVD risk factors in this population. To reduce premature death in this vulnerable group of patients, awareness of somatic comorbidity and elevated cardiovascular risk should be promoted by education of residents as well as psychiatrists and GPs on the topic.

Another important barrier to adequate medical health care for patients with SMI is the current lack of a structural model for collaborative somatic health care between mental health care professionals and GPs. It is often not clear to patients and to treating psychiatrists and GPs where the responsibility of physical health care lies. To date, there is no uniform policy in the Netherlands for the organisation of physical health care for outpatients with SMI, leaving this up to local policy of mental health care institutions (van Hasselt et al., 2015a). A recent qualitative study of van Hasselt et al. gives practical recommendations to improve physical health care of patients with SMI in the Netherlands and stresses the importance of having a structural collaborative model between mental health care professionals and primary care. In this study no consensus was reached about which professional was responsible for the monitoring and treating of cardiovascular risk factors (van Hasselt et al., 2015b). The recommendations from this study have been integrated in the recent Dutch multidisciplinary guideline 'Somatic Screening for Patients with Severe Mental Illness' (Meeuwissen et al., 2015). This guideline recommends having a nurse case manager in the mental health care outpatient clinic responsible for the coordination and continuity of somatic health care. However, the guideline does not make recommendations about where the somatic screening including screening of CVD risk factors should be performed, and consequently responsibility of this screening remains a matter of debate. To create a more structural collaborative model for metabolic risk screening in patients with BD that is tailored to the Dutch health care system more qualitative research including major stakeholders in the Dutch health care system (patients, family carers, GPs, psychiatrists, healthcare insurance companies) could be helpful.

\section{Addressing unhealthy life styles}

Patients with severe mental disorder have high rates of unhealthy lifestyles including unhealthy diet, lack of physical exercise, smoking and substance abuse (De Hert, Correll, et al., 2011); all are risk factors for cardiovascular disease. It is well established that lifestyle advice and intervention programs in the general population are effective in reducing CVD risk factors and should be integrated in clinical care (Elmer et al., 2006). For patients with SMI however, access and adherence to lifestyle programs may be difficult (Roberts \& Bailey, 2011). Systematic reviews on effectiveness of lifestyle interventions in patients with SMI report significant improvements on metabolic syndrome risk factors, but improvements are modest and drop-out rates tend to be 
high (Cabassa et al., 2010; Teasdale et al., 2017; van Hasselt et al., 2013; Verhaeghe et al., 2011). Integrated interventions including exercise, diet and behavioral modification seem to work best, as in the general population (Ward et al., 2015). Lifestyle interventions in patients with SMI generally demonstrate lower effectiveness than in the general population. For example, a systematic review on lifestyle interventions for SMI found a mean weight loss of $1.6 \mathrm{~kg}$ compared to $3.6-5 \mathrm{~kg}$ in the general population (Cabassa et al., 2010). Many studies on lifestyle intervention in SMI do not employ evidence-based features that are known to be important in the effectiveness of lifestyle intervention in the general population, such as the use of multiple components and longer duration of the intervention, which might in part explain the disparity on clinical outcome in patients with SMI. Moreover, psychiatric symptoms and side effects of psychotropic drugs present an additional challenge in adherence to and effectiveness of lifestyle programs in this population (Ward et al., 2015). More efforts should be made to include evidence-based features in lifestyle programs for patients with SMI as well as tailoring these programs to the specific needs of the population.

\section{Metabolic side effects of psychotropic drugs}

The use of psychotropic medications, especially second generation antipsychotics (SGAs), is associated with significant weight gain and metabolic disturbances. Mood stabilizers (McKnight et al., 2012; Verrotti et al., 2011) and antidepressants (Fjukstad et al., 2016; Mclntyre et al., 2010) have also been associated with weight gain and metabolic disturbances. These drugs are vital in clinical practice, however, especially for treating BD. As clinicians we are confronted with making a choice in the delicate balance between effectively treating psychiatric conditions with drugs while taking into consideration their harmful side effects. Meta-analyses indicate that not all SGAs have the same level of toxic metabolic side effects; aripiprazole, for example, is considered less toxic (Bak et al., 2014). Furthermore, weight gain due to antipsychotic treatment is most substantial in antipsychotic-naïve first episode patients (Alvarez-Jimenez et al., 2008), stressing the importance of providing interventions early in antipsychotic treatment. This is supported by a recent meta-analysis on nutrition interventions in SMI, which demonstrated a larger effect size of the interventions in a pooled analysis of studies providing the intervention at the beginning of antipsychotic therapy (Teasdale et al., 2017). Clinicians should be alert for the metabolic side effects of psychotropic drugs for $\mathrm{BD}$ and, where possible, make efforts to choose the drugs with a more favorable metabolic profile as well as providing interventions aimed at weight reduction early in drug treatment.

In short, there are several modifiable factors that can be addressed to reduce metabolic risk in BD. Above all, we need awareness of how serious the problem is, since the lack of acknowledgement of the problem can have fatal consequences. The study presented in this thesis hopes to contribute to awareness of MetS in BD and promote 
regular monitoring and prevention strategies as well as treatment of MetS in this vulnerable population.

Chapter 3 focused on the results of a pilot RCT on the effectiveness of an 8-week mindfulness-based cognitive therapy (MBCT) program for the treatment of depression in patients with chronic pain. This study was funded by an anonymous bequest from a family member of a patient suffering from chronic pain and comorbid depression, who sadly committed suicide as a consequence of the intense suffering associated with chronic pain. Despite important steps forward in our understanding of chronic pain, this did not result in resolution of the symptoms of chronic pain. Because chronic pain is by definition chronic, it is not realistic to expect the intensity of pain to change considerably, and patients are often told that they should learn to live with their pain. That this is easier said than done is reflected by relatively modest effect sizes of established psychotherapeutic interventions such as CBT. This thesis studied a newly developed mindfulness based cognitive therapy specifically tailored to treat depression in patients with chronic pain and demonstrated positive results on depression severity and mental health, but not on pain intensity. These findings on pain and depression are in line with the outcomes of other psychotherapeutic intervention studies on populations with chronic pain that show positive outcomes on the affective outcome measures and quality of life but seem to be less effective in attenuating pain intensity (Williams et al., 2012). The findings are also consistent with the Buddhist theory about pain and suffering that lie at the foundation of mindfulness based interventions. Buddhist teachings use the metaphor of the first and second dart of pain. The first dart refers to the unavoidable physical component of pain, whereas the second dart refers the optional added suffering that is believed to be caused by ones reactions to the physical pain by amongst others worrying, catastrophizing and self blaming (Thera, 2010).

The practice of mindfulness is hypothesized to decrease the added suffering (the second dart), but not the physical pain itself (the first dart). As the old adage says, "Pain is inevitable, suffering is optional."

The MBCT intervention studied in this thesis was specifically developed for a depressed chronic pain population and aims to teach patients how to cope with physical pain and the concurring despair. The results, demonstrating a reduction of depressive symptoms with a large effect size are promising and warrant larger randomized controlled clinical trials testing this specific MBCT protocol.

Chapter 4, which investigated the role of body awareness in the MBCT intervention presented in Chapter 3, addresses an important aspect of mindfulness, which has been relatively understudied. A review of body awareness literature found that it wasn't until recently that body awareness was studied the context of mindfulness. Older literature on body awareness focuses mainly on hypervigilance regarding bodily symptoms in the context of anxiety and somatisation disorders. Indeed, this type of hyperarousal of bodily symptoms is associated with negative clinical outcomes. Body awareness in the 
context of mindfulness is fundamentally different and associated with positive clinical outcomes. Patients suffering from chronic pain are confronted daily with negative bodily sensations, and one could argue that cultivating a different relationship to pain/ adverse bodily sensation would be particular helpful in this population. Also, it would be helpful to have an instrument that could reliably measure the construct of body awareness. The MBCT protocol studied in this thesis includes exercises such as the body-scan, meditation exercises and yoga specifically aimed at relating to painful sensations and teaches participants to relate differently to their bodily sensations. It aims at shifting from relating to them in an anxious catastrophizing way to a more mindful and accepting approach, decoupling the negative automatic thoughts from the pain. The results of the study showed that patients who participated in the MBCT demonstrated an increase in certain aspects of body awareness and suggested that 'not distracting' mediated the antidepressant effect of the treatment. Identification of specific process variables that mediate the effects of treatment on clinical outcome are of key value in the development of more effective and efficient therapies. The study presented in this thesis generates information that can be used to optimize the MBCT program by paying specific attention to those aspects of body awareness that demonstrate particular importance in positive clinical outcome. These results of the study are encouraging and need to be replicated in larger trials with mediation analysis to draw a more definite conclusion regarding which aspects of body awareness are of particular benefit for the treatment of depression in patients with chronic pain.

Chapter 5 studied the efficacy of cranial electrical stimulation (CES) for the treatment of major depressive disorder (MDD). Altering mood through neuromodulation supports the idea that psychiatric disorders have a biological (somatic/physical) basis and are not merely disorders of the 'immaterial spirit,' as Descartes depicted the mind. CES also has favourable clinical outcomes in patients with physical damage to the central nervous system due to trauma or neurodegenerative processes including diagnoses such as Parkinson's Disease (Alon et al., 2012) and neuropathic pain due to spinal cord injury (Tan et al., 2011) suggesting common pathways for both 'physical' and 'mental' illness. The study presented in this thesis failed to find separation between the use of the particular CES device at the settings chosen and the sham intervention. This negative result can have several reasons, including study design characteristics such as an upper limit of the baseline HAMD score and the selection of patient with treatment resistant depression who are in general less likely to respond to any treatment. Another important issue to consider is that CES is a non standardized technique; previous trials used different parameters of stimulation that vary considerably in frequency $(0.5 \mathrm{HZ}$ to $167 \mathrm{~Hz})$, intensity $(100 \mu \mathrm{A}$ to $4 \mathrm{~mA})$ and duration of stimulation (5 min. to 6 consecutive days) (Kavirajan et al., 2014). Recent studies suggest that different electrical settings have a profound influence on the effect on cortical activity (Zaghi et al., 2010). This makes it difficult to interpret our findings, because other device settings might have more profound clinical efficacy. Datta et al. 
(2013) demonstrated in a modeling study that even minor changes in CES electrode montage altered overall brain current flow pattern. Future (modeling) studies should study different locations of electrode montage placement allowing optimal targeting of underlying neural networks associated with depression (Sale et al., 2015). These placement settings could then be used for clinical efficacy testing to get a better idea of which settings are most effective.

\section{CONCLUDING REMARKS}

This thesis stresses the importance of integrated care and calls for more integrated care for patients with psychiatric disorders. Psychiatric disorders are an important risk factor for somatic illness and vice versa, as demonstrated in this thesis by a high prevalence of metabolic syndrome in patients with bipolar disorder and a high prevalence of depression in patients with chronic pain. Psychiatric disorders still seem to have different status than other medical conditions in the clinical care setting and in society in general. This dualistic view on psychiatric disorders has profound adverse effects on the field of psychiatry and leads to stigmatisation of mental illness. This is, for example, painfully reflected by the fact that in 2012 in the Netherlands psychiatric visits required an additional fee of 200 Euros. Fortunately, this has been undone thanks to protest from mental health care organisations, psychiatrists and patients. Since then, however, the government decided to separate mental health care for children from the insurance system by transitioning pediatric mental health care to the local authorities, leaving the treatment options and access to mental health care for severe mental disorders of our next generation dependent on local policy. For general medical conditions, such a policy would be unthinkable. Treating psychiatric disorders as a different entity from somatic conditions is in contrast with the rising evidence from the neuroscience and genetic fields that supports a biogenetic basis for psychiatric disorders. However, the dualistic view seems to be very persistent, even among mental health care workers (Miresco \& Kirmayer, 2006). The rapidly increasing insight in neuroplasticity of the brain argues for a more unified view of psychiatric disorders. Society has a long way to go in addressing stigma of mental illness; adopting a biomedical model for explanation of mental illness would certainly be helpful in this regard. This thesis hopes to contribute to the awareness of psychiatrists as well as other medical health care professionals that psychiatric disorders should not be treated as separate 'disorders of the mind' neglecting the brain and body, but should be seen as medical disorders deserving the same status as other general medical conditions. 


\section{REFERENCES}

Alon, G., Yungher, D. A., Shulman, L. M., \& Rogers, M. W. (2012). Safety and immediate effect of noninvasive transcranial pulsed current stimulation on gait and balance in Parkinson disease. Neurorehabil Neural Repair, 26(9), 1089-1095. doi: 10.1177/1545968312448233

Alvarez-Jimenez, M., Gonzalez-Blanch, C., Crespo-Facorro, B., Hetrick, S., Rodriguez-Sanchez, J. M., PerezIglesias, R., \& Vazquez-Barquero, J. L. (2008). Antipsychotic-induced weight gain in chronic and firstepisode psychotic disorders: a systematic critical reappraisal. CNS Drugs, 22(7), 547-562.

Bak, M., Fransen, A., Janssen, J., van Os, J., \& Drukker, M. (2014). Almost all antipsychotics result in weight gain: a meta-analysis. PLoS One, 9(4), e94112. doi: 10.1371/journal.pone.0094112

Cabassa, L. J., Ezell, J. M., \& Lewis-Fernandez, R. (2010). Lifestyle Interventions for Adults With Serious Mental IIIness: A Systematic Literature Review. Psychiatric Services, 61(8), 774-782.

Chadwick, A., Street, C., McAndrew, S., \& Deacon, M. (2012). Minding our own bodies: reviewing the literature regarding the perceptions of service users diagnosed with serious mental illness on barriers to accessing physical health care. Int J Ment Health Nurs, 21(3), 211-219. doi: 10.1111/j.1447-0349.2011. 00807.x

Datta, A., Dmochowski, J. P., Guleyupoglu, B., Bikson, M., \& Fregni, F. (2013). Cranial electrotherapy stimulation and transcranial pulsed current stimulation: a computer based high-resolution modeling study. Neuroimage, 65, 280-287. doi: 10.1016/j.neuroimage.2012.09.062

De Hert, M., Cohen, D., Bobes, J., Cetkovich-Bakmas, M., Leucht, S., Ndetei, D. M., . . Correll, C. U. (2011). Physical illness in patients with severe mental disorders. II. Barriers to care, monitoring and treatment guidelines, plus recommendations at the system and individual level. World Psychiatry, 10(2), 138-151.

De Hert, M., Correll, C. U., Bobes, J., Cetkovich-Bakmas, M., Cohen, D., Asai, I., . . Leucht, S. (2011). Physical illness in patients with severe mental disorders. I. Prevalence, impact of medications and disparities in health care. World Psychiatry, 10(1), 52-77.

Elmer, P. J., Obarzanek, E., Vollmer, W. M., Simons-Morton, D., Stevens, V. J., Young, D. R., . . Group, Premier Collaborative Research. (2006). Effects of comprehensive lifestyle modification on diet, weight, physical fitness, and blood pressure control: 18-month results of a randomized trial. Ann Intern Med, 144(7), 485495.

Fjukstad, K. K., Engum, A., Lydersen, S., Dieset, I., Steen, N. E., Andreassen, O. A., \& Spigset, O. (2016). Metabolic Abnormalities Related to Treatment With Selective Serotonin Reuptake Inhibitors in Patients With Schizophrenia or Bipolar Disorder. J Clin Psychopharmacol, 36(6), 615-620. doi: 10.1097/JCP.0000 000000000582

Kavirajan, H. C., Lueck, K., \& Chuang, K. (2014). Alternating current cranial electrotherapy stimulation (CES) for depression. Cochrane Database Syst Rev(7), CD010521. doi: 10.1002/14651858.CD010521.pub2

McIntyre, R. S., Park, K. Y., Law, C. W., Sultan, F., Adams, A., Lourenco, M. T., . . Kennedy, S. H. (2010). The association between conventional antidepressants and the metabolic syndrome: a review of the evidence and clinical implications. CNS Drugs, 24(9), 741-753. doi: 10.2165/11533280-000000000-00000

McKnight, R. F., Adida, M., Budge, K., Stockton, S., Goodwin, G. M., \& Geddes, J. R. (2012). Lithium toxicity profile: a systematic review and meta-analysis. Lancet, 379(9817), 721-728. doi: 10.1016/S01406736(11)61516-X

Meeuwissen, J.A.C., van Meijel, B. , van Piere, M. , Bak, M., Bakkenes, M., van der Kellen, D. , ... Hermens, M. (2015). Multidisciplinaire Richtlijn Somatische Screening bij Patiënten met een Ernstige Psychische Aandoening. Utrecht: Trimbos Instituut.

Miresco, M. J., \& Kirmayer, L. J. (2006). The persistence of mind-brain dualism in psychiatric reasoning about clinical scenarios. Am J Psychiatry, 163(5), 913-918. doi: 10.1176/ajp.2006.163.5.913

Mozumdar, A., \& Liguori, G. (2011). Persistent increase of prevalence of metabolic syndrome among U.S. adults: NHANES III to NHANES 1999-2006. Diabetes Care, 34(1), 216-219. doi: 10.2337/dc10-0879

NHG standaard Cardiovasculair Risicomanagement. (2012). from https://http://www.nhg.org/standaarden/ samenvatting/cardiovasculair-risicomanagement 


\section{Chapter 6}

Roberts, S. H., \& Bailey, J. E. (2011). Incentives and barriers to lifestyle interventions for people with severe mental illness: a narrative synthesis of quantitative, qualitative and mixed methods studies. J Adv Nurs, 67(4), 690-708. doi: 10.1111/j.1365-2648.2010.05546.x

Sale, M. V., Mattingley, J. B., Zalesky, A., \& Cocchi, L. (2015). Imaging human brain networks to improve the clinical efficacy of non-invasive brain stimulation. Neurosci Biobehav Rev, 57, 187-198. doi: 10.1016/j.neubiorev.2015.09.010

Tan, G., Rintala, D. H., Jensen, M. P., Richards, J. S., Holmes, S. A., Parachuri, R., . . Price, L. R. (2011). Efficacy of cranial electrotherapy stimulation for neuropathic pain following spinal cord injury: a multi-site randomized controlled trial with a secondary 6-month open-label phase. J Spinal Cord Med, 34(3), 285296. doi: 10.1179/2045772311Y.0000000008

Teasdale, S. B., Ward, P. B., Rosenbaum, S., Samaras, K., \& Stubbs, B. (2017). Solving a weighty problem: systematic review and meta-analysis of nutrition interventions in severe mental illness. Br J Psychiatry, 210(2), 110-118. doi: 10.1192/bjp.bp.115.177139

Thera, N. (2010). Sallatha Sutta: The Dart (SN 36.6). from http://www.accesstoinsight.org/tipitaka/sn/sn36/ sn36.006.nypo.html

van Alphen, C., Ammeraal, M., Blanke, C., Boonstra N., Boumans, H., Bruggeman, R., . .. van Zon, N. (2012). Multidisciplinaire Richtlijn Schizofrenie. Utrecht: Trimbos Instituut.

van Hasselt, F. M., Krabbe, P. F., van Ittersum, D. G., Postma, M. J., \& Loonen, A. J. (2013). Evaluating interventions to improve somatic health in severe mental illness: a systematic review. Acta Psychiatr Scand, 128(4), 251-260. doi: 10.1111/acps.12096

van Hasselt, F. M., Oud, M. J., \& Loonen, A. J. (2015a). [Collaborative somatic care for patients with severe mental illness]. Ned Tijdschr Geneeskd, 159, A9160.

van Hasselt, F. M., Oud, M. J., \& Loonen, A. J. (2015b). Practical recommendations for improvement of the physical health care of patients with severe mental illness. Acta Psychiatr Scand, 131(5), 387-396. doi: 10.1111/acps.12372

Verhaeghe, N., De Maeseneer, J., Maes, L., Van Heeringen, C., \& Annemans, L. (2011). Effectiveness and costeffectiveness of lifestyle interventions on physical activity and eating habits in persons with severe mental disorders: a systematic review. Int J Behav Nutr Phys Act, 8, 28. doi: 10.1186/1479-5868-8-28

Verrotti, A., D'Egidio, C., Mohn, A., Coppola, G., \& Chiarelli, F. (2011). Weight gain following treatment with valproic acid: pathogenetic mechanisms and clinical implications. Obes Rev, 12(5), e32-43. doi: 10.1111/j.1467-789X.2010.00800.x

Ward, M. C., White, D. T., \& Druss, B. G. (2015). A meta-review of lifestyle interventions for cardiovascular risk factors in the general medical population: lessons for individuals with serious mental illness. J Clin Psychiatry, 76(4), e477-486. doi: 10.4088/JCP.13r08657

Williams, A. C., Eccleston, C., \& Morley, S. (2012). Psychological therapies for the management of chronic pain (excluding headache) in adults. Cochrane Database Syst Rev, 11, CD007407. doi: 10.1002/14651858. CD007407.pub3

Zaghi, S., Acar, M., Hultgren, B., Boggio, P. S., \& Fregni, F. (2010). Noninvasive brain stimulation with lowintensity electrical currents: putative mechanisms of action for direct and alternating current stimulation. Neuroscientist, 16(3), 285-307. doi: 10.1177/1073858409336227 
This thesis focuses on the interface between mood disorders and concurrent physical aspects of illness.

Chapter 1 provides an introduction to the topic. It postulates that the field of psychiatry is still hampered by the dualistic view that body and mind are separate and that this has adverse effects on clinical practice. Patients oftentimes remain undermanaged when clinicians take a non-integrative approach to psychiatric and physical disorders, leaving psychiatric disorders underdetected and undertreated in general medicine, and leaving patients with psychiatric disorder somatically undertreated. The chapter provides background information on the topics of the studies including metabolic syndrome in bipolar disorder, the comorbidity of chronic pain and unipolar depression, mindfulness-based cognitive therapy (MBCT) for the treatment of comorbid depression in chronic pain and Cranial Electrical Stimulation (CES) for unipolar depression.

Chapter 2 describes a cross-sectional medical record study investigating the prevalence rate and demographic and clinical factors associated with metabolic syndrome (MetS) in a Dutch sample $(\mathrm{N}=71)$ of patients with bipolar disorder. The study demonstrated high prevalence rate of MetS (42.3\%) and substantial undertreatment of MetS components with approximately over two thirds of the affected patients receiving no drug treatment for these conditions. Males had an 8-fold higher risk for MetS than females, and with every point increase on BMI the risk of MetS increased by $40 \%$.

Chapter 3 reports on the results of a randomized controlled pilot study on mindfulness-based cognitive therapy (MBCT) for unipolar depression in patients with chronic pain $(\mathrm{N}=40)$. This study demonstrated a significantly greater decrease of depressive symptoms in the group that received $\mathrm{MBCT}$ in addition to treatment as usual (TAU) compared to the group that only received TAU. No effect on pain intensity was found.

Chapter 4 describes a study that examined the effects of MBCT on body awareness in patients with chronic pain and comorbid depression compared to treatment as usual $(\mathrm{N}=31)$. Body awareness was measured by a subset of the Multidimensional Assessment of Interoceptive Awareness (MAIA) Scales. The study suggested that MBCT can increase several aspects of body awareness as measured by the MAIA in patients with chronic pain and depression. More specifically, the study demonstrated a significantly greater increase on the 'self regulation' and 'not distracting' scales in the MBCT group compared to the TAU group. The positive effect of MBCT on depression severity was mediated by 'not distracting'. The study also found evidence that the MAIA is a reliable instrument for measuring self reported body awareness in this population, demonstrating adequate to high internal consistency of the MAIA scales in the sample.

Chapter 5 of this thesis describes a three-week double blind pilot study examining the efficacy and safety of cranial electrical stimulation (CES) as an add-on intervention for treatment-resistant major depressive disorder. Although both the treatment group with CES as well as the treatment group with sham CES improved significantly, the study 
failed to show separation between placebo (sham CES) and CES. CES was deemed safe with good tolerability. It was recommended that future studies should test other settings of the CES device used in this study and compare it to other CES devices.

Chapter 6 summarizes the main findings of the studies and provides a discussion of the implications of the findings for (clinical) practice and future research. 


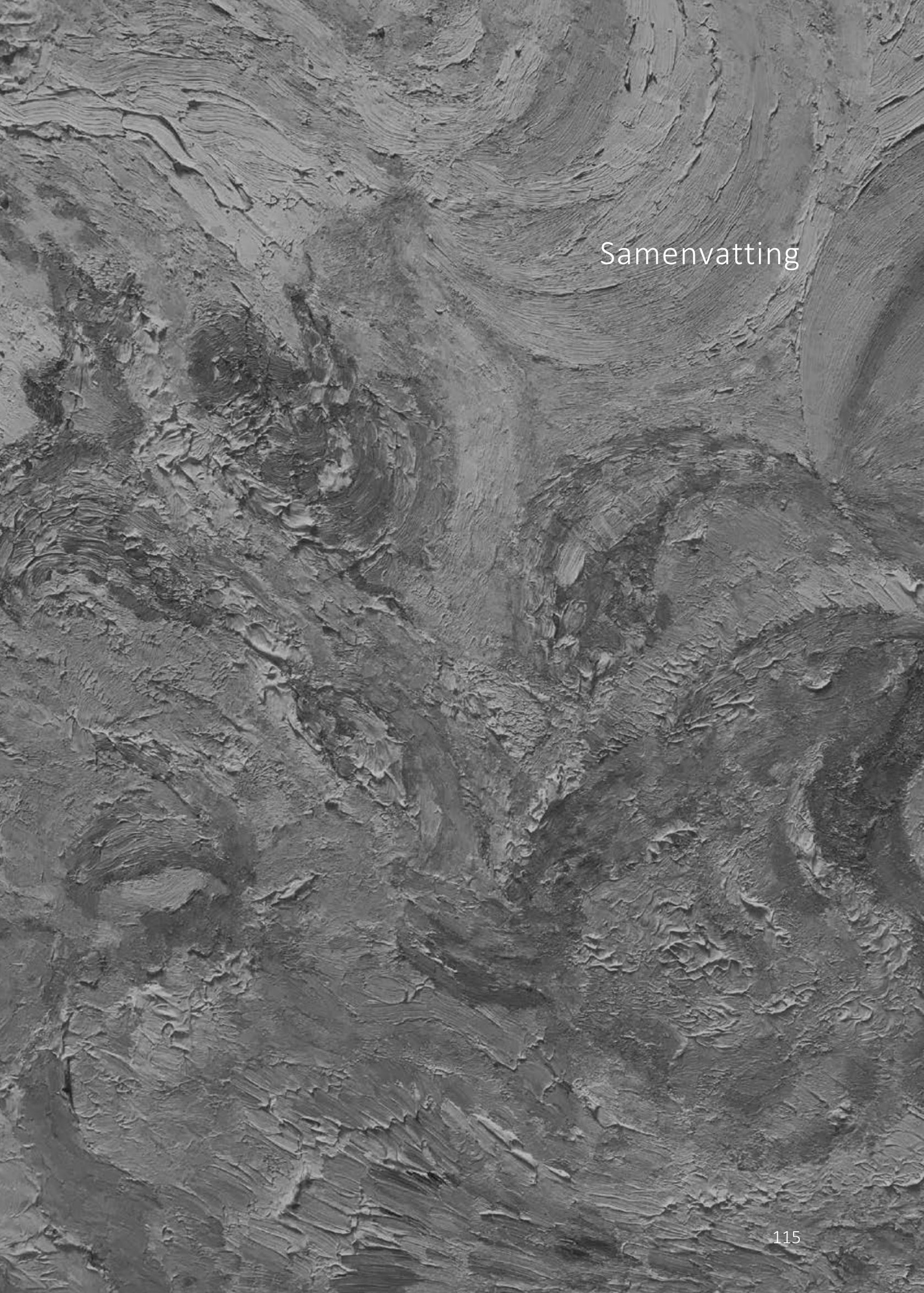



Dit proefschrift richt zich op het raakvlak tussen stemmingsstoornissen en somatische aspecten.

Hoofdstuk 1 voorziet in een introductie van het onderwerp. Er wordt beschreven dat het veld van de psychiatrie nog altijd wordt gehinderd door de dualistische visie dat geest en lichaam aparte entiteiten zijn hetgeen negatieve effecten heeft op de klinische praktijk. Wanneer er een non-integratieve benadering wordt gevolgd ten aanzien van psychiatrische en somatische ziekten is er een risico dat patiënten tussen wal en schip belanden. Hierdoor blijven psychiatrische stoornissen in de algemene medische zorg onopgemerkt en worden patiënten met een psychiatrische stoornis somatisch onderbehandeld. Het hoofdstuk geeft achtergrondinformatie over de onderwerpen van de studies in dit proefschrift, waaronder het metabool syndroom bij de bipolaire stoornis, de comorbiditeit van chronische pijn en unipolaire depressie, mindfulnessbased cognitieve therapie (MBCT) voor comorbide unipolaire depressie bij chronische pijn en Craniale Elektrische Stimulatie (CES) voor unipolaire depressie.

Hoofdstuk 2 beschrijft een cross sectionele dossier studie die de prevalentie van het metabool syndroom in een Nederlandse steekproef $(\mathrm{N}=71)$ van patiënten met een bipolaire stoornis onderzoekt. De studie probeert ook inzicht te verschaffen over demografische en klinische factoren die geassocieerd zijn met het metabool syndroom. De studie toonde een hoog prevalentiecijfer aan van het metabool syndroom (42.3\%) en tevens werd een substantiële graad van onderbehandeling van de metabool syndroom componenten gezien; ongeveer twee derde van de aangedane patiënten ontving geen medicamenteuze behandeling. Mannen hadden een 8 keer hoger risico op het metabool syndroom ten opzichte van vrouwen en met iedere punt verhoging in BMI nam het risico op het metabool syndroom toe met $40 \%$.

Hoofdstuk 3 behandelt de resultaten van een gerandomiseerde gecontroleerde pilotstudie naar mindfulness-based cognitieve therapie (MBCT) voor de behandeling van unipolaire depressie in patiënten met chronische pijn $(\mathrm{N}=40)$. Deze studie toonde een significant grotere afname in depressieve symptomen in de groep die MBCT kreeg in toevoeging op de reguliere behandeling ten opzichte van de groep die alleen de reguliere behandeling kreeg. Er werd geen effect op pijn intensiteit gevonden.

In Hoofdstuk 4 worden de resultaten van een studie naar de effecten van MBCT op lichaamsbewustzijn in patiënten met chronische pijn en comorbide depressie beschreven $(\mathrm{N}=31)$. Lichaamsbewustzijn werd gemeten met een deelverzameling van de Multidimensional Assessment of Interoceptive Awareness (MAIA) schalen. De studie toonde aan dat MBCT verscheidene aspecten van lichaamsbewustzijn kan verhogen zoals gemeten met de MAIA in patiënten met chronische pijn en comorbide depressie. Meer specifiek gaf de studie meer verhoging aan in gemeten 'zelf regulatie' en 'geen afleidbaarheid' bij de MBCT groep ten opzichte van de groep die alleen reguliere behandeling kreeg. Het positieve effect op de ernst van de depressie werd gemedieerd door 'geen afleidbaarheid'. De studie gaf ook aanwijzingen dat de MAIA een betrouwbaar instrument is voor het meten van zelf gerapporteerd lichaamsbewustzijn 
in deze populatie; er werd een adequate tot hoge interne consistentie gevonden van de MAIA schalen in de steekproef.

Hoofdstuk 5 van dit proefschrift beschrijft een drieweekse dubbelblinde pilotstudie naar de effectiviteit en veiligheid van Craniale Elektrische Stimulatie (CES) als een add on interventie voor de therapie resistente depressieve stoornis. Hoewel zowel de groep die met CES werd behandeld, als de groep die met 'nep' CES werd behandeld, significant verbeterden, slaagde de studie er niet in separatie tussen placebo ('nep' CES) en CES aan te tonen. CES werd veilig bevonden en goed verdragen. Er werd aanbevolen om in toekomstige studies andere instellingen van het CES apparaat te testen. Tevens werd het advies gegeven het specifieke CES apparaat dat gebruikt werd in deze studie met andere CES apparaten te vergelijken.

Hoofdstuk 6 vat de belangrijkste bevindingen van dit proefschrift samen en geeft een discussie over de implicaties voor de klinische praktijk en voor toekomstig onderzoek. 


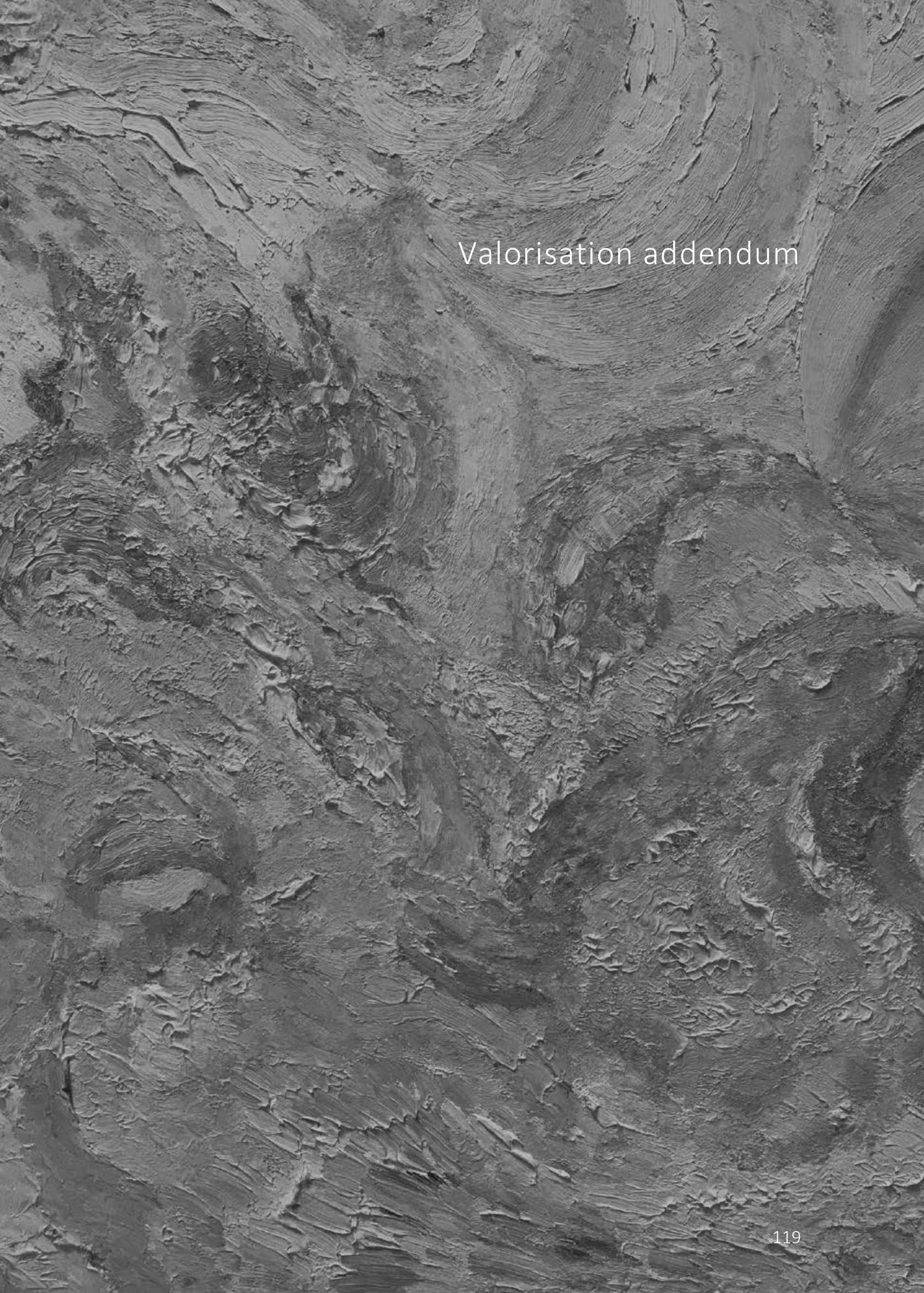



The studies presented in this thesis focus on the overlap between mood disorders and physical conditions and adopt a biomedical model for explanation of mental illness. Addressing this overlap is important in assuring a holistic biomedical approach with integrated somatic and psychiatric care for the treatment of patients with mood disorders. Psychiatric disorders still tend to be seen as a different entity from somatic illness. This thesis pleads for disengagement of the dualistic view on psychiatric disorders and other medical conditions and thereby hopes to contribute to destigmatisation of psychiatric illness in society. In this valorisation addendum we will elaborate more specifically per chapter on the valorisation of the individual studies.

In chapter 2 of this thesis metabolic syndrome (MetS) rate in bipolar disorder (BD) in a Dutch sample was examined. Although this risk estimation does not directly lead to different prevention plans and treatment, the study does contribute to the awareness of the scope and severity of the problem, which is the beginning of tailoring prevention and treatment. Obesity and MetS already take pandemic proportions in the general population and lead to significant health care costs. The estimated annual health care costs for cardiovascular disease in the Netherlands are around 8 milliard euros and comprise around $10 \%$ percent of the total Dutch healthcare costs ('Kosten van ziektenstudie,' 2011). It is ranked second in terms of health care expenditure after costs for mental health care (around 20 milliard euros comprising $20 \%$ of the total health care expenditure). The most recent Dutch national health examination survey on cardiovascular risk factors in the general population demonstrated that more than half of the general population is too heavy (BMI $\left.\geq 25 \mathrm{~kg} / \mathrm{m}^{2}\right), 14 \%$ has obesity (BMI $\geq 30$ $\mathrm{kg} / \mathrm{m}^{2}$ ) and a quarter of the population has metabolic syndrome. To compare in 1981, only one in three Dutch adults were too heavy and 5\% was obese (Blokstra et al., 2011). Our study demonstrates a prevalence rate of $42.3 \%$ of MetS in our sample of patients with $\mathrm{BD}$, indicating almost a doubling of the cardiovascular risk compared to the general population. In the light of the rapid increase of obesity this rate is expected to be even higher in near future. Patients with BD have the unfortunate combination of elevated cardiovascular risk but reduced access to care due to multiple disease related variables. The increased cardiovascular risk and disparities in health care access makes prevention strategies targeted to this specific population warranted. It also stresses the importance of the implementation of a structural screening of cardiovascular risk in this population. In order to effectively screen and treat MetS in BD changes in the organisation of health care for patients with BD and more in general for patients with serve mental illness (SMI) are necessary; there is a need for more effective collaboration between (outpatient) mental health care and primary health care with transparency in responsibilities. In the light of mental health care cuts and reduction of inpatient facilities, this collaboration is required more than ever. At the moment there is a lack of clarity of where the responsibility of cardiovascular risk screening lies. Large scale qualitative research inviting major stakeholders including patients, family members, psychiatrists, GPs and health insurance companies is indicated to get explicitness of 
who is responsible for performing this metabolic screening and in order to create an uniform policy regarding screening and treatment of cardiovascular risk in this vulnerable population. Detection of cardiovascular risk factors and successful treatment of them can diminish societal costs and increase quality of life due to prevention of cardiovascular events such as stroke and myocardial infarction. Increasing physical health by prevention of cardiovascular events also contributes to mental health and in this way screening and prevention of Mets can reduce societal costs of two of the most expensive conditions in terms of health care costs. The results of our study are also of important value to multidisciplinary education of mental health care professionals as well as primary care physicians on the increased cardiovascular risk in BD, as changing policy starts with the realisation of the scope of the problem.

In chapter 3 of this thesis a newly developed mindfulness-based group intervention for the treatment of depression in chronic pain was studied. Chronic pain is associated with intense suffering, greatly impaired quality of life and high direct and indirect healthcare costs. It is a very common condition; in the Netherlands approximately 1 out of 5 people suffers from chronic pain (Bekkering et al., 2011). Having depression, in addition, depletes resilience and coping abilities in patients with chronic pain, thereby worsening the outcome with increased pain intensity, increased functional disability and a significant decrease in quality of life. This makes the treatment of depression in chronic pain a major public health concern. There is a need for more research on effective interventions for pain and mood management in patients with chronic pain that can be used as an adjunctive approach to the existing conventional analgesic and antidepressive treatments. The results of our study demonstrate that MindfulnessBased Cognitive Therapy (MBCT) is a feasible and effective intervention for the treatment of depression in chronic pain and thereby widens the psychotherapeutic armatarium. Because this intervention is provided in a group format, it also increases cost-effectiveness.

In chapter 4 we focus on the role of body awareness in the effectiveness of MBCT. Better understanding of which mechanisms in an intervention are associated with positive clinical outcome are important in optimizing their clinical efficacy. The results of the study showed that patients who participated in the MBCT demonstrated increase in certain aspects of body awareness and demonstrated that one aspect seemed to play a role in the antidepressive effect of the treatment. Identification of specific process variables that mediate the effects of treatment on clinical outcome are of key value in development of more effective and efficient therapies. The study presented in this thesis generates information can be used to optimize the MBCT program by paying specific attention to those aspects of body awareness that demonstrate particular importance in positive clinical outcome. These results of the study are encouraging and need to be replicated in larger trials with mediation analysis to draw a more definite conclusion of which aspects of body awareness are of particular benefit for the treatment of depression in patients with chronic pain. 
The treatment of depression is challenging. Conventional antidepressants have limited efficacy and electro convulsion therapy (ETC), although efficacious, has harmful side effects including memory problems. One has been looking for alternatives and neuromodulation techniques have increased interest. Chapter 5 studies a form of electrical brain stimulation called cranial electrical stimulation (CES). It is of value for the field to investigate the efficacy of this widely used device as previous studies have shown conflicting results and are hampered by methodological issues. In our study CES did not separate from placebo. More research needs to be done to test the CES device in different settings. Modeling studies could be helpful for determining the correct location and harness the brain networks that are known to be involved in depression. Clinical studies could then test the efficacy of these settings.

Bekkering, G. E., Bala, M. M., Reid, K., Kellen, E., Harker, J., Riemsma, R., . . Kleijnen, J. (2011). Epidemiology of chronic pain and its treatment in The Netherlands. Neth J Med, 69(3), 141-153.

Blokstra, A. , Vissink, P., Venmans, L.M. A. J., Holleman, P., van der Schouw, Y.T., Smit, H.A., \& Verschuren, W.M.M. (2011). Measuring the Netherlands. A monitoring study of risk factors in the general population, 2009-2010: Rijksinstituut voor Volksgezondheid en Milieu (RIVM).

Kosten van ziektenstudie. (2011). from https://http://www.volksgezondheidenzorg.info/kosten-van-ziekten 



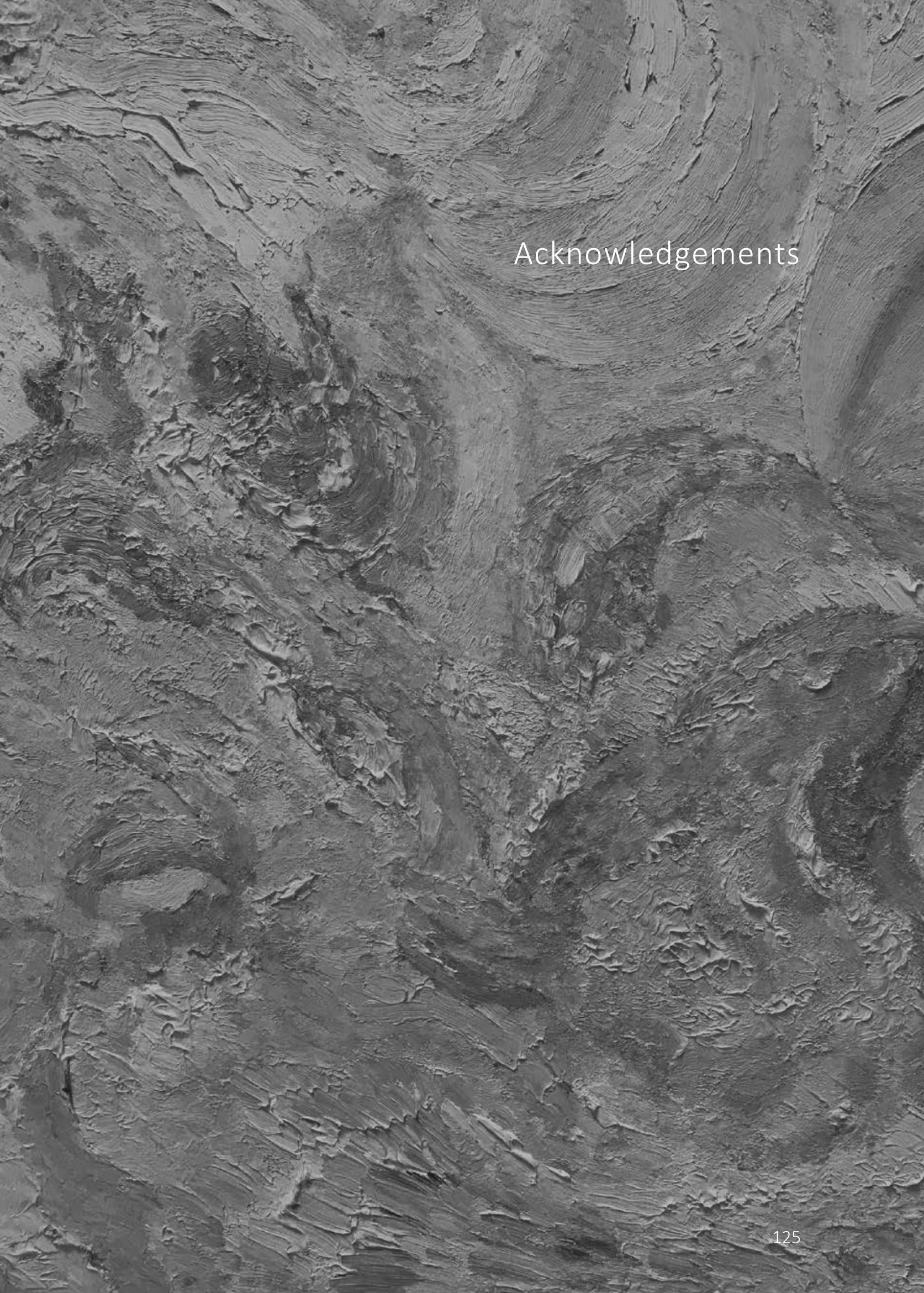



Bedanken gaat toch het beste in je eigen taal, dus het grootste deel van het dankwoord zal ik in het Nederlands schrijven met uitzondering van het dankwoord aan mijn collega's uit Boston van het Depression Clinical and Research Program (DCRP).

First I would like to thank my promotor and research mentor from the DCRP, Prof. dr. David Mischoulon. Dear David, I have been so extremely lucky to have you as my mentor. You have been invaluable in your contribution to this thesis. Actually, I believe without you there would have been no thesis at all. You have been my guidance throughout the entire process of conducting a research study, from grant preparation and tackling stumbling blocks and hurdles with the Institutional Review Board and recruitment, to teaching me how to write a proper research paper. Your passion for research, wit and thoughtfulness have inspired me enormously. Whenever I emailed you with a question (and I had lots of them) I would get back a practical answer within seconds to minutes. Whenever I was disheartened and felt like research wasn't my thing after all you gave me the support to persevere and the result is reflected in this thesis. You have shown me that research is a lot of fun and have motivated me to pursue in clinical research to the betterment of patient care. Thank you so much! I miss our weekly skype calls and look forward to continue our fruitful collaboration.

Also, a big thank you to all my other colleagues at the DCRP, including Dr. Maurizio Fava and Dr. Jon Alpert for giving me the chance to work as a research fellow at the DCRP. I would also like to thank the research assistants of the DCRP, especially Aya Inamori, Moneika Dipierro, Rosie Walker, Jim Doorley and Chelsae Dale. I would like to thank all of the subjects for their contribution to the MBCT and CES study.

I also would like to thank Laurie Rhoades, who was the mindfulness teacher in our MBCT study. Laurie, you are a very inspiring mindfulness teacher and have been of great importance for our research. Because of your teachings I have a deeper understanding of what mindfulness really entails and I benefit from it on a daily basis. You are also the reason that my husband wears a watch. I cannot express my gratitude enough for this.

I would kindly like to thank the Mind and Life Institute (Mind and Life Francisco J.Varela research grant), the Brach Family Foundation and Fisher Wallace Inc. for their funding of the studies included in this thesis.

Terug naar het Nederlands. Allereerst wil ik mijn promotor Prof. dr. Frenk Peeters bedanken. Frenk, jij bent van grote waarde geweest in het tot stand komen van het proefschrift. Het was denk ik niet altijd even gemakkelijk om met mij samen te werken. Vooral in het begin, toen ik, in mijn enthousiasme, de MBCT studie uitgebreider gemaakt heb dan realistisch was en mezelf (en jou) met behoorlijk wat extra werk heb opgezadeld. Ik beloof je plechtig dat ik bij verdere samenwerking jouw realistische tijdsplanning ter harte zal nemen. Ik heb de stelling 'bezint eer ge begint' niet voor niets in dit proefschrift opgenomen. Je hebt gedurende het gehele traject betrokkenheid 
getoond voor het onderzoek en bent van praktische en inhoudelijke steun geweest zowel bij het schrijven van het protocol voor de medisch ethische commissie als voor het schrijven van de artikelen. Je bent zelfs in Boston op bezoek geweest en hebt hiermee deel uit gemaakt van de zeer bijzondere tijd; heel erg bedankt voor je tijd en inzet om dit proefschrift tot een goed einde te brengen.

Ik wil graag alle collega's bij PsyQ, Mondriaan bedanken voor het creëren van een hele fijne werksfeer hetgeen onmisbaar is bij het leveren van goede patiëntenzorg en klinisch onderzoek. In het bijzonder wil ik Jolanda Belleflamme, verpleegkundig specialist, bedanken voor haar waardevolle bijdrage aan het metabool syndroom onderzoek bij patiënten met een bipolaire stoornis. Ook wil ik alle patiënten bedanken voor het vertrouwen dat ze mij geven om met mij hun moeilijkheden te delen. Ik zie het als een groot voorrecht dat ik als psychiater mag proberen bij te dragen aan mentale en lichamelijke gezondheid.

Peter Vervoort, jij bent de rode draad door mijn carrière in de psychiatrie, eerst als supervisor tijdens de opleiding en nu nog altijd als mentor in mijn jaren als 'jonge psychiater'. Een ware 'leermeester'. Dank voor al die keren dat je meedacht over lastige casuïstiek en heel waardevol: dank ervoor dat je op het juiste moment mij gemotiveerd hebt voor ons prachtige vak. Je hebt gelijk, psychiater zijn is zo gek nog niet!

Ik wil Annette Heffels bedanken voor haar steun tijdens de moeilijkste periode van ons leven. Annette, de manier waarop jij oprechte aandacht en betrokkenheid toont zijn een grote bron van inspiratie voor mij.

Sara en Yanti, wat ben ik blij met zulke lieve en slimme vriendinnen als paranimfen.

Sara, mijn lieve Belgische vriendin, als er iemand goed is in het moment te leven dan ben jij het. Er gaat een bepaalde ontspanning van jou uit die afstraalt op je omgeving en ik word altijd relaxed bij onze uitjes. Dat je van present moment awareness ook weerbaar wordt, daar ben je zeker ook een goed voorbeeld van. Wat ben ik blij voor jou dat jouw zonnestraaltje Lotte in je leven is gekomen. De ideale partner voor Lex. Bedankt dat je mijn vriendin bent en me komt steunen bij de verdediging.

Lieve Yanti, als ik aan mijn studententijd denk, dan denk ik aan jou. Wat hebben wij een lol gehad samen. Die studententijd duurde natuurlijk veel te kort en daarom hebben we hem met zijn tweeën nog maar even voortgezet, onder andere in Amsterdam. Nu zijn we dan eindelijk echt op de leeftijd dat we moeten toegeven dat we de studententijd langzaam maar zeker achter ons moeten gaan laten. Ten tijde van het schrijven van dit dankwoord ben je bijna 30 weken in verwachting en ten tijde van de verdediging ligt jullie baby al in de baby bay. Een nieuwe fase is aangebroken; het 'echte leven' is begonnen. Ook leuk. Zeker als ik het kan blijven delen met jou.

Ellen, mijn dierbare vriendin, op middelbare schooltijd waren we al vriendinnen en collega's (toen Mac Donalds) en twintig jaar later nog altijd (maar nu in de GGZ bij PsyQ). Dank voor jouw aanwezigheid en steun door alle levensfases heen. 
Mijn Dordtse duifies, Anne, Fleur en Liset. Decennia lang delen we al lief en leed. Ik kijk altijd uit naar onze duivendates en hoop dat er nog vele zullen volgen.

Mijn geneeskunde vriendinnen 'Vesper Fixa': Caar, As, Kim, Jel en Yant; vriendinnen voor het leven. Wat ben ik blij dat ik jullie heb leren kennen. Al woont de helft inmiddels niet meer in Nederland, we blijven contact houden.

Ik wil Claire en Selke bedanken voor hun goede zorgen voor ons gezin en huishouden. Claire, je bent in de periode toen ik net mama geworden was van grote steun geweest voor ons gezin. Ik kon naar het werk gaan en heb geen minuut meer hoeven nadenken of alles goed ging thuis. Dat heeft me erg geholpen bij de focus op dit proefschrift. Bedankt voor al jouw goede zorgen. Selke, beloofd is beloofd, ik noem je in mijn proefschrift. Jij hebt me heel wat uurtjes huishoudelijk werk bespaard, waarvoor grote dank.

Lieve papa, ik wil je bedanken voor alle vertrouwen, gezelligheid en steun die je me hebt gegeven. Je bent er altijd voor me geweest en je hebt me de schoonheid van het leven laten zien. Ik heb helaas jouw artistieke talent niet, maar kan wel intens genieten van mooi licht en die bepaalde kleur. Samen met Lex maak je van duplo de prachtigste kunstwerken, ik ben blij dat je jouw creativiteit doorgeeft aan jouw kleinkinderen. Grote dank dat je zo'n lieve opa bent voor Lex en Lynn. Ook veel dank voor het steeds opnieuw doornemen van alle versies die dit proefschrift heeft mogen kennen.

Oma en opa, u kunt helaas de verdediging van mijn proefschrift niet meer bijwonen. Ik weet zeker dat $\mathrm{u}$ trots zou zijn geweest. Oma, in het bijzonder bedankt dat ik uw werklust heb mogen erven, want 'Er moet wel gewerkt worden'.

Peter, altijd sta je voor ons klaar met praktische en mentale ondersteuning, van erwtensoep tot chauffeuren en een hart onder de riem steken wanneer het moeilijk was, ik ben je heel dankbaar voor al jouw zorg voor onze familie.

Gerry, je bent altijd zo betrokken geweest bij de familie de Jong dat het aanvoelt alsof je familie bent. Bedankt voor jouw gezelligheid, steun en liefde voor ons.

Karin en Wolfgang, mijn lieve schoonouders. Altijd staan jullie voor ons klaar. Bedankt voor alle support voor ons gezin. Ik prijs mezelf echt gelukkig met zo'n fijne schoonfamilie.

Lieve mama, het proefschrift heb ik aan jou opgedragen dus een woordje van dank is wel op zijn plaats. Jouw leven was niet makkelijk en is vroeg geëindigd. Ik ben er van overtuigd, dat als er betere medische zorg was geweest, jouw leven er anders had kunnen uitzien. Het heeft niet zo mogen zijn. Jij bent de drijfkracht achter mijn motivatie voor goede psychiatrische zorg, bedankt voor alles wat je me hebt meegegeven. 
Tim, lieverd, voor jou kwam ik naar Boston en dit heeft ons op meerdere gebieden veel goeds gebracht. Bedankt voor je steun tijdens het gehele promotietraject. Naast de onontbeerlijke mentale support kon ik inhoudelijk ook altijd terecht bij jou met onderzoeksvragen. Jij hebt mij 3 prachtige kinderen gegeven. Ik ben je oneindig dankbaar. Max, mijn lieve ventje, mijn eerstgeborene, bedankt dat je er bent. Lex en Lynn, lieverds. Mama gaat de komende tijd wat minder 'arbeiten' en zich meer richten op mindful mothering, beloofd. Ik hou van jullie. 






Marasha de Jong was born on December $6^{\text {th }} 1979$ in Dordrecht, The Netherlands. After graduation from high school at the Johan de Witt gymnasium in Dordrecht she studied medicine at Maastricht University, where she obtained her medical degree with the predicate 'cum laude' in 2006. She worked from 2006-2007 as a resident in pediatrics and started her career in psychiatry in 2007 at the outpatient department for mood disorders at the RIAGG Maastricht. She was a resident in psychiatry from 2007-2011 at the 'Universitaire Opleiding Psychiatrie Zuid-Limburg'. During this time she traveled around from Maastricht to Amsterdam for a fellowship in Acute Psychiatry and to Boston, USA, for her elective year where her research career started at the Depression Clinical and Research Program (DCRP), a Harvard University affiliated expert center for the treatment of depression. After completion of her residency program she continued to work at the DCRP as a researcher collaborating on a variety of studies on unipolar depression until the end of 2012. In 2013 she came back 'home' to Maastricht, and since then she works as a psychiatrist at Mondriaan, Institute of Mental Health, PsyQ Department of Mood Disorders in Maastricht. Marasha is married to her husband Tim and proud mother of three children: Max ${ }^{\dagger}$, Lex and Lynn. 



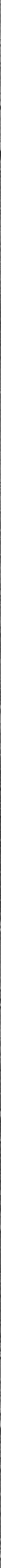



Mischoulon, D., de Jong, M. F., Vitolo, O. V., Cusin, C., Dording, C. M., Yeung, A. S., Durham K., Parkin S.R., Fava, M., Dougherty, D. (2015). Efficacy and safety of a form of cranial electrical stimulation (CES) as an add-on intervention for treatment-resistant major depressive disorder: A three week double blind pilot study. J Psychiatr Res, 70, 98105. doi: 10.1016/j.jpsychires.2015.08.016

de Jong, M., Lazar, S. W., Hug, K., Mehling, W. E., Holzel, B. K., Sack, A. T., Peeters, F., Ashih, H., Mischoulon, D., Gard, T. (2016). Effects of mindfulness-based cognitive therapy on body awareness in patients with chronic pain and comorbid depression. Front Psychol, 7, 967. doi: 10.3389/fpsyg.2016.00967

de Jong, M., Belleflamme J., Dale, C., Gard, T., Gamel, C., Mischoulon, D., Peeters, F. (2017). Metabolic syndrome in Dutch patients with bipolar disorder; a cross sectional study. Submitted

de Jong, M., Peeters, F., Gard, T., Ashih, H., Doorley, J., Walker, R., Rhoades, L., Kulich, R., Kueppenbender, K., Alpert, J., Hoge, E., Britton, W., Lazar, S., Fava, M., Mischoulon, D. (2017). A randomized controlled pilot study on mindfulness-based cognitive therapy for unipolar depression in patients with chronic pain. J Clin Psychiatry. doi: 10.4088/JCP.15m10160

Shapero, B.G., Greenberg, J.,Pedrelli, P. ,de Jong, M., Desbordes, G. (2018). MindfulnessBased Interventions in Psychiatry. FOCUS, Vol. 16, No. 1, pp. 32 - 39 
$+2$

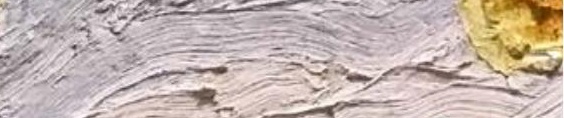
H.

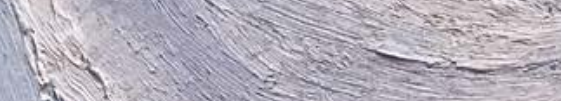

di

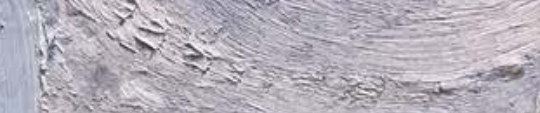

$$
\text { mets. }
$$

,

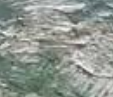

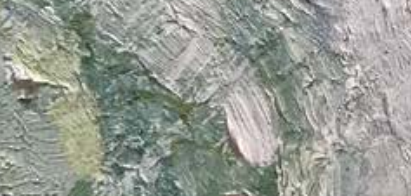

atsose

(a)

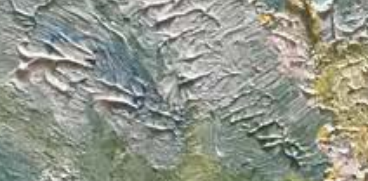

(5)

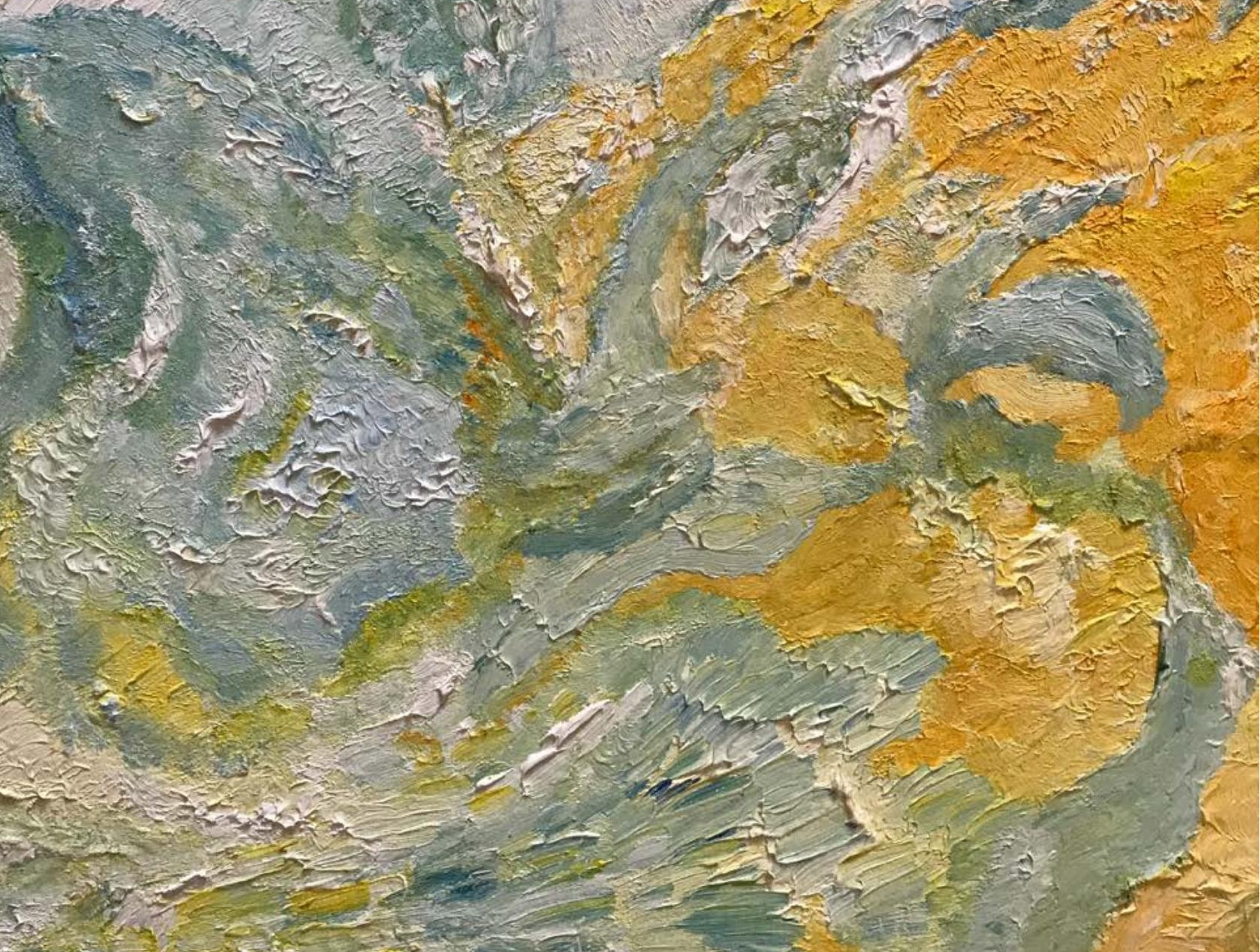

$\frac{1}{4}+x^{2}=2$

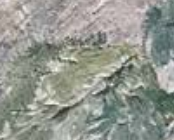

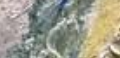

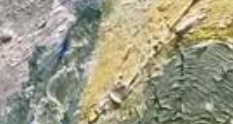

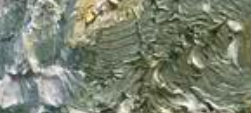

T.8.

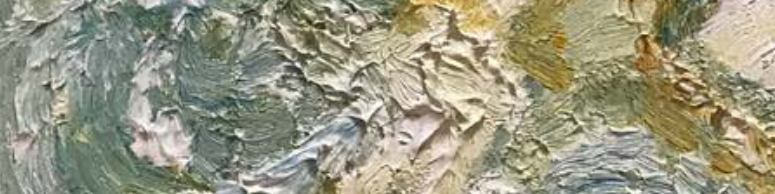

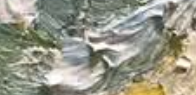

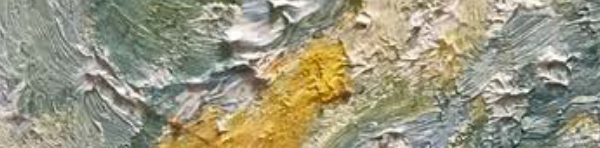

$\left.3 x^{2}\right)^{2}$

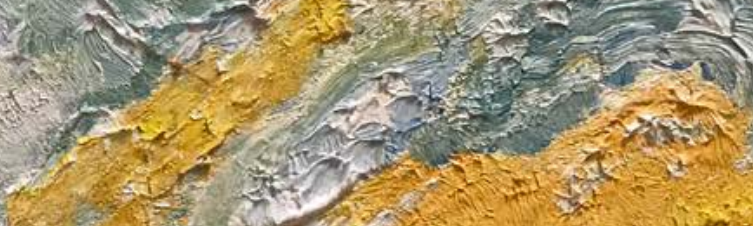
3

$x^{2}$ ren -5 दis. 